International Stock Market Linkages in Southern Africa

Keith Jefferis, Charles Okeahalam and Tebogo Matome BIDPA Working Paper 17 Janụary 1999 
Keywords

Financial Market

Capital Movements

Botswana

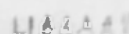

Southern Africa

\section{International Stock Market Linkages in Southern Africa}

\section{Keith Jefferis, Charles Okeahalam and Tebogo Matome BIDPA Working Paper 17 \\ January 1999}

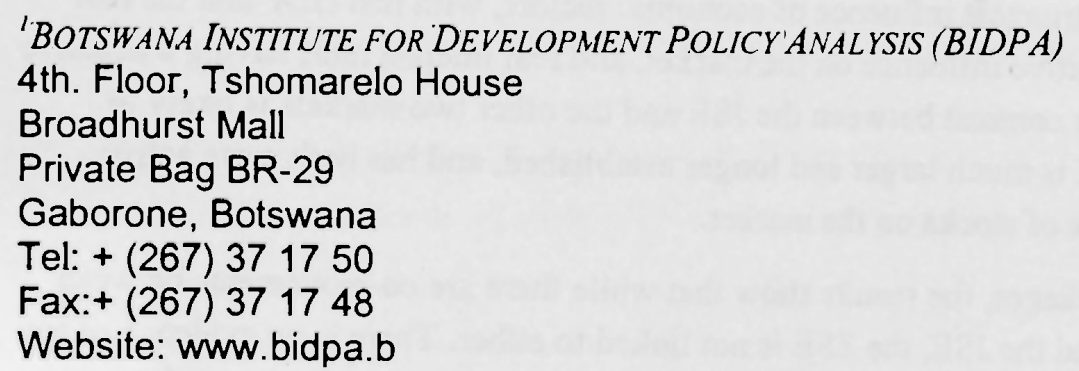

'Botswana Institute for Development Policy Analysis (BIDPA) is an independent trust set up by a Presidential Decree. It started operations in 1995 as a non-government policy research institution

IDS

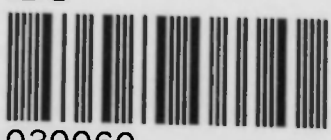




\title{
International Stock Market Linkages in Southern Africa
}

\begin{abstract}
Stock markets are taking on an increasingly prominent role in financial development, and many developing and transition economies are establishing stock markets as part of financial reform processes. In theory stock markets can contribute to the mobilisation of savings and the allocation of investment, but there are questions as to whether this works in practice. One important issue is whether stock markets are efficient (in the financial sense), and a related question is whether share prices reflect economic fundamentals; both of these questions are important in addressing whether stock markets properly allocate capital. Another issue relates to the question of international linkages between markets: with greater integration of capital markets globally, financial market developments appear to be rapidly transmitted between markets around the world. While this can have beneficial impacts, in terms of improving the global allocation and pricing of capital, it may be disruptive if international capital flows are large relative to national markets and economies.

This paper addresses such questions in the context of stock markets in three southern African countries. Botswana, Zimbabwe and South Africa. It uses a variety of empirical techniques to address the following questions:
\end{abstract}

(i) are the markets efficient (using unit root tests of stock prices, and event studies of stock price reactions to news);

are markets influenced by economic fundamentals such as GDP growth, exchange rates, and interest rates.

to what extent are there linkages (in terms of common movements) in the market indices of the three southern African markets;

(iv) to what extent are there co-movements between the market indices of the three southern African markets and both emerging and developed stock markets elsewhere in the world (specifically Asian markets, Latin American markets, London and New York).

The research covers the period 1989 to 1996 . With regard to efficiency, the results indicate that the South African market is efficient while the Botswana market is not efficient, according to both the unit root and the event study tests. There are conflicting results for Zimbabwe, but the more powerful event study test indicates that it too is inefficient. The Johannesburg Stock Exchange also shows the strongest influence of economic factors, with real GDP and the real exchange rate having a positive influence on the market, and real interest rates having a negative influence, as expected. The contrast between the JSE and the other two markets is likely to reflect the fact that the JSE is much larger and longer established, and has both more active trading and a broader range of stocks on the market.

With regard to regional linkages, the results show that while there are co-movements between stock prices on the BSE and the JSE, the ZSE is not linked to either. There is no evidence of any significant long term linkages between any of the southern African markets and any of the other markets internationally. This is somewhat surprising, given the impressionistic evidence that the JSE in particular appears to be influenced by other stock markets internationally, but presumably indicates that in the long term (if not in the short term), the southern African markets remain most strongly influenced by domestic rather than international factors. 


\section{Acknowledgements}

BIDPA Working Paper No. 17, presents the results of a research project entitled "International Stock Market Linkages in Southern A frica". This project was carried out during the period 1996 to 1998 , and was financed by a research grant from the African Economic Research Consortium (AERC), based in Nairobi. Earlier versions of the research report have been presented to the biannual AERC research workshops. The authors are:

Keith Jefferis, Ph.D., Senior Research Fellow at BIDPA, and former Deputy Director of Research at the Bank of Botswana.

Charles Okeahalam, Ph.D., Professor of Banking and Finance, University of Namibia, formerly with the Faculty of Business at the University of Botswana.

Tebogo Matome, Ph.D., Lecturer in Finance at the University of Botswana.

The authors wish to thank the many people whose efforts have contributed to making this research possible. Particular thanks are due to: the African Economic Research Consortium, for funding the research project; resource persons and participants at the bi-annual AERC Research Workshops, for comments and contributions which have been of great assistance during the evolution of the research; the Bank of Botswana and the University of Botswana for providing institutional support; Graham Smith at SOAS, University of London, for comments and advice; Alex Kganetsano of the Bank of Botswana and I. Bah of the University of Botswana for research assistance; and the Emerging Markets Data Base section of the IFC, and officials of the Botswana, Zimbabwe and Johannesburg Stock Exchanges for providing data. The usual disclaimer applies. 


\section{CONTENTS}

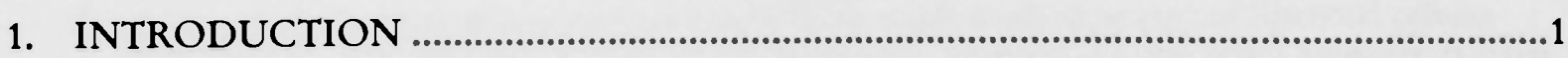

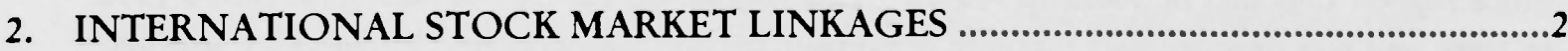

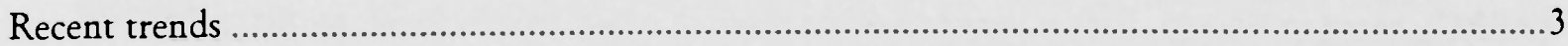

Portfolio Investment Flows to Developing Countries ...............................................................

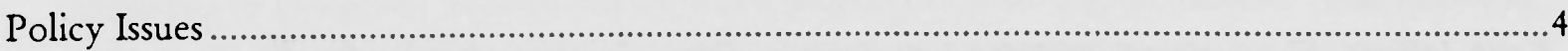

3. RESEARCH ON INTERNATIONAL STOCK MARKET LINKAGES ..........................4

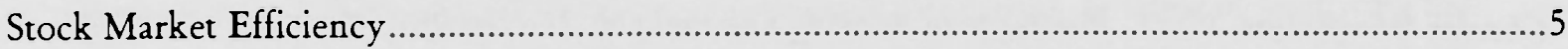

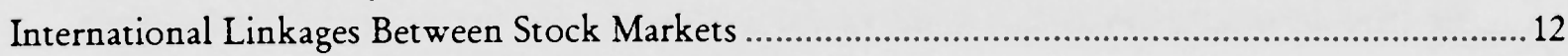

Stock Markets and the Influence of Economic Fundamentals .....................................................15

4. STOCK MARKETS IN SOUTHERN AFRICA ..........................................................18

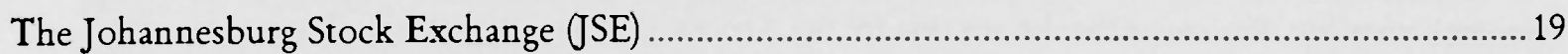

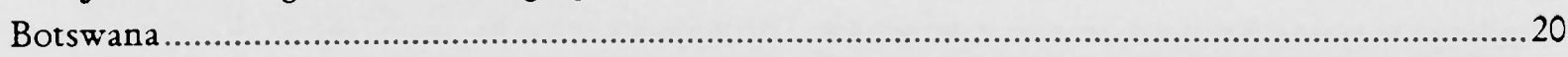

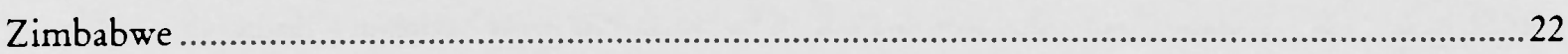

5. RESEARCH OBJECTIVES AND METHODOLOGY .................................................22

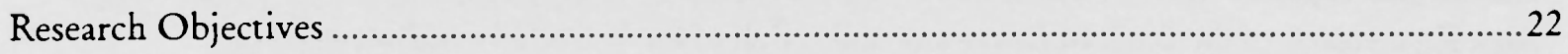

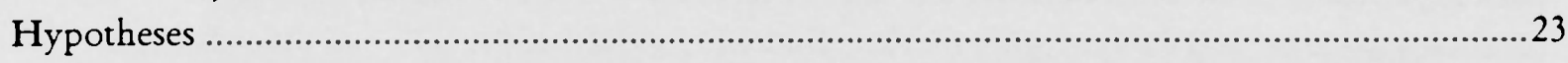

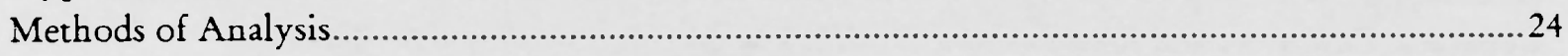

6. RESULTS: STOCK MARKET LINKAGES ............................................................28

Data

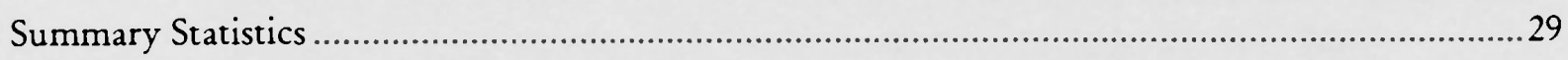

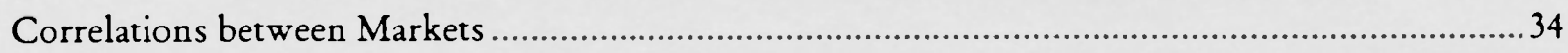

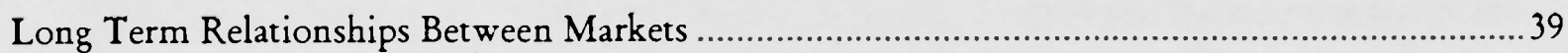

7. RESULTS: STOCK MARKETS AND ECONOMIC FUNDAMENTALS.....................44

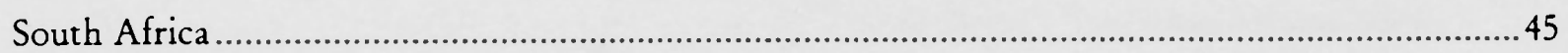

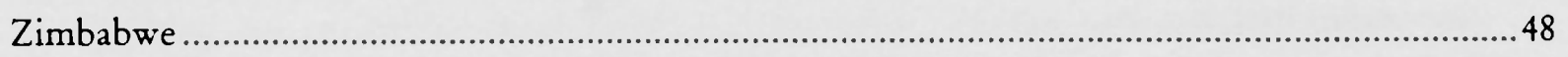

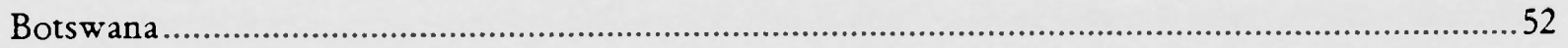

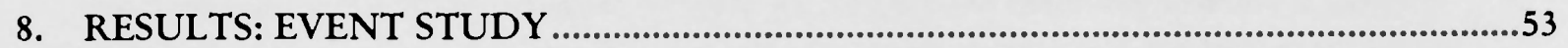

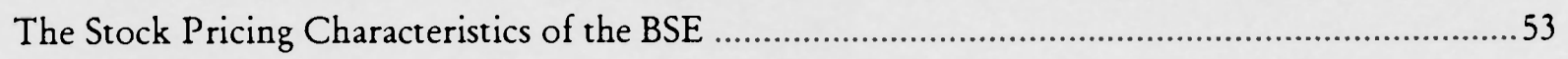

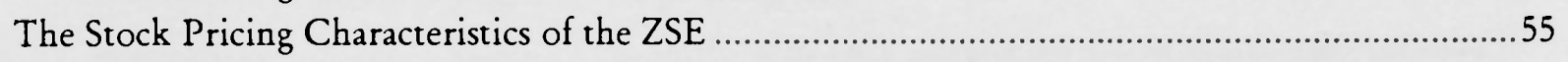

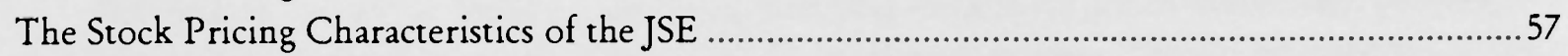

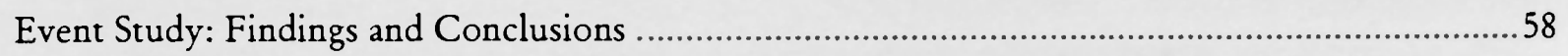

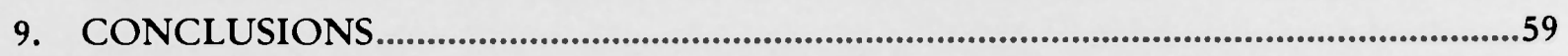

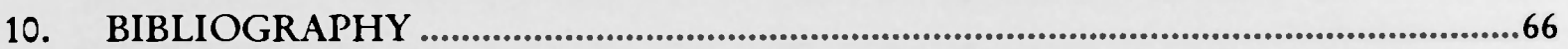




\section{FIGURES}

Fig. 1

Fig. 2

Fig. 3

Fig. 4

Fig. 5

Fig.6

Fig.7

Fig. 8

Fig. 9

Table 1

Table 2

Tables $3 a$ to $3 \mathrm{c}$

Table $4 \mathrm{a}$ to $4 \mathrm{c}$

Table 5a to 5c

Table 5d to $5 \mathrm{f}$

Table 6a to 6d

Table 7a to 7c

Table 8

Table 8b

Table 9

Table 10

Table 11

Table 12

Table 13

Table 14

Table 15

Table 16

Tables 17a-b

Table 18

Table 19

Table 20

Table 21

Table 22

Table 23

Appendix 1

Appendix 2

Appendix 3
Stock Market Indices: Southern Africa, Local Currencies

Stock Market Indices: Southern Africa, US Dollars

Stock Market Indices: Emerging Markets, US Dollars

Stock Market Indices: US and UK, US Dollars

Market Returns and Risk

South Africa and Botswana Stock Market Indices, SA Rands

Cumulative Abnormal Returns - Botswana Stock Exchange

Cumulative Abnormal Returns - Zimbabwe Stock Exchange

Cumulative Abnormal Returns - Johannesburg Stock Exchange

\section{TABLES}

African Stock Markets, 1996

Stock Markets in Southern Africa: Summary Data, 1989-96

Southern African Stock Market Returns, Local Currencies

Stock Market Returns, US Dollars

Correlations of Stock Market Returns, Local Currencies

Correlations of Stock Market Returns, SA Rand

Correlations of Stock Market Returns, US Dollars

Stock Market Indices: Unit Root Tests

Stock Market Indices: Cointegration Tests

Cointegration Tests, Botswana and South Africa, 1991-96

Variable Definitions - Economic Fundamentals

Economic Variables: Unit Root Tests

Economic Variables: Cointegration Tests, South Africa

Economic Variables: Cointegrating Vector, South Africa

Economic Variables: Error Correction Model, South Africa

Economic Variables: Cointegration Tests, Zimbabwe

Economic Variables: Cointegrating Vector, Zimbabwe

Economic Variables: Error Correction Model, Zimbabwe

Economic Variables: Botswana

Estimation of BSE Event Study Model Parameters

Cumulative Abnormal Returns, Botswana

Estimation of ZSE Event Study Model Parameters

Cumulative Abnormal Returns, Zimbabwe

Estimation of JSE Event Study Model Parameters

Cumulative Abnormal Returns, South Africa

\section{APPENDICES}

Estimates of the BSE abnormal returns using equal weighted market returns

Estimates of the ZSE abnormal returns using equal weighted market returns

Estimates of JSE abnormal returns using equal weighted market returns 


\section{STOCK MARKET LINKAGES IN SOUTHERN AFRICA ${ }^{1}$}

\section{INTRODUCTION}

Recent years have seen considerable attention devoted to analysis of linkages between stock markets in different countries. Much of the research was prompted by the nearly simultaneous world-wide collapse of equities markets in October 1987, which apparently provided evidence of strong linkages between price movements in the major world stock markets. Interest in the topic has also been enhanced by the globalisation of financial markets, the progressive relaxation of controls on international capital movements, and the increasing importance of cross-border equity flows.

In the financial economics sphere there are three key questions which arise with respect to changes in international stock market linkages: first, what are the implications for the rapid international transmission of national financial disturbances; second, what are the implications of these trends for the efficiency of stock markets in different countries, and third, what are the implications of linkages between stock markets for the international diversification of equity portfolios? The internationalisation of equity flows would appear to be accompanied by enhanced information flows, and hence greater market efficiency, while the removal of barriers between markets should lead to a tendency towards the equalisation of the price of risk. However, if markets become more closely linked in the sense that there are stronger co-movements of prices across markets, then this may result in changes to optimal international portfolio diversification strategies.

The issue of stock market linkages is also relevant, from a policy perspective, in an environment where moves towards greater regional economic integration are being promoted. Increased linkages between stock markets is a component of regional or international capital market integration, which is in itself important for integration of goods and services markets to be effective.

Most of the research to date on international stock market linkages has been concentrated on the major world stock markets (US, Japan, UK and Germany), although there has also been some work on the smaller developed country markets and Asian markets (Hong Kong, Singapore etc.). The Mexican crash of 1994/95 and its apparent transmission to other Latin American markets, as well as the recent episode of seemingly rapid transmission of financial market disturbances around East Asia, may well prompt more research into linkages between emerging markets. However we are not aware of any research into linkages between African stock markets, even though stock markets have been growing in importance in several African countries in recent years. In this paper, we investigate the extent of linkages between three stock markets in southern Africa, specifically Botswana, Zimbabwe and South Africa. We also consider the extent to which these markets are related to emerging markets more generally and to the larger international markets. The study also reviews the efficiency of individual markets, at both market index and individual stock levels. Finally, it also examines the extent to which stock prices in these markets are related to economic fundamentals. The paper is structured as follows: section 2 considers some of the general issues around international stock market linkages; section 3 reviews some of the previous research in this

Final research report for the project supported under. $A E R C$ research grant $R 7536$. All viewes expresses herein are those of the authors and do not necessarily reflect those of any institutions with which they are currently or nave formerly been associated. 
area; section 4 discusses the basic characteristics of the three markets; section 5 presents the research objectives and methodology to be followed; sections 6,7 and 8 present results, and section 9 concludes.

\section{INTERNATIONAL STOCK MARKET LINKAGES}

\section{Recent trends}

It is generally accepted that the major world stock markets have become more closely linked in recent years. A range of factors can be identified which have strengthened the linkages between stock markets in different parts of the world, including:

(i) the increasing importance of international capital flows and mobility, resulting from the progressive removal of controls on capital movements by the major industrialised countries and some developing countries; this is especially the case since the move from a fixed to a flexible exchange rate system amongst major world currencies in 1973;

(ii) a general world-wide move to deregulate financial markets; the reduction of the degree of government intervention allows freely floating (market determined) prices and quantities to transmit excess demand pressures to other related markets (Ma, 1993:288);

(iii) technological advances which have improved the speed of international financial transactions; improved the international flow of information between markets; helped to reduce transactions costs; and led to effective twenty-four hour trading;

(iv) increases in the number of multinational companies whose shares are cross-listed on more than one major international stock exchange; such companies also tend to be involved in economic activities in a number of different countries around the world and hence their performance will increasingly tend to be affected by global rather than country specific factors;

(v) increasing international trade.

Although the above trends have had an impact on a range of different financial markets, it is in equity markets that globalisation has proceeded most rapidly (Aburachis 1993: 32).

One impact of increased linkages between stock markets internationally is that price movements and other shocks are likely to be transmitted more rapidly between markets; increased interdependence between markets leads to a more rapid and larger transmission of national financial disturbances - through "contagion" effects - to other markets (von Furstenburg and Jeon, 1989, p125). More specifically, a price fall in one market may lead to falls in other major markets - as apparently illustrated by the October 1987 collapse of equities prices world-wide, and on a smaller scale by the impact of the Mexican market crash in January 1995 on other markets in Latin America. More recently, in 1997, major disturbances in both currency and stock markets in East Asia appeared to be transmitted rapidly around the region, and subsequently had an impact on major developed country stock markets. These developments are of particular concern if market movements are excessive in relation to changes in economic fundamentals, in that the impact on other markets may be unnecessarily and undesirably disruptive, distorting the allocation of financial capital within an economy.

A second impact of increased stock market linkages results from changes in the co-movements between prices in different markets, which can have a major impact on international portfolio diversification. As is well known from standard portfolio diversification theory, if the returns on 
assets in a portfolio have a correlation of less than unity, then diversification can reduce risk. In the extreme case, where the returns are perfectly negatively correlated, then diversification can in theory eliminate risk entirely. Grubel (1968) gave one of the earliest expositions of how these benefits could be extended by diversifying a portfolio internationally, and in recent years international portfolio diversification has become fashionable because of the belief that the returns on financial assets from different countries had relatively low correlations; indeed, "the main driving force in [global equity] markets has been the fact that international portfolio diversification lowers risks without sacrificing expected returns" (Aburachis 1993:32). If international stock market integration leads to changes in the correlations of price changes between those markets, or alters the stability of correlations between markets ${ }^{2}$, then there are implications for international diversification and for portfolio capital flows between countries. The amount of benefit from international portfolio diversification is different under segmented markets than under internationally linked markets (Chou, $\mathrm{Ng}$ and $\mathrm{Pi}, 1994$ ). If stronger linkages lead to greater comovements between markets internationally, the benefits of diversification may be reduced and hence there may be a reduction in portfolio investment flows ${ }^{3}$. As von Furstenburg and Jeon (1989, p.163) have noted: "the spectacle of nearly simultaneous price collapses around the world in the [1987] crash should have led investors to revise their views about how much diversification gain could really be reaped from investing in different national stock markets".

\section{Portfolio Investment Flows to Developing Countries}

This issue is particularly important for developing countries, some of which have benefited significantly from portfolio capital inflows as developed country investors have started to take an interest in emerging markets - notably Mexico, Brazil, Argentina, Chile, Malaysia, Indonesia, Thailand and South Korea. Although high returns may be expected in these markets, these are undoubtedly volatile and therefore accompanied by higher risks than in the major developed country markets, as long as those risks (i.e. the variability of returns) have relatively low correlations with developed markets, there are significant benefits to investors. These benefits are potentially very large. It has been estimated that, on the basis of the performance of the US and emerging stock markets over the period 1987-91, if investors had held 20 percent of their portfolios in emerging markets, instead of actual holdings of less than 0.5 percent, they would have increased their average return by about 1 percent a year and significantly reduced their risks (World Bank, 1993). Even by 1993, US pension funds still held only about 1 percent of their assets in emerging markets, at a time when these accounted for 12 percent of global stock market capitalisation (The Economist, January 28th 1995).

Apart from South Africa, sub-Saharan Africa has not yet been a major beneficiary of inward portfolio investment, for a number of reasonst. First, the region's stock markets are - with the exception of the Johannesburg Stock Exchange - small, even by emerging market standards, and

2 If the correlation structure is not stable over time, then the efficient frontier will be continuously changing and it will be difficult to identify any optimal portfolio selection (Maldonado and Saunders, 1981).

3. Although there will still be benefits of diversification as long as $r<1$. Furthermore, technical progress reducing transactions costs, and the greater openness of many markets to foreign investors, will serve to offset the reduced diversification benefits as market integration increases.

- Recorded portfolio flowe into sub-Sabaran Africa were $\$ 17$ million in 1993, $\$ 641 \mathrm{~m}$ in 1994, and $\$ 297 \mathrm{~m}$ in 1995 . For South Africa, the figures were $\$ 144 \mathrm{~m}$ in 1992 rising to $\$ 4.6$ billion in 1995 , "the largest such flow to any developing country in that year" (Finance and Development. June 1997, p.4) 
there are few stocks of interest to major foreign investors ${ }^{5}$. Second, economic performance has generally been poor over the past decade, with economic reforms slower to take effect than elsewhere in the world. Third, there remain important restrictions on the entry of foreign investors into Africa's stock markets, although are progressively being eased. Nevertheless, interest in African markets is increasing, partly as a result of reform in South Africa which has removed some of the political barriers to investment in that country. The subsequent investor interest has also had positive spillover effects into neighbouring markets such as Botswana, Namibia and Zambia.

A number of benefits of portfolio investment inflows are typically cited:

(i) improving the operation of domestic stock markets, through increasing the number of market participants, boosting demand for shares, and raising turnover and liquidity;

(ii) the standards required by international portfolio investors will improve information flows and disclosure, thereby reducing the potential for fraud and corruption. Both of these developments should then contribute to increased market efficiency;

(iii) increased capital inflows can also help the stock market by boosting share prices and thereby reducing the cost of equity capital for firms, stimulating the overall rate of investment and improving gearing ratios;

(iv) at a macroeconomic level, portfolio capital inflows can help to redress a shortfall of domestic savings below investment needs, and (temporarily) improve the balance of payments.

(v) recent research also indicates a positive relationship between the size and liquidity of stock markets and the long run rate of economic growth (Levine and Zervos, 1995, 1998).

However there may be drawbacks of portfolio capital inflows, which may be short term and highly volatile - as is evident from Mexico's experience in late 1994 and early 1995, and East Asia's in 1997. Inflows may be used to finance current account deficits due to high levels of consumption rather than investment, and can leave a country exposed to sudden capital outflows and with reduced discretion over domestic economic policy.

\section{Policy Issues}

A number of policy issues are raised in considering the question of linkages between stock markets in southern Africa:

1. the efficiency of regional stock markets in southern Africa, and the extent to which movements in stock markets reflect changes in underlying economic influences (such as interest rates and economic growth). Both of these factors have implications for the effectiveness of stock markets in allocating finance to different potential uses;

2. whether there are any significant linkages between the various stock markets in southern Africa, and between those markets and the rest of the world, with implications for encouraging inflows of portfolio investment into different countries of the region;

3. whether linkages between stock markets in the region are increasing, indicating a contribution to the broader process of regional economic integration.

The two largest stock markets outside of South Africa - Nigeria and Zimbabwe - are the smallest markets in the IFC's Emerging Markets Index. 


\section{RESEARCH ON INTERNATIONAL STOCK MARKET LINKAGES}

Although there has been a steady stream of research on international stock market linkages over the past two decades, interest appears to have grown since the late 1980s. This is partly a result of the increasing importance and implications of such linkages due to the factors noted above, but was particularly stimulated by the October 1987 crash. This event, which involved nearly simultaneous price collapses around the world, caused equity markets world-wide to lose about $\$ 1.2$ trillion in market capitalisation. It has been described by Shiller (in von Furstenburg and Jeon, 1989:171) as "the most dramatic single event in world financial history", and as Aderhold et al (1988:34) note: "the speed, size and simultaneity of the price declines in such a wide variety of markets stunned participants and observers alike and prompted a search for explanations". Research interest has also been prompted by the development of new statistical techniques for the analysis of asset market efficiency and interdependence (unit root and cointegration tests), techniques which have been more widely applied to the analysis of foreign exchange markets (see for example MacDonald and Taylor, 1989) but which have only recently been applied to stock markets.

Madura (1985) provides a review of the earlier studies dealing with international stock markets; his classification of the literature into the following three main areas is also followed by Chan, Gup and $\operatorname{Pan}(1992)$ :

(i) studies of the gains from international portfolio diversification;

(ii) examination of intertemporal patterns of correlation coefficients among international stock markets; and

(iii) the application of more sophisticated methodologies to investigate the co-movements of world stock markets.

In addition, more recent studies consider:

(iv) the extent to which greater equity market integration is linked to broader processes of regional economic unification (e.g., Harris and Smith, 1996).

There are also two related areas of research applicable to individual national stock markets (rather than linkages between stock markets) but which are highly relevant to the current topic. These are:

(v) evaluating the efficiency of individual stock markets;

(vi) examination of the impact of economic fundamentals on stock markets.

Most of the empirical studies in this area have been applied to the world's major stock markets (USA, Japan, UK and Germany), although some of them have incorporated markets in some of the other industrialised countries (such as Canada, Italy, France, Belgium, Holland, Australia etc.). Some of the more recent studies cover the Far Eastern markets, e.g. Chan, Gup and Pan (1992) on Singapore, Hong Kong, South Korea and Taiwan, and Yong (1993) on Malaysia. To date, none have dealt with African markets (except for Chan and Lai's (1993) inclusion of the JSE in their study of fourteen international markets).

Below we review some of the literature on international stock markets, paying particular attention to categories (ii) - (iv) above; category (i) - the benefits of international portfolio diversification - will only be dealt with indirectly. 


\section{Stock Market Efficiency}

One of the most important areas of research into stock markets is the question of "efficiency". In this context, the term "efficiency" has a very precise meaning that is somewhat different to the conventional economic concept relating to the efficiency with which inputs to a production process are transformed into outputs. In financial economics, efficiency relates to the use of or response to information in the formation of stock prices (or the price of other assets, such as foreign exchange or commodities). In the literature, the efficiency of individual markets is typically assessed prior to the evaluation of linkages between markets.

According to Fama (1970), a market is efficient if prices always fully reflect available information. Prices will then act as a signal for the allocation of capital between different firms and sectors in an economy according to their relative profitability. This conclusion is based upon two important assumptions. Firstly, that stock prices accurately reflect the expected future profitability of firms. Secondly, that expectations about profitability are themselves based upon economic fundamentals (relating to individual firms, particular sectors of an economy, or the economy as a whole) and are not arbitrary guesses. Fama's proposition is usually termed the Efficient Markets Hypothesis $(\mathrm{EMH})$, which is that share prices always reflect available information about economic fundamentals.

Although the EMH states that prices always fully reflect available information, Fama suggested that there are different categories of efficiency depending upon how much information is assumed to be available:

1. weak-form efficiency, where current prices reflect all historical information about share prices; changes in share prices cannot therefore be predicted from past trends in prices;

2. semi-strong form efficiency, where current prices also reflect all current public information relating to profit expectations, and prices should therefore adjust speedily to public announcements of such relevant information;

3. strong form efficiency, where prices also reflect private information relating to profit expectations

The issue of efficiency is important because it has major implications for the behaviour of stock prices. If markets are efficient, all available information at time $t$ is incorporated in the price of the stock at time $t$. The price of a share therefore always reflects its fundamental value. The price will therefore change as new information about economic fundamentals becomes available. However, as the flow of future information cannot be predicted from current information (because any future information which could be predicted is necessarily part of the current information set), future information flows are random. Hence stock price movements are random, and future prices cannot be predicted from currently available information, or alternatively that the best predictor of the stock price at time $t+1$ is the price at time $t$. Stock prices should therefore follow a random walk. The alternative to efficiency is that price changes are not random; at time $t$ the market price has not fully incorporated the information available at time $t$, and hence future price movements can be predicted from currently available information.

One implication of efficiency is to undermine the position of professional market analysts who claim to be able to predict future market movements on the basis of past trends (the chartists) or current information. More precisely, if markets are weak-form efficient, consistently good predictions will only be possible on the basis of access to information prior to other economic agents, and if they are semi-strong efficient consistently good predictions will only be possible on 
the basis of inside (non-public) information. Efficiency also suggests that past performance is no guide to future performance - clearly some stocks do perform better than others over any given time period, but this is essentially random and is no guide to which stocks will do better in the future.

\section{Testing for stock market efficiency}

A stock price (or stock price index) series can be modelled as follows:

$$
P_{t}=\alpha+\beta T+\rho P_{t-1}+\varepsilon_{t}
$$

where $P_{t}$ is the price at time $t$, the variable $T$ is a time trend, and $\varepsilon$ is an error term. The values of the coefficients $\alpha, \beta$ and $\rho$ determine the basic character of the time series. $\alpha$ represents "drift", i.e. a fixed movement in each time period, while $\hat{D}$ represents the impact of a time trend. However, the most important coefficient for determining the character of the series is $\rho$, as can be seen by reconfiguring the model in terms of changes rather than levels.

$$
\Delta P_{t}=\alpha+\beta T+(\rho-1) \bar{P}_{t-1}+\varepsilon_{t}
$$

If $\rho<1$ then $(\rho-1)<0$ and the price change $(\Delta P)$ depends upon the price at $t-1$. This denotes a lack of efficiency. Such a series is called mean- or trend-reverting, and enables forecasts to be made of future prices from past prices. Any shocks away from the trend will eventually be dissipated.

By contrast, if $\rho=1$ then $(\rho-1)=0$, and the price change in any period simply consists of the drift and trend component (if any) plus a random change $\varepsilon_{t}$. Thus future prices cannot be forecast from past prices and the market is efficient. Such a series is termed a random walk (with trend and/or drift). Any shocks will be permanently incorporated into the price and there is no trend-reverting tendency.

The time series described above may therefore be either stationary (if $\rho<1$ ) or non-stationary (if $\rho=1)^{6}$. We can test for market efficiency by testing for the value of $\rho$, that is, by testing whether the series has a unit root.

Examples of the use of unit root tests of stock market efficiency can be found in Chan and Lai (1993) and Chan, Gup and Pan (1992). Chan and Lai examine weak form efficiency in fourteen major stock markets over the period 1988 to 1990 . They use weekly data, in log form, with the following two models:

$$
\begin{array}{lll}
\text { Model 1: } & X_{t}=\mu+b(t-T / 2)+\alpha X_{t-1}+\varepsilon_{t} & \text { (with trend and drift) } \\
\text { Model 2: } & X_{t}=\mu+\alpha X_{t-1}+\varepsilon_{t} & \text { (with drift) }
\end{array}
$$

where $X_{t}$ is a stock price series, $\mu$ is the drift, $T$ is the total number of observations and $\varepsilon_{t}$ are error terms. They test the hypothesis $\mathrm{H}_{0}: \alpha=1$ against the alternative $\mathrm{H}_{1}: \alpha \neq 1$, using the PhillipsPerron test. They also ran unit root tests on the first difference of stock prices to see if the stock price series has a second unit root.

The results show that the hypothesis of unit roots is not rejected except for New York (in Model 1) and Brussels (in Model 2). They conclude that:

In the exceptional cases of New York and Brussels, one of the two models does support the unit root hypothesis. Hence it is appropriate to suggest that there exists unit root in stock prices in all markets. Moreover, unit roots in the first difference of stock prices (i.e., stock

6 A series is (weak sense) stationary if the mean, variance and covariance are invariant with respect to time. 
returns) are rejected at the 1 percent level. These findings suggest that changes in stock prices are stationary. Thus the stock prices are I(1), implying that the stock price level of the ith market at $\mathrm{t}$ is solely dependent on the stock price at $\mathrm{t}-1$, plus an error term. The markets are individually weak form efficient (1993: 282-3).

However, we should note that their rejection of the unit root hypothesis for one of the two models in the case of New York and Brussels may indeed indicate that those markets are not efficient. Their methodology, however, does not permit the selection of the appropriate model and hence an unequivocal conclusion about the efficiency of these two markets.

Chan, Gup and Pan (1992) apply a very similar analysis to the major Asian markets and the United States. The use three regression models, adding the following model to the two used in Chan and Lai (1993):

$$
X_{t}=\alpha X_{t-1}+\varepsilon_{t}
$$

They test for unit roots $(\alpha=1)$ using the Phillips-Perron test on both daily and weekly data over the period 1983 to 1987 . The countries covered are Hong Kong, Singapore, South Korea, Taiwan, Japan, and the USA. The tests indicate that the null hypotheses of unit roots in both daily and weekly stock prices in all countries are not rejected, while unit roots in the first difference of stock prices are all rejected at the 1 percent level. Stock prices are all I(1), and all markets are therefore weak form efficient.

Dwyer and Hafer (1990) test for unit roots in stock price index series for a number of countries (Australia, Canada, France, Germany, Japan, UK, USA) using daily data during the period in 1986 and 1987 leading up to the October 1987 crash. Using the Dickey Fuller test, they cannot reject the hypotheses that all series have unit roots.

\section{Event Studies}

The basic principle underlying event studies is that relevant economic information should have an impact on the value of an economic asset. These type of studies are variously referred to as analysis of market micro-structure, market based accounting research (MBAR) and, more generally, event study tests of the efficient markets hypothesis (EMH). The definitions are probably due to the epistemology of the researchers. In the first definition the researchers are attempting to examine the intrinsic factors which determine the structural relationships within capital markets; so the question, what determines the stock price?, is only an aspect of this (Lease, Masulis, and Page, 1991). The MBAR definition recognises the fact that accounting information is primarily ex-post data. The announcements made usually refer to financial performance achieved in $t_{.1}$, while the date of publication is assumed to be $t_{0}$. Accordingly, MBAR studies usually use historic accounting data to assess information efficiency of financial markets by evaluating the price effects of the historic data on ex-ante prices. Event studies are arguably a more specific form of market micro-structure studies and more general form of MBAR studies, in that they use the same methodology as described above to evaluate the impact that the announcement of an event might have on the price of a financial market asset.

The impact of financial information on financial market asset prices has been extensively analysed. Indeed, Mackinlay (1997) notes that the first recording of empirical application of the impact of an event on the price of a financial asset was by Dolley (1933). This early study made an attempt of assessing the effect that a stock split might have on the stock price. The more recent studies of Ball and Brown (1968) and Fama (1970) developed the methodology that is still the basic standard used in event studies today. The standard (Ball and Brown) method for examination of firm values 
assumes that a firm's stock price is equivalent to the present value of expected future benefits that accrue to its shareholders. Accordingly under this framework the magnitude of a firm's reaction to a value influencing announcement (the earnings response coefficient - ERC) should be related to the effect of the announcement on the expectations of future benefits accruing to its equity holders.' However the EMH is difficult to test directly, because to do this it is necessary to know each market's anticipated net operational cash flows and anticipated required rates of return for all future periods, and all information relevant to security prices and the way in which this information is reflected in the prices. Accordingly it is therefore necessary to design tests (such as event studies) of the EMH which are based on available information and statistical techniques.

When conducting an event study the first step is to determine the event(s) which are to be analysed, and then define the event window. This is the period of time over which stock prices will be analysed to measure the effect of the event. For example, if the event study is attempting to determine the information content of dividend announcement, if daily data is used, then the announcement of the dividend is the event, and the event window is a period of time which includes the day of the announcement with regard to dividends. To enable analysis of periods before and after the event, the event window is usually longer than the actual date of interest. Accordingly it is normal practice to expand the period of interest beyond the actual date of interest. So, in an analysis using daily data, the period of interest would include the day of the event and several days before and after the event. If the study uses weekly data then the event window for analysis will include the week of the announcement and several weeks before and after the week in which the event is announced. The main reason for this approach is that the market may gain information before the event takes place and therefore it is possible to investigate this by examining the stock price over periods prior to the event announcement.

The next step in the event study is to determine the criteria for the selection of industry sectors and firms for investigation. Sometimes, as is the case in the empirical exercise contained herein, this is dictated by the availability of data. ${ }^{8}$ This is not the case with regard to research on stocks in developed capital markets where there are several extensive data bases. ${ }^{9}$

\section{Review of Different Event Study Models}

The impact of announcement is measured by estimating the abnormal return. An abnormal return is the actual ex-post return of a security over the event window minus the normal return of the firm over the event window. The normal return is the return is the expected return in the absence of the event taking place. The abnormal return for firm $i$ on event date $t$ is

$$
A R_{i t} R_{i t}-E\left(R_{i t} \mid X_{t}\right)
$$

where $A R_{i p} R_{u}$ and $E\left(R_{u t} \mid X\right)$ are the abnormal, actual, and normal returns for time period t. $X_{t}$ is the

7 Therefore in the context of a two period model the impact of an announcement as measured by the size of the returns reaction is a function of the persistence of earnings. We can postulate the following joint bypothesis. Firstly, the stock price is equal to the present value of the expected future benefit accruing to equity bolders. Secondly, the present value of the revisions in expected future earnings approximates the present value of the revisions in these expected future benefits, and, thirdly, a univariate time series model of earnings approximates market expectations. Accordingly the magnitude of the $E R C$ to announcements should be positively related to measures of persistence of earnings across firms. For more on announcements and earnings persistence, see Kormendi and Lipe (1987).

8 Okeahalam (1994) uses asymptotic estimation to attempt to overcome the difficulties that the absence of data has on carrying out event studies on capital markets in Africa.

- An extensive list and description of the major data bases for event studies is provided in Board, Pope and Skerratt (1991). 
conditioning information for the normal return model and is determined by the choice of normal return selected. Usually, either the constant mean return model or the market model is used. In the former, $X_{t}$ is a constant and the assumption is that the mean return of a stock is constant through time. In the market model $X_{t}$ is specified as the market return and here the assumption is that there is stable relationship between the market return and the specific stock return.

Thus, statistical models are based on statistical assumptions about the behaviour of asset returns and are not dependent on economic assumptions. Statistical models assume that asset returns are jointly multivariate normal and independently and identically distributed. This asset-returns assumption, allows for both the constant mean return model and the market model to be correctly specified. Although this is a strong assumption, this approach is used primarily because the inferences derived from the model are robust to deviations from this assumption. Furthermore, by using a general method of moments approach, the statistical assumptions can be modified for consistency in autocorrelation and heteroskedasticity in the analysis of abnormal returns. The statistical constantmean return model can be specified as follows:

$$
\begin{aligned}
R_{i t} & =\mu_{i}+\lambda_{i t} \\
E\left(\lambda_{i t}\right) & =0 \quad \operatorname{var}\left(\lambda_{i t}\right)=\sigma_{i_{i}^{2}}
\end{aligned}
$$

The constant-mean return model is a simple one, yet it is used because the variance of the abnormal return is not much reduced by the specification of more sophisticated models. Indeed, Brown and Warner (1985) find that it provides similar estimates to those derived from more complex models. When the model is applied to daily data then nominal returns are usually specified. However, when monthly data is used, the model can be used to estimate real or excess returns, i.e., returns in excess of the risk-free rate, proxied as the yield of the one month to maturity Treasury bond or gilt instrument.

Another statistical model is the market model. It is an improvement on the constant mean return model because it removes the part of the return that is related to variations in the market return. This leads to a reduction in the variance in the abnormal return and leads to an increase in the

$$
\begin{aligned}
& R_{i t}=\alpha_{i}+\beta_{t} R_{m t}+\varepsilon_{i t} \\
& E\left(\varepsilon_{i t}=0\right) \quad \operatorname{var}\left(\varepsilon_{i t}\right)=\sigma_{\varepsilon}^{\prime}
\end{aligned}
$$

model's ability to detect the effect of events. It is specified as follows:

where $R_{u}$ and $\mathrm{R}_{\mathrm{mt}}$ are the firm $i$ and market $m$ returns for period $t$ respectively, $\varepsilon_{\mathrm{it}}$ is the zero mean disturbance term, and $\alpha_{i}, \hat{p}_{i}$ and $\sigma$ are the parameters of the market model.

Other statistical models are also used in event studies. These include factor models such as the market model, which uses portfolios of traded securities to reduce the variance of the abnormal returns by defining more of the variation in the normal return. The market model is a one factor model, but multi-factor models that utilise industry sector indices in addition to the market have been developed. However, there are no significant benefits in using multi-factor models in event studies. This is because the marginal explanatory power derived by including additional factors to the market factor is small and there is only minor reduction in the variance of the abnormal return. Variance reduction is largest where the sample of firms have a common characteristic, such as being 
in the same industrial sector ${ }^{15}$.

In situations of limited data, the market-adjusted return model can be used. This is particularly so when the pre-event estimation period for the normal model parameters is unknown or not feasible. In such instances, the market-adjusted return model is a restricted market model with $\alpha_{1}$ constrained to zero and $\beta_{1}$ constrained to one. Since the model parameters are prespecified, it is not necessary to specify an estimation period to get parameter estimates.

On the other hand, economic models are dependent upon assumptions regarding the behaviour of investors, and not only statistical assumptions. The two main economic models are the capital asset pricing model (CAPM) (Sharpe, 1964, and Lintner, 1965), and the multi-factor normal performance arbitrage pricing theory (APT) model developed by Ross (1976).

The CAPM develops an equilibrium framework in which the expected return of an asset is a function of its' covariance with the market portfolio. The debate on the efficiency of CAPM rages on. Several studies have identified that deviations from the linear CAPM risk-return trade-off is dependent on other variables: firm size (Banz, 1981), earnings yield (Basu, 1983), and leverage (Bhandari, 1988). The ratio of the firm's book value of equity to its market value has also highlighted certain difficulties with CAPM. Fama and French (1992) examined the cross-section of average returns and beta, and fmd only a weak relationship for a fifty year period and no relationship for a 27 year period. They also find, as Banz (1981) had done earlier, that firm size and book to market equity effectively capture cross-sectional variation in average returns over the same 27 year period. Their book-market results are further reinforced in Fama and French (1995). However, the findings of several studies, in particular Kothari, Shanken and Sloan (1995), support CAPM in that they find ex-post returns compensation for the same 50 year period examined by Fama and French. This suggest that book to market equity is at best weakly related to arerage stock returns, and implies that the findings of Fama and French (1995) are the result of survivorship bias. However, while the debate continues, CAPM is being used less frequently in event studies because of questions raised regarding the validity of the restrictions imposed by it on the market model. Accordingly results of studies based on CAPM may be affected by these restrictions. Although this sensitivity to restrictions may be overcome by using the market model, the CAPM is rarely used without extensive relaxation of assumptions. ${ }^{11}$

With regard to multi-factor normal performance APT models, the general conclusion is that the major factor is analogous in behaviour to the market model and that the addition of further factors does not increase explanatory power. Accordingly the benefits of using the APT, as opposed to the more simple market model, are small. A possible benefit of using the APT model is that it removes the biases of the CAPM. However, this is something which the statistical models do as well with less complexity, and is probably why statistical models are used more frequently in event studies.

10 'As in the empirical exercise in this study, where all the stocks are classified into two industry sectors - retail stores and banking and financial services.

"I CAPM assumes that firstly the market portfolio is efficient and that secondly the expected returns are linearly related to betas. These two assumptions are not separate because either implies the other bowever Kandel and Stambaugh (1995) bave shown that either can hold nearly perfectly while the other fails grossly. Their argument is that there is an exact linear relationship between expected retums and betas of a given portfolio if and if the portfolio lies exactly on the minimum variance boundary. If the portfolio is inefficient, ie., it does not lie on the minimum tariance boundary then 1 plot of expected returns versus betas bears no relation to the position of the portfolio in mean-variance space. It is possible to bave an OLS slope and $R^{2}$ close to zero when the portfolio is close to the minimum variance boundary. At the sume time however a near perfect linear relation can occur with any desired intercept and slope if the portfolio is grossly inefficient. Such findings add to the growing disquiet regarding CAPM. 


\section{International Linkages Between Stock Markets}

Moving beyond the issue of the efficiency of individual markets, we can consider ways of analysing the linkages between stock markets in different countries. This has been of interest to researchers for some time (for early investigations see Ripley, 1973 and Panton, Lessig and Joy, 1976), but has recently achieved more prominence. This reflects the greater importance of international capital flows and of other international economic linkages over the past two decades.

\section{Correlation Analysis}

The simplest approach to analysing international stock market linkages is to construct correlation coefficients for the levels of stock price indexes in two different markets, or alternatively for changes in stock price index levels. Dwyer and Hafer (1988) analyse correlations between stock markets (using exchange rate adjusted daily data) in the USA, UK, Japan and Germany for the period surrounding the 1987 Crash. They find that although correlations are high, they are also unstable - i.e. there are major differences in correlation coefficients when the sample is divided into pre- and post crash periods. Dwyer and Hafer interpret this as follows. In the absence of restrictions on international capital flows, and ignoring issues of country risk, arbitrage will ensure that the expected rate of return (in a common currency) for investors in different markets are equalised (a situation which they term "stock return parity"). However, stock price levels in the two countries will diverge because the market indexes are comprised of different firms' stocks, which will react in different ways to economic and other developments. Even with equalisation of expected returns, actual or ex post returns will differ due to the impact of unexpected developments which affect stock prices in the two countries as well as the exchange rate. More specifically, if the stock markets in two different countries are efficient and follow random walks, the relative stock price (the ratio of the level of stock prices in the two countries) will also follow a random walk.

Relative stock prices next period simply are equal to relative stock prices this period plus the difference between the unexpected parts of the bolding period returns [in each market] and the unexpected change in the exchange rate. In other words, even if expected rates of return are identical, relative stock prices in terms of a common currency are a random walk . . [and] . . show no tendency to return to any particular value. This is important because it means that even if the expected bolding period returns of two stock were perfectly correlated, the levels of the prices will show no stable relationship. Because relative stock prices are characterised as random walks, correlations between the levels of national stock price indexes are unstable (Dwyer \& Hafer 1988, p.5).

Although the correlations between the levels of national stock price indexes are unstable, the authors find that correlations between changes in the indexes (as opposed to levels) are positive and significantly different from zero. They conclude that:

these results are consistent with the notion that movements in the indexes, unlike levels of the indexes, are indeed related. . . either financial transactions or international trade of goods and services affect the different indexes in the same direction (p.10)

They also carry out a similar analysis over the 31 year period from 1957 to 1987 , using monthly data, which encompasses both fixed and floating exchange rate periods for the major world currencies. These show that although correlations (of changes in levels) between the pairs of national stock prices indexes are positive and significantly different from zero in both sub-periods, they are higher in the floating rate period (from April 1973), suggesting that the markets are more 
closely linked in this period. However, they also note that while the correlations are positive and significant, they are also far from one.

A similar approach is adopted by Aburachis (1993) who carries out regressions of US stock returns (i.e. changes in stock prices) against stock returns in Canada, France, West Germany, Italy, Japan and the UK. Using monthly data for December 1979 to December 1989, he carries out regressions for two sub-periods (i.e. pre and post the October $1987 \mathrm{Crash}$ ) as well as for the whole period, and examines the correlation coefficient $\left(R^{2}\right)$. He finds that, apart from Canada, there were very large increases in correlations in the post-Crash period, with the $\mathrm{R}^{2}$ more than doubling in most cases.

Eun and Shim (1993) summarise a number of studies examining the relationship among national stock markets, and conclude that correlations among returns to national stock markets are surprisingly low. However, most of the studies cited were carried out in period 1970 - 1976, therefore mostly using data relating to the fixed exchange rate period. The low correlations found are not surprising, and are in keeping with Dwyer and Hafer's results.

Harris and Smith (1996) calculate correlation coefficients using daily data for fourteen European stock markets during 1983 to 1987 and 1990 to 1995 , with the second period distinguished by the absence of exchange controls on capital movements between most of the markets considered. They find that while in the first period around half of the correlation coefficients for pairs of markets are not significantly different from zero, in the second period all are significantly different from zero. In 103 of the 105 pairs of markets examined, the correlations of daily stock market returns are higher in the period following capital account deregulation.

\section{Cointegration Analysis}

While correlation analysis represents the traditional method of ascertaining the strength of linkages between stock markets, and changes in those linkages over time, it is now generally acknowledged that this approach does have some shortcomings. Correlations are determined by short term trading noise as well as long term relationships between the markets; such short term variations in prices can obscure the picture of the long run (Chou, $\mathrm{Ng}$ and $\mathrm{Pi}, 1994$ ). Further insight into the existence (or otherwise) of long term relationships between stock markets can be gained directly, with reference to the concepts of stationarity and integrated time series ${ }^{12}$. If two stock price series are individually random walks, they will each be integrated of order 1. Analysis of correlations between the levels of stock prices may therefore produce spurious results, in the same way as the regression of one $I(1)$ series on another, and indicate a relationship when in fact none exists. Therefore, as Dwyer and Hafer note, "using the levels of the stock market indexes to judge whether there is any relationship between the markets is fallacious" (p.10).

One way to judge whether the relative stock price follows a random walk, as suggested, is to carry out unit root tests on the relative price series. Dwyer and Hafer find that for the period around the 1987 crash, relative stock prices for all of the pairs of countries considered do indeed have unit roots, supporting the random walk hypothesis. This result suggests that there is no constant relationship between the levels of national stock price indexes, and goes against the belief that the intensity of the 1987 crash was made more severe because markets in different countries tended to move together. They find similar results for unit root tests on relative stock prices during the floating exchange rate period.

12 Following Engle and Granger (1987), a non-stationary series which can be transformed into a stationary series by differencing $\mathrm{d}$ times is said to be integrated of order $\mathrm{d}$ A series $X_{t}$ integrated of order $\mathrm{d}$ is denoted: $X_{t}=I(d)$. 
Cointegration analysis can also be used to test for long term relationships between stock price indexes in different countries. If two markets are cointegrated, stock price indexes in the two markets will tend, over a long period of time, to follow each other. In fact the unit root test used by Dwyer and Hafer above on relative stock prices is equivalent to testing whether two stock price indexes are cointegrated with a coefficient $(\lambda)$ of unity. Their finding that unit roots exist in the relative stock price series indicates that the two series are not cointegrated in this way, i.e. that there is no long term relationship between the indexes.

An alternative interpretation of cointegration analysis as applied to stock markets is that it is a test for collective market efficiency. If there is a long term relationship between stock price levels in two markets, then the stock price in one market will be constantly adjusting towards the long term equilibrium value of the relative stock price of the two markets. This conflicts with the requirement of weak form efficiency that a market already incorporates all historical information.

Chan and Lai (1993) express this more formally in terms of cointegration and error correction. If stock price index series for two markets $\tilde{s}_{t}$ and $S_{t}$ are $I(1)$ and are cointegrated such that $\tilde{s}_{t} \cdot \lambda S_{t}$ is $\mathrm{I}(0)$, this gives error correction equations of the form:

$$
\begin{aligned}
& \Delta S_{t}^{\prime}=a_{1}\left[S_{i-i}^{i}-\alpha_{1} S_{t-1}^{J}\right]+\operatorname{lagged}\left(\Delta S_{t}^{\prime} \text { and } \Delta S_{t}^{\prime}\right)+e 1 t \\
& \Delta S_{t}^{\prime}=a_{2}\left[S_{t-1}^{\prime}-\alpha_{2} S_{t-1}^{\prime}\right]+\text { lagged }\left(\Delta S_{t}^{\prime} \text { and } \Delta S_{t}^{J}\right)+e 2 t
\end{aligned}
$$

where $a_{1}$ and $a_{2}$ are non-zero coefficients and the $e_{i t} s$ are stationary error terms.

The error correction equation simply states that if stock prices in markets $i$ and $j$ are cointegrated, then stock prices in market $i$ are predictable by $\left[S_{t}{ }^{i}-\alpha_{1} S_{j}\right]$. This is in conflict with the requirements of efficiency. Therefore, cointegration implies inefficiency (Chan \& Lai 1993: 281), a finding which echoes the conclusions of Granger (1986) and MacDonald and Taylor $(1988,1989)$ that asset prices from two efficient markets cannot be cointegrated.

Chan and Lai (1993) use cointegration analysis to test for long term relationships between fourteen major international stock markets. They find that most of these markets have some degree of interdependence with other markets, and in particular that nine markets are cointegrated with London. They conclude that "virtually all the stock markets were not collectively efficient during the period from 1988 to 1990 " (p.283), meaning that stock price movements in one market could be predicted by using stock prices in another market. This result appears to contradict their findings regarding the individual efficiency of the stock markets considered.

This result is interpreted in terms of the potential for international diversification of investment portfolios. Such diversification is ineffective if the returns on the different financial instruments in the portfolio are highly correlated. Chan and Lai conclude that cointegration of markets implies that the gains from international diversification would be limited, as some of the unsystematic risk cannot be diversified away.

An similar analysis is carried out by Chan, Gup and Pan (1992) who test for cointegration between the US and five major Far Eastern stock markets, using both daily and weekly data over the period 1983 to 1987 . They find that in all cases there is no evidence of cointegration between pairs of stock markets, and conclude that the markets are "pairwise weak-form efficient . . . stock prices of one country cannot be predicted by that of another single country" (p.302). This contrasts with Chan and Lai's result above. The differing results may be due to the different group of markets covered, or to the different time period used. However, it is perhaps significant that Chan and Lai's finding 
of cointegration between markets stems from the post-1987 Crash period whilst the finding of no cointegration stems from the pre-1987 period.

Taylor and Tonks (1989) paper addresses the issue of the internationalisation of stock markets in respect of a specific policy question, that is, the abolition of UK exchange controls in 1979. They analyse bivariate cointegration between the UK and four other developed country stock markets (the USA, Japan, West Germany, and the Netherlands) in pre- and post-liberalisation periods. They find no cointegration between the UK and the other markets in the pre-1979 period, but reject no cointegration (except with the US) in the post-1979 period. They conclude that cointegration has increased as a result of capital account liberalisation, and that this means that in the long run, correlations between returns in the UK and the Japanese, German and Dutch stock markets will be highly correlated. As a result, "the reduction in long-term portfolio risk from international diversification will be slight ... as long-run covariances between stock markets are higher than those in the short run" (p.336).

More recent analyses of cointegration between stock markets use multivariate rather than bivariate tests of cointegration. This enables cointegration to be tested between groups of markets rather than simply pairs of markets. As Chou, $\mathrm{Ng}$ and $\mathrm{Pi}(1994, \mathrm{p} .2)$ note: "not finding cointegration in a small system does not imply no cointegration in a larger system .... the finding of cointegration in a larger system, but not in a smaller subsystem of prices, can be interpreted as indicating that the linkage among international stock markets is broader and hence the markets are more integrated ${ }^{\text {i3 }}$. They employ the multivariate cointegration technique of Johansen (1988) and Johansen and Juselius (1989) to analyse linkages between six markets (the USA, the UK, Japan, France, Germany and Canada) from 1976 to 1989, using weekly data. They find that there are multivariate cointegrating vectors in the set of six stock market indices, indicating that there are long run equilibrium relationships between them. Using subsets of indices they find that there is cointegration between the three European market indices, and between the USA, Canada and Japan. Splitting the data into two sub-periods (1976-83 and 1983-89) they find that cointegrating relationship have become stronger over time, which they interpret as being consistent with the increasing liberalisation and globalisation of financial markets.

Harris and Smith (1996) undertake a similar multivariate analysis with fourteen European stock markets, using daily data, and specifically address the issue of whether greater economic integration within Europe has been accompanied by greater stock market integration. Again splitting the sample into two sub-periods, they find that cointegration has increased since 1990, and that a European equity market is emerging, with London playing a central role.

\section{Stock Markets and the Influence of Economic Fundamentals}

The standard model of share valuation holds that the equilibrium price of a share at time $t\left(p_{t}\right)$ is equal to the discounted present value of the expected future cash (dividend) flows from that share.

$$
p_{t}=\sum_{i=1}^{\infty} \beta^{i} E_{t} d_{t+i}
$$

where $E_{t+1}$ is the expected value at time $t$ of the dividend in period $t+i, \beta=(1+r)^{-1}$, and $r$ is the expected real interest (discount) rate.

13 Although, as pointed out earlier, a true test for capital market integration requires an 1 ssessment of the pricing of risk in different markets. The correct interpretation should simply be one of linkages between $\mathrm{rarkets}$. 
Anything which changes expected future profits (and hence dividends), or the discount rate, will therefore affect the share valuation. As noted above, in an efficient market share prices respond to information regarding economic fundamentals because of the impact on expected profitability of firms. An alternative approach to examining the determination of share prices in different countries is therefore to analyse the extent to which they are influenced by economic fundamentals.

The prices of individual company shares should be influenced by four sets of economic factors: those relating to individual firms, to particular sectors of the economy, to the national economy as a whole, and to the international economy. By considering national stock market indexes rather than the shares of individual firms or groups of firms the first two sets of information become redundant, and we can therefore consider the impact of national and international economic factors.

It is questionable whether the large declines in share prices that have been observed during crisis periods can really be explained by changes in economic fundamentals. During the 1987 Crash for instance, the US stock price index fell by $22 \%$ during the month of October, while many other countries' market indices fell by even larger amounts during the same period (Australia, for instance, fell by over 40\%). In 1997, large declines were experienced in several Asian markets; for instance, the Hong Kong stock market fell by $23 \%$ on October 22, 1997, while the South Korean stock market fell by almost $50 \%$ during the last four months of 1997 . However, it is not just in crash periods - which may be times of exceptional rather than typical behaviour - that the question becomes relevant. A similar question has been posed as a result of the long equity market bull run stretching into 1997 and 1998; does the steady rise in equity prices, especially in the US where there have been several years of double-digit returns, reflect a strengthening of economic fundamentals and a rise in corporate profitability? If the answer is yes, then the rise should be sustainable. If not, then the market looks increasingly overvalued with regard to those fundamentals, and a correction is likely.

A number of researchers have investigated the impact of economic fundamentals on share prices. Von Furstenburg and Jeon (1989) examine the causes of changes in stock prices in the USA, the UK, Japan and Germany using daily data during 1986-1988, and consider the impact of exchange rates, interest rates, and oil and gold prices. The results are unimpressive, and they are "unable to link stock price movements consistently with the broad economic fundamentals" (p.153). Shiller, in his discussant's comments on the this article, considers that:

A number of researchers have investigated the impact of economic fundamentals on share prices, and in some cases have attempted to separate out these influences from international influences. von Furstenburg and Jeon (1989) examine the causes of changes in stock prices in the USA, the UK, Japan and Germany using daily data during 1986-1988, and consider the impact of exchange rates, interest rates, and oil and gold prices. The results are unimpressive, and they are "unable to link stock price movements consistently with the broad economic fundamentals" (p.153). Shiller, in his discussant's comments on the this article, considers that:

probably the reason that we cannot explain stock price movements in terms of such fundamentals is that stock price indexes are not so determined. Most stock price index movements seem to be due to social attitude changes, spontaneous changes of public opinion (von Furstenburg and Jeon, 1989, p.173).

He also notes that there is no convincing explanation of the 1987 Crash in terms in expectations for long-run fundamentals; for instance, there was virtually no change in either the long-term rate of 
discount or in the expected growth of earnings. Instead, he attributes both the New York Crash and the international correlation of stock price movements to investor or market psychology.

However, this work is hampered by the use of high frequency (daily) observations. It is much more conceivable that changes in stock price indexes and economic fundamentals are closely linked only over longer periods. It has been pointed out that "changes in variables such as exchange rates or interest rates cannot be interpreted as changes in fundamentals at the high frequencies represented by daily price changes. Therefore the lack of correspondence between changes in those variables and stock prices is not surprising" (Durlauf, in von Furstenburg and Jeon 1989, p.175).

This is consistent with the findings of Fama (1990) that changes in the rate of growth of production (as a proxy for the changing economic conditions that would impact on expected dividend growth) have a significant impact on returns on the New York Stock Exchange. He finds in this and earlier work (Fama 1981) that real economic activity explains larger fractions of the variations in stock market returns for longer return horizons. For instance, whereas production growth explains only $6 \%$ of the variation in monthly returns on the NYSE (during 1953-1987), it explains $43 \%$ of the variation in annual returns. These results suggest that whereas short term (daily or weekly) changes in stock market indexes may well be largely influenced by "investor psychology" as Shiller has suggested, over the longer term economic fundamentals are more important, although even over the longer period a large proportion of stock market return variation is unexplained by real activity variables. Chen, Roll and Ross (1986) examine a range of economic factors that change expected cash flows and/or the discount rate. They find that several macroeconomic variables - the dividend yield, the spread between long and short term interest rates, inflation, and real output - significantly influence stock returns.

Remolona (1991) attempts to identify the impact of domestic and foreign economic fundamentals on excess stock market returns (where excess returns are the returns over a quarter minus the three month interest rate at the beginning of the quarter) in the USA, UK and Japan. The results show that real domestic growth rates have an influence on excess stock market returns (although the results are not particularly robust in statistical terms), but that foreign economic factors have no impact. What is interesting, and is the main point of the research, is that foreign excess returns appear to have an impact on domestic excess returns, and that domestic markets tend to overreact to changes in foreign markets, thereby driving market prices away from fundamental values.

Bennett and Kelleher (1988) examine the impact of both foreign stock market indexes and domestic economic fundamentals (including short and long term interest rates, industrial production, inflation and unemployment) on stock markets in the USA, Japan, the UK and West Germany, using regression analysis on monthly data over an approximately thirty year period to 1987 . The results show that there is some relationship between domestic and foreign stock price indexes. They also find that in all countries both short and long term interest rates have a significant impact on stock price indexes, and that in the UK, USA and Germany industrial production also has an impact. However, these results should be taken with some caution given the likelihood that some or all of the data series used are non-stationary and hence there is the possibility of spurious correlation arising in the regressions.

Dwyer and Hafer (1990) investigate the impact of a variety of domestic and foreign economic factors on changes in real stock prices in five industrial countries, using monthly data from 1973 to 1987. The variables considered include change in the interest rate, unexpected change in industrial production, and change in real exchange rate. Of these, the change in the domestic interest rate is the only variable that is consistently significant. However the overall explanatory power $\left(R^{2}\right)$ of the 
regressions is disappointingly small; they conclude that "there appears to be some relationship between changes in stock prices and interest rates, but the fraction of variation in these indexes explained is hardly overwhelming" (p.62).

The methods of analysis used in the above studies are now rather outdated, and do not take into account recent developments in econometrics. Typically, models are estimated by OLS, without testing the time series characteristics of the data, or examining whether long run cointegrating relationships are present. This may have an impact on the results. Dwyer and Hafer's (1990) model, for instance, models changes in real stock prices in terms of changes in domestic and US real interest rates, changes in domestic and US industrial production, and changes in the real exchange rate (vs. the US dollar). As these variables are likely to be stationary (i.e., if their levels are I(1)), this essentially models short term movements in stock prices, and does not examine long term relationships between stock prices and economic variables. Nevertheless, their approach is instructive for our purposes as it includes both domestic and foreign determinants of stock returns, and therefore potentially provides a means of modelling linkages between markets in different countries through economic variables.

\section{STOCK MARKETS IN SOUTHERN AFRICA}

Although there are a number of stock markets in Africa, all of them except for South Africa are small by global standards. As at the end of 1996, 14 stock markets existed in Africa, of which 11 were in sub-Saharan Africa (see Table 1). New markets are being established in Malawi, Uganda and Tanzania.

Table 1

African Stock Markets, 1996

(ranked by turnover)

\begin{tabular}{lrrrr}
\hline & $\begin{array}{r}\text { Capitalisation } \\
\text { (US\$ million) }\end{array}$ & $\begin{array}{r}\text { Turnover } \\
\text { (US\$ million) }\end{array}$ & $\begin{array}{r}\text { Turnover } \\
\text { ratio }\end{array}$ & $\begin{array}{r}\text { No. of } \\
\text { stocks }\end{array}$ \\
\hline Zambia & 229 & 3 & $1.0 \%$ & 5 \\
Swaziland & 1642 & 8 & $0.6 \%$ & 6 \\
Ghana & 1493 & 17 & $1.1 \%$ & 21 \\
Cote D'lvoire & 914 & 20 & $2.2 \%$ & 31 \\
Botswana & 326 & 31 & $9.0 \%$ & 12 \\
Namibia & 473 & 38 & $12.1 \%$ & 12 \\
Kenya & 1846 & 67 & $3.7 \%$ & 56 \\
Nigeria & 3560 & 72 & $2.6 \%$ & 183 \\
Mauritius & 1676 & 79 & $5.4 \%$ & 40 \\
Zimbabwe & 3635 & 255 & $\mathbf{8 . 8 \%}$ & 64 \\
Tunisia & 4263 & 281 & $6.8 \%$ & 30 \\
Morocco & 8705 & 432 & $5.9 \%$ & 47 \\
Egypt & 14173 & 2463 & $\mathbf{2 2 . 2} \%$ & 646 \\
South Africa & $\mathbf{2 4 1 5 7 1}$ & $\mathbf{2 7 2 0 2}$ & $\mathbf{1 0 . 9 \%}$ & $\mathbf{6 2 6}$ \\
\hline TOTAL & 284506 & 30967 & $10.9 \%$ & 1779 \\
Excluding South Africa & 42935 & 3765 & $8.8 \%$ & 1153 \\
\hline
\end{tabular}

Source: IFC Emerging Markets Factbook 1997

Most of the sub-Saharan African (SSA) markets are relatively small, whether measured in terms of capitalisation, turnover, or number of stocks, with the main exception being the Johannesburg Stock Exchange (JSE). Although the Nigerian market has a large number of stocks, trading levels 
are low, the market is illiquid, and is dominated by trading in government securities. In fact, African stock markets in general, including the JSE, are illiquid by global standards, a characteristic that may well have negative implications for market efficiency. As liquidity has also been found to be one of the most important factors linking stock market development with economic growth (Levine and Zervos, 1998), this could explain why the emergence of stock markets in Africa has as yet had little broader economic impact.

Of the SSA markets, those in Nigeria and Zimbabwe have been part of the IFCs Emerging Market Index (South Africa has been incorporated since the beginning of 1995). However, they are the two smallest markets in the Index. Although data is limited on overall portfolio capital flows into Africa, the small size of African markets suggests that they have been largely by-passed by the rapid increase in portfolio flows to emerging markets more generally in recent years, a situation which has been reinforced by the relatively strict controls on foreign ownership of shares in many of the countries where stock markets exist. However, with the ending of apartheid in South Africa, that country has become of interest to portfolio investors since 1994, and there have been substantial inflows. Anecdotal evidence suggests that the smaller stock markets in other southern African countries are benefiting from this renewed interest in the region.

Below and in Table 2 we summarise some of the key characteristics of the three southern African stock markets included in this study. The summary draws upon a number of sources, primarily IFC (1997), ZhuParris (1993), and Matome (1997).

\section{The Jobannesburg Stock Exchange (JSE)}

The JSE is the oldest stock market in Africa, having been established in 1887 shortly after the discovery of gold on the Witwatersrand. In the early years most of the capital required for the development of gold mines was raised overseas (primarily in London) and the role of the JSE as a forum for raising capital was limited, it being characterised more by speculative behaviour with frequent booms and crashes. Over the past century the market has grown steadily and become more diversified, but in some ways has changed little. It remains dominated by mining related firms, and is heavily influenced by the fortunes of the mining sector. And despite its apparent sophistication, the JSE is still criticised for being primarily a forum for speculative activity rather than for serious capital raising.

By the end of 1996 the JSE had 626 listed shares with a total market capitalisation of R1130 billion (US\$242 billion). In 1996 the JSE ranked as the 16th largest stock market in the world in terms of market capitalisation, and the third largest emerging market (after Malaysia and Taiwan). As a result it dwarfed all other stock markets in Africa, accounting for $85 \%$ of the total capitalisation of African stock markets (see Table 1). Over the period 1989-1996, market capitalisation grew by $240 \%$ in local currency terms, and $84 \%$ in US dollar terms, the difference resulting from the substantial depreciation of the rand against the US dollar over the period. The number of listed stocks, however, fell from 748 in 1989 to 626 in 1996. Market capitalisation also represents a very high proportion of GDP, at $206 \%$ in 1995 , which is much larger than the other two markets considered here. By these standards, therefore, the JSE is a very large market. 
Market capitalisation can however be a misleading indicator of the size of a market, and in terms of the value of business transacted, the JSE ranks much lower, at 26th in the world in 1996, and 10th among emerging markets. This reflects the relatively low liquidity of the market; in 1996 total trade (turnover) amounted to only $10.9 \%$ of market capitalisation, although this is a significant improvement from the $1.6 \%$ turnover ratio recorded in $1989^{14}$.

The illiquidity of the market itself reflects another characteristic of the JSE: the domination of share ownership by a small number of large conglomerate companies, which have their origins as mining houses. Because of this, most of the shares in companies quoted on the JSE are effectively unavailable for sale. This in turn reduces the number of shares available for purchase by the growing number of domestic institutional investors in South Africa as well as foreign portfolio investors. These institutions, with their preference for shares in blue chip companies, tend to hold on to such shares when they do manage to get hold of them, thus reducing further the shares available for trading. The situation is compounded by a combination of exchange controls, which restricts outward capital flows by both companies and institutional investors, and which effectively bottles up capital inside the country, and the preference of those capital owners for investing in financial rather than physical assets.

The analysis here splits the overall period into two sub-periods (1989-93, and 1994-96) (see section 6). In local currency terms, the first sub-period showed stronger growth, with market capitalisation increasing at an average annual rate of $22 \%$ in the first period, and $15 \%$ in the second period. The market index increased by $124 \%$ over the period as a whole, but this represented an average annual growth rate of $13.2 \%$ in period 1 , and $10.8 \%$ in period 2 . In US dollar terms (as reported by the IFC), however, the situation was reversed, with both market capitalisation and the index growing faster in the second period than the first. This difference is largely due to the impact of the financial rand, which applied to capital transactions until March 1995, and which sharply reduced the dollar value of local currency values in the first period. Although growth in local currency terms was slower in the second period, trading volumes were nonetheless higher. This is reflected in the increase in market liquidity (turnover ratio) noted above, and suggests that trading was generally keener in the second period.

Besides being affected by the political changes taking place in South Africa over this period, and in particular the lifting of formal and informal financial sanctions against the country, the JSE experienced a major set of reforms in late 1995. These reforms included permitting corporate membership of the exchange for the first time; the introduction of regulations covering the protection of investors and members; and the introduction of electronic trading, replacing the old open outcry system; and the permitting of negotiable brokerage fees. Furthermore, foreign investors have been exempt from paying withholding tax on dividends since October 1995. Together, these reforms should contribute to greater transparency and efficiency on the JSE.

\section{Botswana}

The Botswana Stock Market (BSM) was established in June 1989, as part of the government's attempts to diversify and expand the financial sector, and to provide a secondary market for publicly held shares. The BSM, which initially operated under a set of interim regulations, was formally established as the Botswana Stock Exchange (BSE) in 1995, following the passing of the Botswana Stock Exchange Act in 1994. Until early 1998, the market had only a single broker that

By comparison, the US had a turnover ratio of $84 \%$ in 1996, the UK 33\%, and Taiwan $172 \%$. 


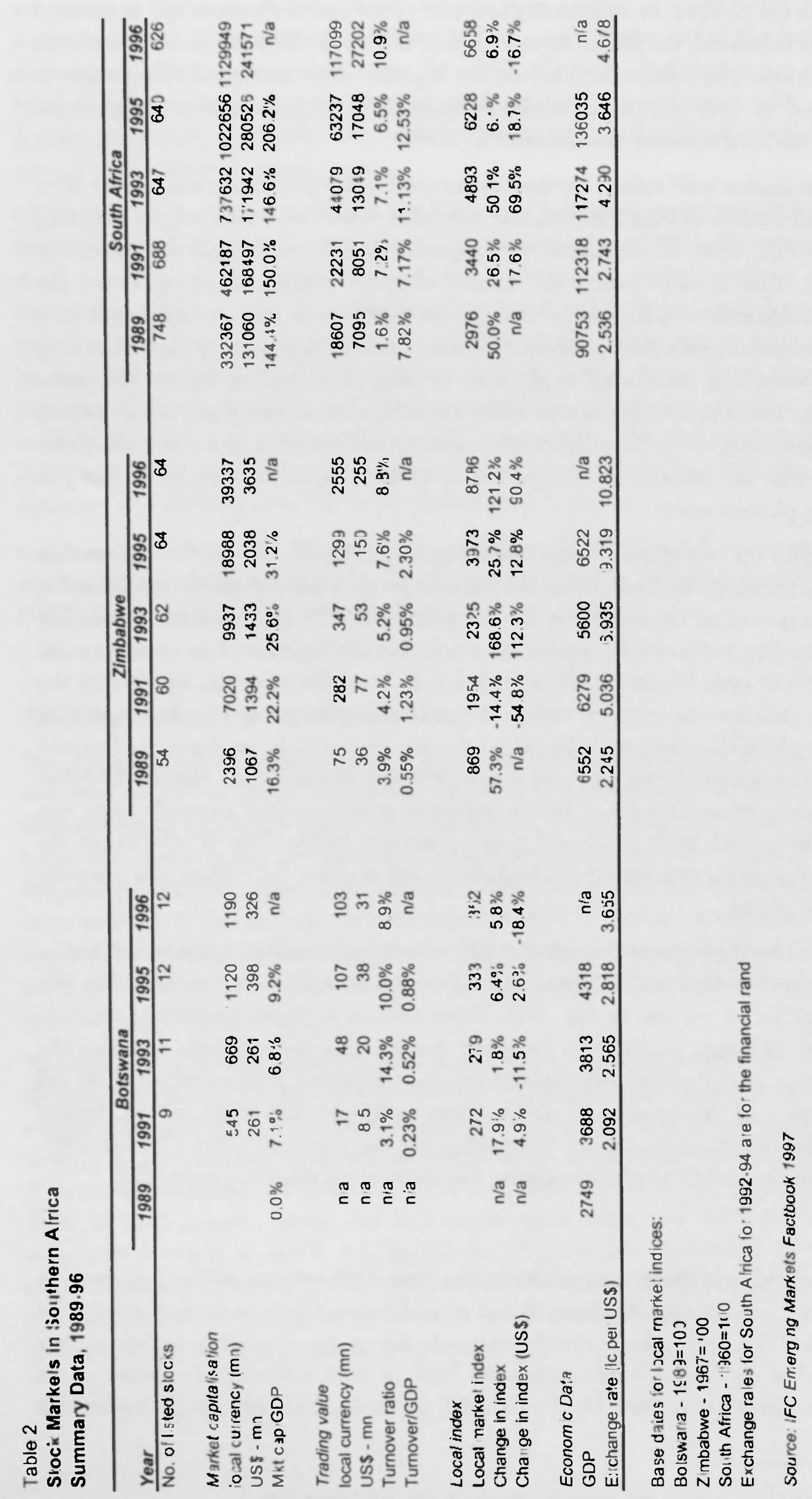


matched buy and sell orders but did not take positions; in other words, the BSE does not have a market maker. Many of the Act's provisions will only become relevant as more brokers are established ${ }^{15}$.

As at the end of 1996 there were 12 listed securities with a total market capitalisation of $1190 \mathrm{~m}$ (US\$326m). These listed securities cover a very narrow industrial spread, with more than half belonging to the financial institutions sector (including banks, insurance, etc.). Other activities represented include trade, property, and brewing. None of the companies active in Botswana's important mineral sector are represented on the BSE. Market capitalisation was equivalent to approximately $9 \%$ of GDP in 1995.

Market turnover is small by world standards, with total turnover of $\$ 32 \mathrm{~m}$ in 1996 , giving an average daily turnover of only $\$ 160,000$. Relative to total capitalisation, this gives market liquidity (measured annually) of $9.0 \%$ in 1996 , which is higher than that of most other SSA stock markets although low by world standards. The progress of the aggregate market is measured by a single allshare index (the Botswana Share Market Index), which is computed as a weighted average of relative prices. Although trading takes place daily, the index is calculated only on a weekly basis.

The BSM/BSE has grown rapidly since its establishment in 1989, when there were only five listed shares. Capitalisation grew by $900 \%$ between 1989 and 1996 in local currency terms, and $409 \%$ in US dollar terms, and listed shares grew to 12 . The average annual growth rates of market capitalisation were $47 \%$ and $21 \%$ in local currency terms in the first and second sub-periods respectively, and $37 \%$ and $8 \%$ in US dollar terms. Although the lower growth rates in dollar terms result from the depreciation of the pula (linked to the rand) against the dollar, this encouraged foreign buying, especially in the second sub-period, as shares on the BSE were viewed by foreign fund managers as being undervalued.

Over the period as a whole the market index grew at an average annual rate of $17 \%$ in pula terms and $7 \%$ in dollar terms. Growth rates were much higher in the $1989-93$ period, with the index rising at an average annual rate of $23 \%$ and $15 \%$ in pula and dollar terms respectively, compared to $8 \%$ and $-3 \%$ in dollar terms in the $1994-1996$ period. Nevertheless, both market liquidity and trading volume increased sharply in the second sub-period, largely reflecting the increased role of foreign investors.

There are some exchange control restrictions on inward investments by foreigners, although different restrictions apply to direct and portfolio investors. In the case of the latter, the restrictions are relatively loose and are effectively non-binding. There are no restrictions on the outflow of capital from share sales. Capital gains from investments in listed securities are exempt from capital gains tax, and there is a $15 \%$ withholding tax on dividends.

Although the BSE has grown rapidly since its establishment it remains small and has had only a limited impact on the availability of finance for investment (Jefferis, 1995). Previous research also suggests that, in its early days at least, the market was not efficient (Chisambi and Matome, 1993). Ownership of shares remains highly concentrated, with large shareholdings held by controlling parent companies.

In early 1998 a second broker was established, and the BSE now holds formal daily meetings between the two brokers to match trades. 


\section{Zimbabwe}

The Zimbabwe Stock Exchange (ZSE) is one of the world's oldest stock markets, having been established in 1896, although the current ZSE's uninterrupted operations only date back to 1946. It is the second largest in sub-Saharan Africa, with a total capitalisation of US\$255 million as at the end of 1996, and 64 listed securities. The ZSE has four broker members and employs a call-over trading method. The ratio of market capitalisation to GDP in 1995 was $31 \%$, rather more than Botswana but much less than South Africa. However, this figure is substantially ahead of the $17 \%$ capitalisation to GDP ratio recorded in 1989. Between 1989 and 1996, market capitalisation increased by $1542 \%$ in local currency terms and $240 \%$ in US dollar terms. The fastest growth occurred between 1994 and 1996, with capitalisation rising at an average annual rate of $36 \%$ in US dollar terms, compared to $8 \%$ in Zimbabwe dollar terms. The discrepancy between local currency and US dollar growth rates reflects the rapid depreciation of the Zimbabwe dollar, which fell from 2.25 to the US dollar at the end of 1989 to 10.82 at the end of 1996 . The market index has shown a similar growth pattern, rising by $110 \%$ in US dollar terms over the $1989-96$ period, representing an average annual rate of $-3.5 \%$ from 1989 to 12993 and $34 \%$ from 1994 to 1996.

The market has received a boost in recent years through the gradual relaxation of controls on foreign investment since late 1993, which has encouraged an inflow of foreign portfolio investors. Foreign presence has increased to such an extent that trading by such investors accounted for $78 \%$ of total trading in the year to March 1996. Nevertheless, some restrictions on foreign investors remain: a single foreign investor is not permitted to own more than $5 \%$ of a listed company, and total foreign ownership is not permitted to exceed $25 \%$ of the outstanding shares of a single company. Taxes are also relatively high: dividends are subject to a $20 \%$ semi-annual tax, and capital gains are taxed at a maximum rate of $30 \%$. The exact rate of capital gains tax depends on the length of time for which an investment has been held, and serves to discourage speculative trading on the market.

The increasing activity on the ZSE led to a rise in turnover from US\$36m in 1989 to US $5255 \mathrm{~m}$ in 1996, and a consequent increase in market liquidity from $4 \%$ to $9 \%$. Although historically a very illiquid market, the ZSE now has liquidity levels comparable to those of Botswana and South Africa. The rise in liquidity is matched by an increase in trading volumes between the two subperiods, due largely, as noted above, to the presence of foreign investors in the market.

\section{RESEARCH OBJECTIVES AND METHODOLOGY}

\section{Researcb Objectives}

The broad objectives of the current study are to analyse the efficiency of southern African stock markets, to analyse factors that determine movements in the market indices, and to evaluate the extent of linkages between those markets and with larger international stock markets. The more specific objectives are as follows:

1. to examine the (individual) efficiency of three stock markets in southern Africa (Johannesburg, Zimbabwe and Botswana), and to investigate the factors which may cause differing levels of efficiency across markets - such as the numbers of market participants, market liquidity, etc.;

2. to examine the extent of linkages between the three stock markets in southern Africa (to what extent are prices or price changes (rates of return) correlated across markets; whether there are any long term relationships between prices in the different markets; whether the strength of linkages appears to be changing over time); 
3. to examine the extent of linkages between the region's stock markets and larger international stock markets (focusing on New York and London) and emerging markets more generally;

4. to examine the impact of economic fundamentals (domestic, regional and international economic variables) on stock markets in the region.

5. to examine the efficiency of the markets in terms of the responsiveness of individual stocks to news or announcements.

Objectives 1, 4 and 5 are to enable conclusions to be drawn on the extent to which the region's stock markets are proving to be efficient in allocating financial capital through the efficient pricing of shares. Objectives 2 and 3 are aimed at evaluating the extent to which the Southern African markets are linked to each other and to the worlds stock markets more generally, and thereby to provide a preliminary assessment (from the perspective of co-movements in stock market indices) of the extent to which these markets are integrated with each other. This will provide information as to the extent of the benefits of international portfolio diversification. If those markets do not move closely with the larger international markets, then diversification into these markets offers benefits to potential inward international investors to the region. Similarly, if the regional stock markets are not closely linked, then inward portfolio investors would benefit from investing in all of the regional markets. If regional markets are closely linked, then diversification across markets has limited potential benefits and inward international investors to the region would achieve most or all of their gains by investing in one regional market only.

\section{Hypotheses}

The working hypotheses to be tested are as follows:

1. The smaller markets (Botswana and Zimbabwe) are not (weak form) efficient (due to an insufficient range of listed shares and market participants).

2. The Johannesburg Stock Exchange, as by far the largest market in the region and reasonably large by international standards, is efficient.

3. Changes in share prices in the smaller markets (Botswana and Zimbabwe) are correlated with changes in share prices on the JSE.

4. There is a long term relationship between share prices in the smaller markets with share prices on the JSE.

5. The JSE is linked to the major world stock exchanges (London and New York) as well as to emerging markets.

6. The smaller markets are not linked to the major world stock exchanges (London and New York) or to emerging markets.

7. The strength of linkages between stock markets in the region has increased over the period since 1989.

8. Share prices on the JSE reflect domestic and international economic factors.

9. Share prices on the smaller markets are influenced by: economic fundamentals in their respective domestic economies; the South African economy; and the world economy. 


\section{Methods of Analysis}

The methodology used here follows the approaches of several of the studies cited above which have researched stock market efficiency, international linkages between stock markets, and the impact of economic variables on stock markets. The following methods of empirical analysis are employed:

\section{(.x) Correlation analysis}

Following Dwyer and Hafer (1988) and a number of other authors, we analyse correlations between the changes in national stock market indexes $\left(\rho_{(\mathrm{dx})(\mathrm{dy})}\right)$. If changes in the indexes are found to be correlated this will be consistent with the view that there are factors (such as international financial transactions and capital flows, or trade in goods and services) which affect the different indexes in the same direction (Dwyer and Hafer 1988: 88).

\section{(b) Unit root tests of individual market efficiency}

Following Chan and Lai (1993) and Chan, Gup and Pan (1992) we examine the weak form efficiency hypothesis using unit root tests. Three models are used (model with both trend and drift, model with drift, and model with neither trend nor drift):

Model 1: $\quad y_{t}=\overline{Q_{u}}+\beta\left(t-\frac{T}{2}\right)+\beta_{2} y_{t-1}+u_{t} \quad$ (with trend and drift)

Model 2: $\quad y_{t}=\mathcal{R}_{0}^{*}+\overrightarrow{\beta_{2}} y_{t-1}+u_{i} \quad$ (with drift)

Model 3: $\quad y_{t}=\beta_{2}^{* *} y_{t-1}+u_{t}^{* *}$

where:

$$
\begin{aligned}
& y_{\mathrm{t}}=\text { any stock price series (in natural logs) } \\
& \mu \quad=\text { drift } \\
& T=\text { total number of observations } \\
& \mathrm{u}_{\mathrm{t}}=\text { error term }
\end{aligned}
$$

The hypothesis is:

$$
\mathrm{H}_{0}: \alpha=1 \quad \mathrm{H}_{1}: \alpha \neq 1
$$

If the hypothesis of a unit root in stock prices in a particular country is not rejected, it implies that the consecutive changes in stock prices over the relevant period are random. Therefore, the market index follows a random walk and its movement in any period cannot be predicted from information in the index in any previous period(s), and the market is weak form efficient (in the Fama (1970) sense). Tests for market efficiency are carried out individually for all of the markets in this study. Market efficiency tests are also carried out for various sub-periods. We note that in some cases, the predictability of stock returns can be affected by time-varying risk premia. Analysing subperiods therefore enables an assessment of the degree to which market efficiency changes over time.

In carrying out the unit root tests we employ a sequential testing technique which helps to distinguish series which are trend stationary from those which are difference stationary (see Dolado, Jenkinson and Sosvilla-Rivero, 1990; Harris, 1995), i.e., which of the models 1,2 or 3 is appropriate. Starting with the general model (Model 1) incorporating both trend and drift, we test the null hypothesis that $\vec{v}_{2}-1$ (i.e., that there is a unit root and the series is not $\mathrm{I}(0)$ ). If this is not 
rejected, we test the null hypothesis that $\beta_{l}=0$ (i.e., that the trend is insignificant). If that is not rejected we use the simplified Model 2, and test the null hypothesis that $\beta^{*}=1$. If this is not rejected we test the null hypothesis that $\vec{B}_{0}{ }^{*}=0$. If this is not rejected then we use a further simplified model (Model 3) without trend or drift, and test the null hypothesis that $\beta_{3}^{* *}=1$. Using this sequence of tests, it is possible to determine which, if any, of the three possible unit root models are appropriate. If the hypothesis of a unit root (i.e., the series is not $\mathrm{I}(0)$ ) was not rejected, then unit root tests are then carried out on the first differences of the selected model, to determine whether the selected series is I(1) or characterised by a higher order of integration.

\section{(c) Event Study}

An event study is carried out to gain insight into the efficiency of three stock markets in the southern Africa region. The aim is to evaluate the efficiency of the regional markets so as to determine the extent to which they may be integrated. Two tests are carried out. Firstly we use the market model to evaluate the response of each of the three markets to new information. This is done by using weekly data to calculate abnormal returns over a six month event window. Secondly, analysis and evaluation of cumulative abnormal returns is carried out. These tests aim to establish whether the three markets are (weak form) efficient with respect to earnings announcements.

Since the market model is used for the empirical exercise that follows herein, it is useful to clearly explain how measurement and analysis of abnormal returns are carried out. The standard methodology is as follows Firstly returns are measured in event time $t$. The event date is $t=0$ and $t=T_{1}+1$ to $t=T_{2}$ is the event window. The estimation window is $t=T_{0}+1$ to $t=T_{1}$ is the estimation window. Accordingly $L_{1}=T_{1}-T_{0}$ and $L_{2}=T_{2}-T_{1}$ are the length of the estimation window and the event window. The event window length should normally be larger than one so as allow for analysis of abnormal returns around the event day. If the event window is included in estimation of the normal model parameters, the event returns might bias the normal return measure. A further effect would be that the normal returns and the abnormal returns would capture the event impact. This is contrary to the epistemology of event studies, in that the basic assumption is that the event is captured only by the abnormal returns. To ensure that this does not happen and to ensure further that there are estimators of the parameters of the normal return model which are not influenced by the returns around the event, specifications ensure that the estimation window and the event window do not normally overlap. The post-event window data is used with estimation window data to estimate the normal return model. This assess the validity of the normal market return measure as its parameters are changed (see Campbell, Lo, and Mackinlay, 1997, pp.157-163 for further details).

The standard market model is used as follows to test the asset pricing efficiency of the three markets. The constant and slope of the regression are evaluated by weekly data. To estimate the distribution of abnormal returns over time, cumulative abnormal returns (CAR) are estimated. CAR are aggregated average abnormal returns calculated over the event window. To capture the residuals between actual stocks returns and returns to the market indexes, the market model is estimated as described above. For the market model residual returns we assume that the nominal stock returns are generated by the following process:

$$
R_{u t}=\alpha+\beta_{1} R_{m t}+e_{t t}
$$

$R_{u}$ is the natural logarithm of the return for firm $\imath$ in week $t$, and $R_{m u}$ is the natural logarithm of the return on the relevant market index, $\alpha$ and $\beta$ are the parameters to be estimated for the 60 -week period. The benefit of using the market model is dependent on the $R^{2}$ of the market model 
regression. The higher the $R^{2}$ the greater is the variance reduction of the abnormal return, and the larger is the gain.

\section{(d) Cointegration tests of long term relationships between markets}

The unit root tests allow us to examine whether the markets are individually efficient. However, individual market efficiency does not tell us anything about linkages between markets. Cointegration tests can be used to examine whether two asset markets are collectively efficient; if they are, then there will be no long term relationship between the markets and they will not be cointegrated (Granger, 1986; MacDonald and Taylor, 1988, 1989). Cointegration therefore implies inefficiency. As investors typically want to diversify away unsystematic risk, cointegration between markets reduces the benefits to investors of diversification. Following Chan and Lai (1993), the null hypothesis is that there is no cointegration among stock prices in different markets. Cointegration analysis is carried out both within the southern African markets and between these markets and other emerging markets and two of the larger developed country markets. Bivariate tests for cointegration are applied to the levels of stock market indexes in pairs of countries, and multivariate tests are applied to broader groups of markets. This is done for both the whole period and for different sub-periods, in order to assess whether the strength of linkages (if any) between the markets has been changing over time. It should be noted that while many authors interpret such cointegration tests as tests of the degree of integration of equity markets, they are more appropriately interpreted as tests of co-movements between markets. Capital market integration should rather be assessed in terms of whether the price of risk is equated across markets, which requires completely different empirical techniques such as the international capital asset pricing model or international arbitrage pricing theory.

In order to ensure comparability between countries, national stock price indexes (which are calculated in national currencies) are adjusted for exchange rate changes and expressed in a common currency. In keeping with much of the literature on this topic, we do not attempt to incorporate dividends into stock returns. Data on dividends (for markets as a whole) are much less readily available than on stock price indexes, for the markets under consideration, especially at the frequency of data to be used in this analysis.

\section{(e) Impact of Economic Fundamentals}

Correlation analysis and tests of market efficiency do not themselves determine what factors cause stock market indexes to change. Efficiency tests examine whether markets incorporate available information, but cannot determine what kind of information the markets respond to. We therefore examine two aspects of this question. At the micro level, event study methodology is used to determine the responsiveness of individual stock prices to items of news (see section (c) above). At the macro level, we model the relationship between stock market indices in Botswana, South Africa and Zimbabwe and macroeconomic variables from those countries, to determine the extent to which individual stock markets respond to national economic fundamentals. However, as wee are interested in linkages between national stock markets, we also include foreign economic variables as channels for generating linkages between markets. It is possible that any linkages found between the Botswana, Zimbabwe and South African markets may be partly due to the impact that the South African economy has on the smaller economies of the region. Similarly, if the southern African markets are linked to broader international markets, this may be due to the impact of international economic developments.

Our approach does not attempt to derive a fundamentals model from first principles, and must be considered a somewhat preliminary attempt to link southern African stock market indices with 
economic variables. It is based upon the "atheoretic" model of Dwyer and Hafer (1990), with some adaptations in terms of the variables included and the empirical techniques used. The choice of variables is focused upon factors that might influence share valuations, either through expected future dividends or the discount rate. We therefore include the domestic interest rate, and gross domestic product (Dwyer and Hafer use industrial production, but this data series is not available for the countries under consideration). Dwyer and Hafer incorporate possible influences of foreign developments (for countries other than the USA) by including US industrial production, the US interest rate, and the real exchange rate (relative to the USA). We follow this approach by including (for Botswana and Zimbabwe) the South African interest rate and GDP, and the real exchange rate relative to South Africa. For South Africa, we include the US interest rate and GDP, and the real exchange rate relative to the USA (as a proxy for international economic conditions).

The model to be estimated is therefore:

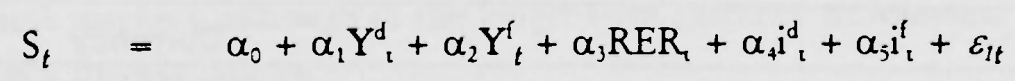

where: $S$ is the real stock market index; $Y^{d}$ and $Y^{f}$ are domestic and foreign real GDP; $\imath^{d}$ and $t^{f}$ are domestic and foreign real interest rates; $X$ is real exports; and $R E R$ is the real exchange rate (precise definitions are provided in Table 9).

A priori, it is expected that the real stock market index will be positively related to real GDP, the real exchange rate and foreign interest rates, and negatively related to domestic interest rates. The link between the level of real GDP and profits is straightforward, while for the real exchange rate, a rise (depreciation) will boost the profitability of domestic producers of tradables (exports and import substitutes) vis-a-vis foreign competitors. Modelling factors that might influence the discount rate is more difficult. Whereas Dwyer and Hafer use interest rates, Chen, Roll and Ross (1986) employ a more sophisticated approach that includes both interest rates and risk premia. They point out that the discount rate is an average of different rates over time, and therefore incorporate term-structure spreads across different maturities of instruments (measured by the spread between the 1-month Treasury Bill rate and the long term government bond yield). Risk premia are measured by spreads between yields on low-grade bonds and long-term government bonds. In the three Southern African markets under consideration, however, data on these different rates of return are not available (either because the instruments do not exist, or if they do exist the data are not reported). Hence this analysis retains the rate of interest as the proxy for the discount rate.

The role of domestic and foreign interest rates will depend upon the degree of an economy's integration into international capital markets. Higher real interest rates are typically expected to depress the stock market index, whether through a substitution effect (the improved attractiveness of interest-bearing instruments vis-a-vis shares), an increase in the discount rate (and hence a reduced present value of future expected profits), or a depressing effect on investment and hence on future expected profits. However, whether domestic or foreign interest rates are more relevant is an interesting issue. If an economy is integrated into international capital markets (and thus there is capital mobility), foreign real interest rates would be the relevant benchmark. Without international capital market integration, however, (for instance, if capital mobility is limited through the use of exchange controls), then domestic rather than foreign interest rates would be more relevant. The expected sign on foreign real GDP is uncertain. If exports are important, then the growth of export markets should boost profits and hence share values. However, at the same time higher foreign GDP will boost the attractiveness of foreign shares, and this may depress (at least in relative terms) domestic share prices. It is worth noting that Dwyer and Hafer found a 
negative impact for changes in US real GDP when included in their regressions for stock market returns in Canada, Japan, and Germany.

The estimation of the model follows the approach of testing for the stationarity (or otherwise) of the variables, determining whether there is a long run (cointegrating) relationship between any nonstationary variables, and, if appropriate and possible with the data, estimating a short run error correction model.

\section{RESULTS: STOCK MARKET LINKAGES}

\section{Data}

Data was obtained on the following stock market indices:

\begin{tabular}{llr}
\hline Market & Index & Currency \\
\hline South Africa: & Johannesburg Stock Exchange, all share index & ZAR \\
Zimbabwe: & Zimbabwe Stock Exchange, industrial index & ZWD \\
Botswana: & Botswana Stock Exchange, all share index & BWP \\
Emerging Markets: & IFC Emerging Markets Price Index & USD \\
Latin America: & IFC Latin American Index & USD \\
Asia: & IFC Asia Index & USD \\
USA: & Standard \& Poors Composite Index & USD \\
UK: & FT All Share Index & GBP \\
\hline
\end{tabular}

The data obtained is weekly stock market index data (closing values), covering the period June 1989 - December 1996. This period was chosen to ensure that information on all of the markets listed above was available throughout ${ }^{16,17}$. This gives a total of 393 observations on each variable. It should be noted that the market indices reflect different compositions of stocks in terms of industrial sectors.

In addition to the stock market indices, data was obtained on the relevant weekly exchange rates over the period (ZAR/USD, ZWD/USD, BWP/USD, GBP/USD) in order to covert local currency indices into US dollars ${ }^{18}$. US dollar indices are more relevant for comparison of returns between countries ${ }^{19}$.

All variables were transformed into $\log$ form and, where appropriate, first differenced to obtain rates of return. Rates of return are therefore given as the percentage rate of change in the market index. In common with most of the literature and empirical work on this topic, dividend payments are excluded from returns. This is because dividend data is not available on a consistent and regular basis for some of the markets considered, and dividends are likely to be relatively small compared to market index movements over a weekly period.

16 June 1989 was chosen as the starting date as this was when the Botswana Share Market, the newest of the markets included, commenced operations.

17 It was originally intended to include stock markets in Namibia and Swaziland. However it proved impossible to obtain an unbroken and consistent time series of market index data for these countries. Following comments made at an earlier $A E R C$ research workshop, the researchers also attempted to obtain data on the Nairobi Stock Exchange. However, as NSE data could only be obtained for the $1994-96$ period, it was not included in the study.

18 The exchange rates used were opening spot mid-rates on the last day of each week.

19 Data sources were as follows: Market indices - Botswana Stock Exchange, Zimbabwe Stock Exchange, Johannesburg Stock Exchange, International Finance Corporation (IFC), Datastream; Exchange rates - Bank of Botswana. 


\section{Summary Statistics}

Charts of the various market indices and rates of change in US dollars for all markets, and also in local currency for southern African markets, are shown in Figs. 1 to 4 . Summary statistics for rates of change in local currencies and US dollars are shown in Tables $3 a$ to $3 c$, and $4 a$ to $4 c$. Key findings from the summary statistics include:

- For the southern African markets, mean rates of return were lower in US dollar terms than in local currency terms (see Tables $3 a$ and 4a). This is a result of the depreciation of local currencies against the US dollar over the period.

- For southern African markets, volatility in rates of return (as measured by standard deviations) were higher in US dollar terms than in local currency terms. This suggests that in the short term, exchange rate fluctuations exacerbated stock market fluctuations for foreign investors in these markets, although in the longer-term currency movements tended to offset movements in stock market indices.

- Mean rates of return for southern African markets in US dollar terms were higher than for emerging markets as a whole, and were comparable with those in the USA and the UK.

- Latin American markets showed the highest mean returns as well the highest volatility of returns.

- Asian markets showed the lowest mean returns, perhaps surprisingly in view of the region's economic success over the period.

In order to evaluate whether there have been changes in stock market performance over the period, the data has been split into two sub-periods. Period 1 runs from June 1989 to December 1993 (237 observations), and Period 2 runs from January 1994 to December May 1996 (156 observations). This break point was chosen for a number of reasons relevant to the southern African markets.

- South Africa's first democratic general election was held in 1994, and this year marked the full return of South Africa to international economic acceptability.

- Zimbabwe undertook substantial liberalisation of exchange control regulations in late 1993, which resulted in substantial opening up of the stock market to international investors.

- Botswana also undertook exchange control liberalisation on the capital account, beginning in 1994 (although some of these changes did not take effect until 1995).

Comparing the two sub-periods (in Tables $3 b$ and $3 c$, and $4 b$ and $4 c$ ), several changes are evident.

- In US dollar terms, mean returns were lower in Period 2 in South Africa and Botswana, and rose in Zimbabwe, with little change in volatility of returns. In local currency terms the same changes are evident, but are less marked.

- In Period 2, negative mean returns were evident in Botswana, Emerging Markets as a whole, Latin America, and Asia.

- In neither period were mean returns in Emerging Markets as high as those in the USA and the UK.

- The biggest contrast between the two sub-periods is evident in the case of Zimbabwe, which showed the lowest mean returns of all markets in Period 1 and the highest in Period 2. Of the developing country markets, only Zimbabwe achieved positive mean returns in Period 2. 
Fig.1 Stock Market Indexes (logs): Levels and Changes

Southern Africa - Local Currencies

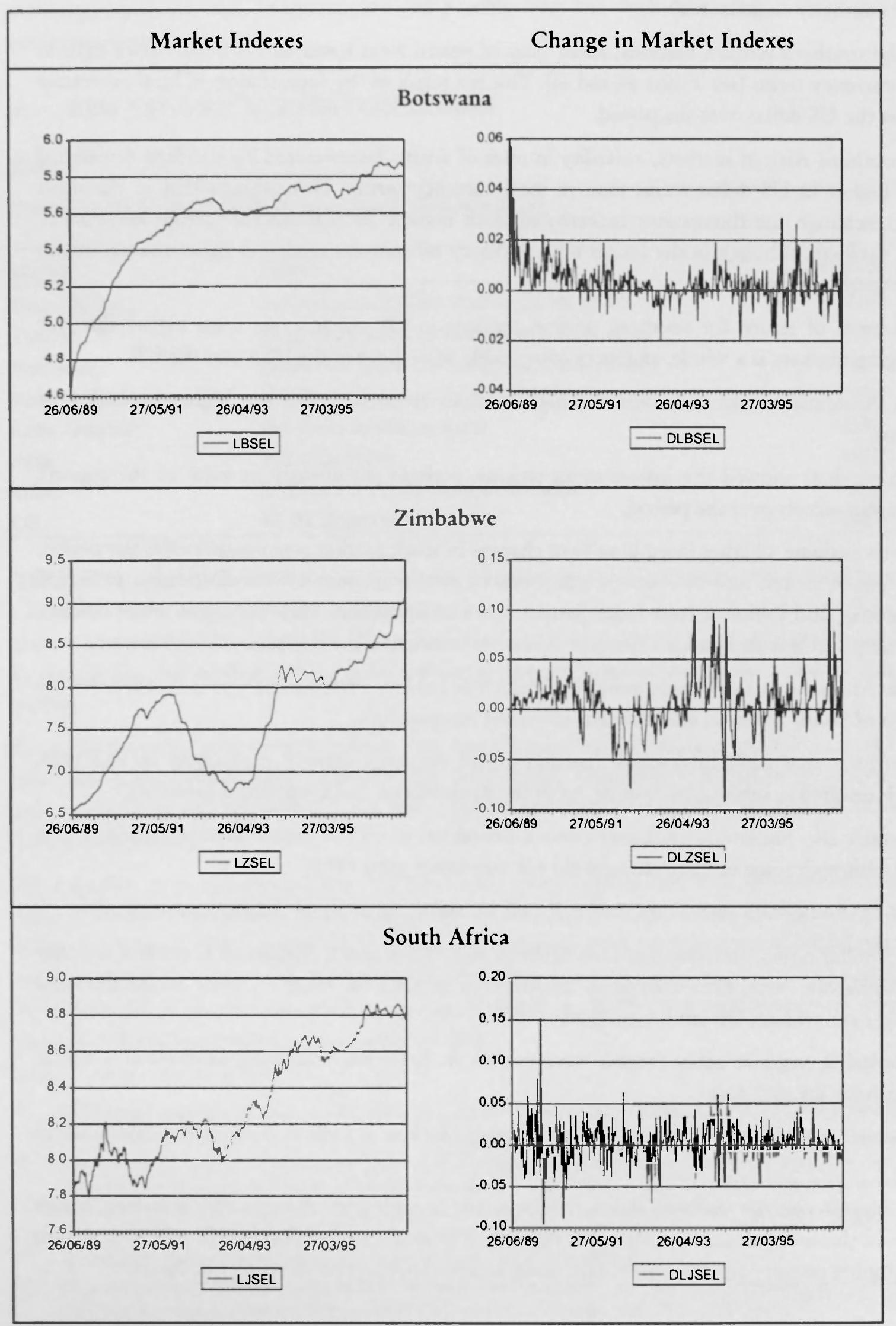


Fig.2 Stock Market Indexes (logs): Levels and Changes

Southern Africa - US Dollars

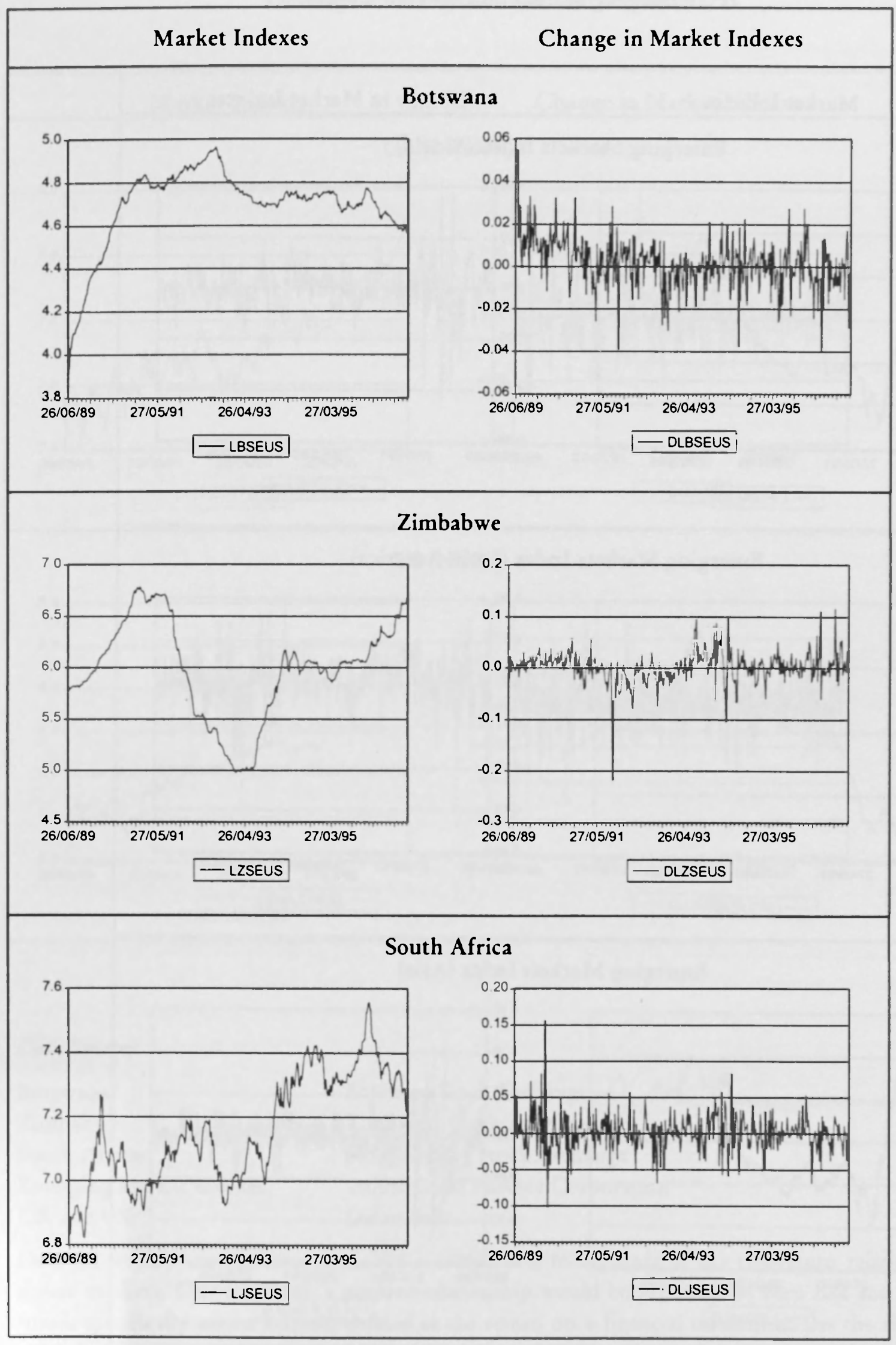


Fig. 3 Stock Market Indexes (logs): Levels and Changes

IFC Emerging Market Indexes - US Dollars

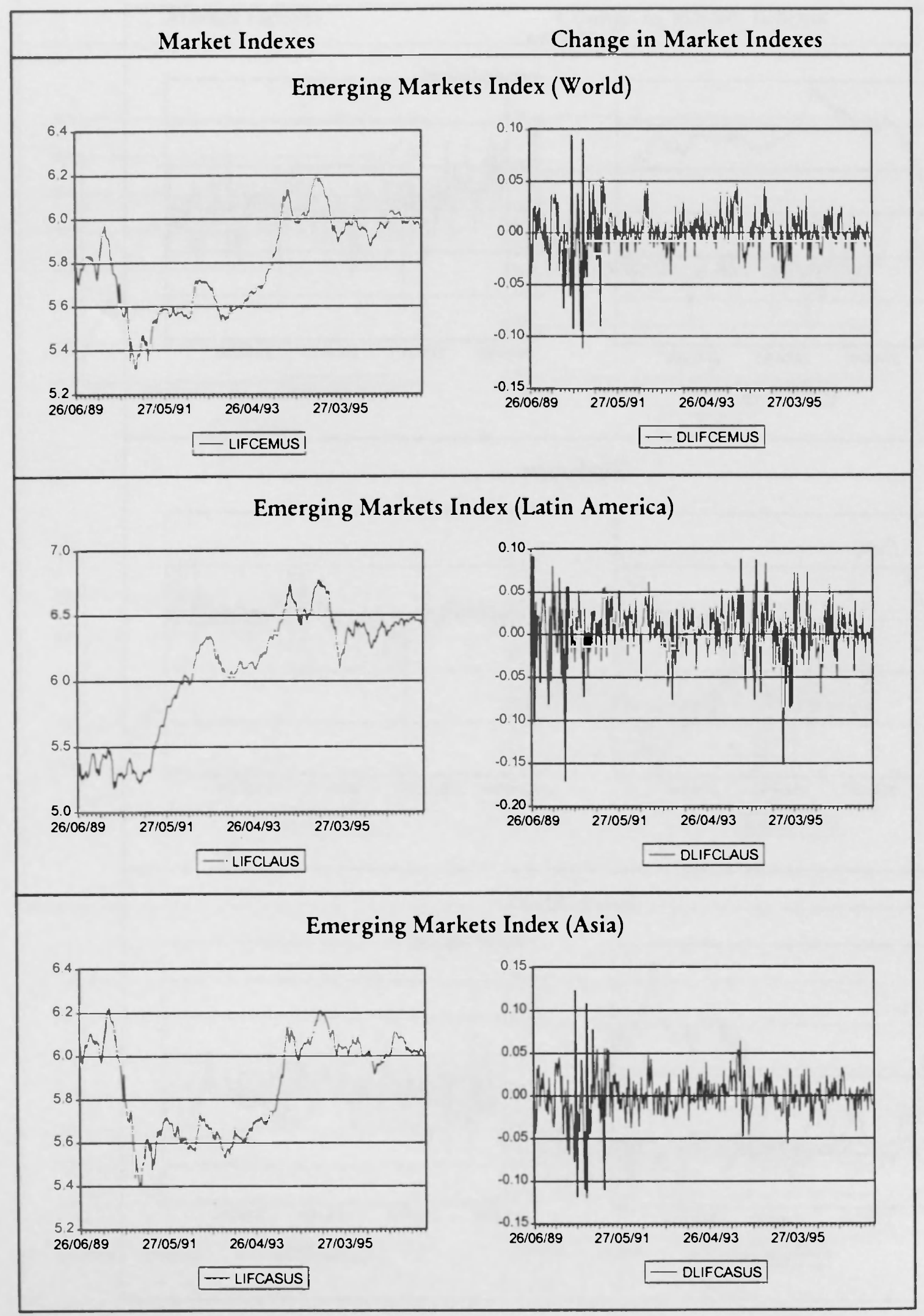


Fig.4 Stock Market Indexes (logs): Levels and Changes

Developed Markets: UK and US (US Dollars)

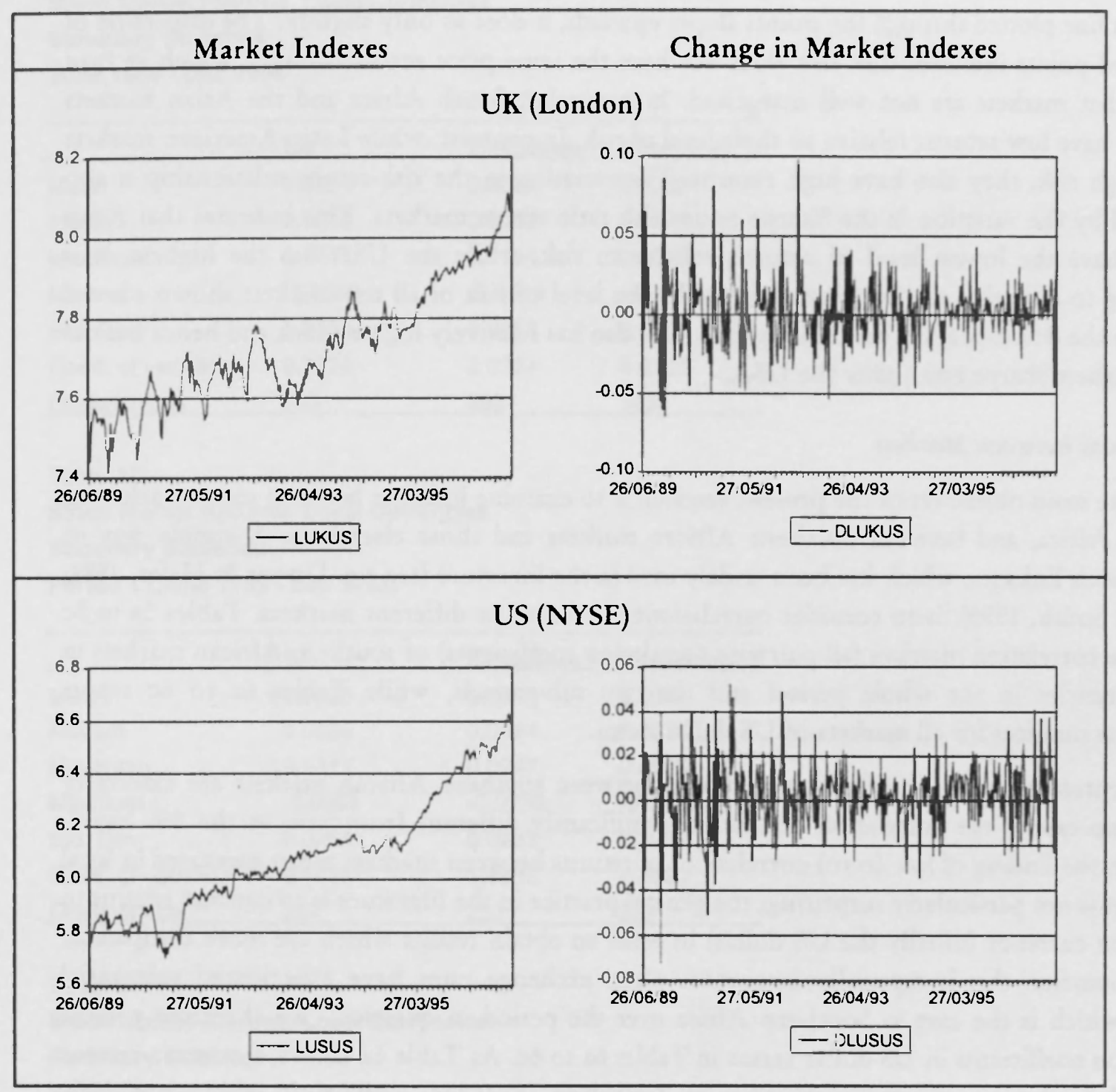

Data Sources:

Botswana:

Zimbabwe:

South Africa:

Emerging Market Indexes:

UK and US:
Botswana Stock Exchange

Zimbabwe Stock Exchange

Johannesburg Stock Exchange

International Finance Corporation

Datastream

Data on weekly market returns enables a comparison to be made of the risk-return relationship across markets. Ceteris paribus, a positive relationship would be expected between risk and return (more specifically excess returns, defined as the return on a financial instrument less the risk-free return). A simple measure of the risk-return relationship over the period 1990 to 1996 across the 
seven markets is plotted in Figure 5. This shows the mean weekly stock market excess return (measured as the actual return minus the average interest rate on US Treasury Bills over the period) plotted against the standard deviation of weekly excess returns (all returns are measured in US dollar terms).

Figure 5 indicates that there is no strong relationship between risk and excess returns. Although the regression line plotted through the points slopes upwards, it does so only slightly. The dispersion of the plotted points indicates that risk does not have the same price across markets, which in turn suggests that markets are not well integrated. In particular, South Africa and the Asian markets appear to have low returns relative to their level of risk. In contrast, while Latin American markets have a high risk, they also have high returns. The variation in the risk-return relationship is also illustrated by the variation in the Sharpe return-risk ratio across markets. This indicates that Asian markets have the lowest level of returns relative to risk, while the USA has the highest. It is interesting to note that the Botswana has the lowest level of risk of all the markets shown - lower even than the developed UK and US markets - but also has relatively high returns and hence has the second-highest Sharpe ratio, after the USA.

\section{Correlations between Markets}

One of the main objectives of the present research is to examine linkages between stock markets in southern Africa, and between southern African markets and those elsewhere. A simple way to evaluate such linkages, which has been widely used in the literature (see e.g. Dwyer \& Hafer, 1988; Harris \& Smith, 1995), is to consider correlations of returns in different markets. Tables 5a to 5c report the correlation matrices (all pairwise correlation coefficients) of southern African markets in local currencies in the whole period and the two sub-periods, while Tables $6 a$ to $6 \mathrm{c}$ report correlation matrices for all markets in US dollar terms.

In local currency terms, correlations of returns between southern African markets are extremely low. In no case is the correlation coefficient significantly different from zero at the $5 \%$ level ${ }^{2}$. However, the finding of low (zero) correlations of returns between markets when measured in local currencies is not particularly surprising; the general practice in the literature is to convert returns to a common currency (usually the US dollar) in order to obtain results which are more comparable across countries. this is especially important when exchange rates have experienced substantial change, which is the case in Southern Africa over the period in question. We therefore present correlation coefficients in US dollar terms in Tables 6a to 6c. As Table 6a shows, Botswana returns (in US dollars) are correlated with those in Zimbabwe $(\rho=0.224)$ and South Africa $(\rho=0.300)$. Taking the two sub-periods separately, however, shows the surprising conclusion that correlations have decreased, despite liberalisation. In Period 1 all three pairwise correlation coefficients in southern African markets are significantly different from zero, but in Period 2 only one is (Botswana-SA). And although the Botswana-SA correlation appears to have increased between the two periods, there is no statistically significant difference in the correlation coefficient in the two sub-periods (see Table 6d); it has therefore been relatively stable over time. The only statistically

20 The test statistic used was $\sqrt{ }((\mathrm{T}-2) \mathrm{r} /(1-\mathrm{r}))$ which bas a $\mathrm{t}$-distribution with $\mathrm{T}-2$ d.f. where $\mathrm{r}$ is the sample correlation coefficient; $T$ is the number of observations. This tests $\mathrm{H}_{0}: \rho=0$ against $\mathrm{H}_{1}: \rho=1$. 
significant change in the correlations of returns between Southern African markets is between Zimbabwe and Botswana, where the correlation fell between the two periods ${ }^{21}$.

\section{Table 3a}

Stock Market Returns, Local Currencies

Summary Statistics

June 1989 - Dec 1996

\begin{tabular}{llll}
\hline & SA & Zimbabwe & Botswana \\
\hline Mean & 0.0024 & 0.0064 & 0.0032 \\
Median & 0.0019 & 0.0062 & 0.0024 \\
Maximum & 0.1517 & 0.1124 & 0.0569 \\
Minimum & -0.0963 & -0.0918 & -0.0200 \\
Std. Dev. & 0.0238 & 0.0253 & 0.0081 \\
Coeff. of variation & 9.7728 & 2.5304 & 3.9405 \\
Observations & 393 & 393 & 393 \\
\hline
\end{tabular}

Table 3b

Stock Market Returns, Local Currencies

Summary Statistics

Period 1 (June 1989 - Dec 1993)

\begin{tabular}{llll}
\hline & SA & Zimbabwe & Botswana \\
\hline Mean & 0.0028 & 0.0051 & 0.0043 \\
Median & 0.0029 & 0.0064 & 0.0030 \\
Maximum & 0.1517 & 0.0947 & 0.0569 \\
Minimum & -0.0963 & -0.0788 & -0.0200 \\
Std. Dev. & 0.0264 & 0.0233 & 0.0082 \\
Coeff. of variation & 9.4831 & 1.8982 & 4.5890 \\
Observations & 237 & 237 & 237 \\
\hline
\end{tabular}

Table 3c

Stock Market Returns, Local Currencies

Summary Statistics

Period 2 (Jan 1994 - Dec 1996)

\begin{tabular}{llll}
\hline & SA & Zimbabwe & Botswana \\
\hline Mean & 0.0019 & 0.0085 & 0.0015 \\
Median & 0.0007 & 0.0057 & 0.0013 \\
Maximum & 0.0613 & 0.1124 & 0.0288 \\
Minimum & -0.0499 & -0.0918 & -0.0198 \\
Std. Dev. & 0.0192 & 0.0281 & 0.0076 \\
Coeff. of variation & 10.1010 & 5.1232 & 3.3127 \\
Observations & 156 & 156 & 156 \\
\hline
\end{tabular}

The test statistic used was $\left[\ln \left(\left(1+r_{1}\right) /\left(1-r_{1}\right)\right)-\ln \left(\left(1+r_{2}\right) /\left(1-r_{2}\right)\right] / 2 v\left[1 /\left(T_{1}-3\right)+1 /\left(T_{2}-3\right)\right]\right.$, where $T_{1}$ and $T_{2}$ are the number of observations in Periods 1 and 2 respectively, and $r_{1}$ and $r_{2}$ are the correlation coefficients for the two periods (Kendall and Stewart, 1967). 


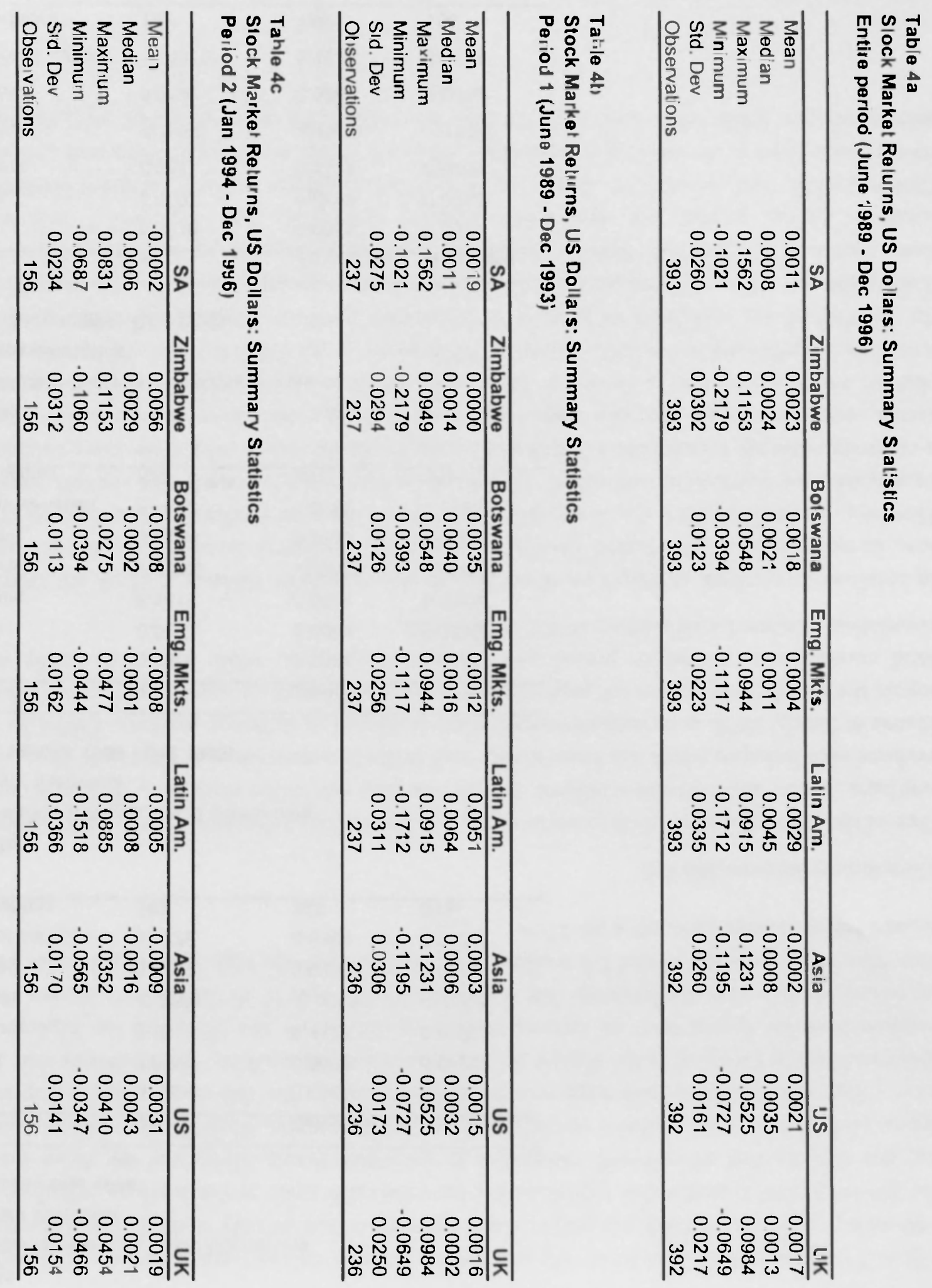




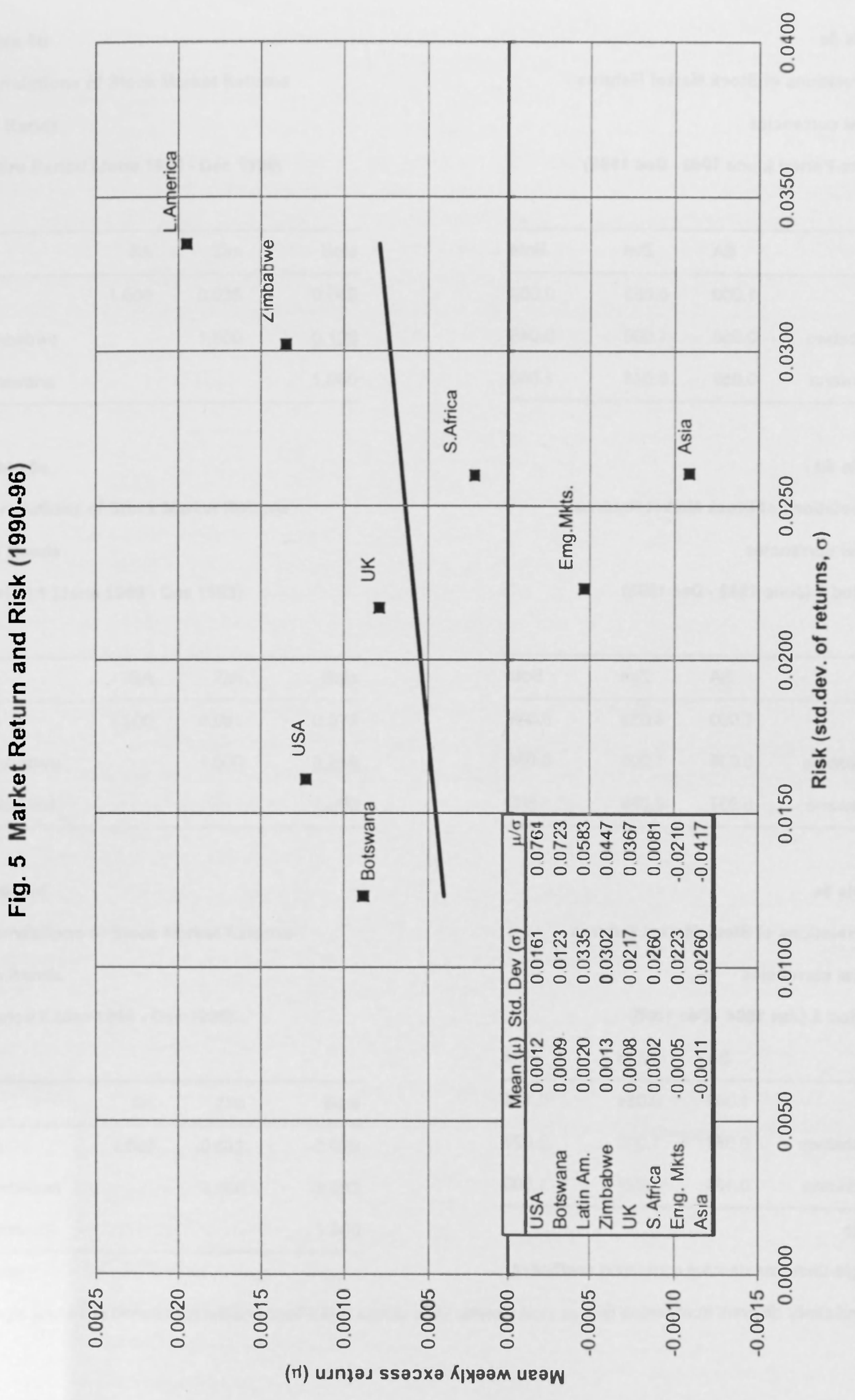


Table 5a

Correlations of Stock Market Returns

Local currencies

Entire Period (June 1989 - Dec 1996)

\begin{tabular}{lrrr}
\hline & SA & Zim & Bots \\
\hline SA & 1.000 & 0.053 & 0.059 \\
Zimbabwe & 0.053 & 1.000 & 0.048 \\
Botswana & 0.059 & 0.048 & 1.000 \\
\hline
\end{tabular}

Table 5b

Correlations of Stock Market Returns

Local currencies

Period 1 (June 1989 - Dec 1993)

\begin{tabular}{lrrr}
\hline & SA & Zim & Bots \\
\hline SA & 1.000 & 0.039 & 0.037 \\
Zimbabwe & 0.039 & 1.000 & 0.086 \\
Botswana & 0.037 & 0.086 & 1.000 \\
\hline
\end{tabular}

Table 5c

Correlations of Stock Market Returns

Local currencies

Period 2 (Jan 1994 - Dec 1996)

\begin{tabular}{lrrr} 
& SA & Zim & Bots \\
\hline SA & 1.000 & 0.084 & 0.104 \\
Zimbabwe & 0.084 & 1.000 & 0.027 \\
Botswana & 0.104 & 0.027 & 1.000 \\
\hline Note & & &
\end{tabular}

Note

single underline denotes correlation coefficient

significantly different from zero at $5 \%$ 
Table 5d

Correlations of Stock Market Returns

SA Rands

Entire Period (June 1989 - Dec 1996)

\begin{tabular}{lrcc}
\hline & SA & Zim & Bots \\
\hline SA & 1.000 & 0.035 & 0.049 \\
Zimbabwe & & 1.000 & $\underline{0.139}$ \\
Botswana & & & 1.000 \\
\hline
\end{tabular}

Table $5 e$

Correlations of Stock Market Returns

SA Rands

Period 1 (June 1989 - Dec 1993)

\begin{tabular}{lrrr}
\hline & SA & Zim & Bots \\
\hline SA & 1.000 & 0.081 & 0.079 \\
Zimbabwe & & 1.000 & $\underline{0.219}$ \\
Botswana & & & 1.000 \\
\hline
\end{tabular}

Table $5 f$

Correlations of Stock Market Returns

\section{SA Rands}

Period 2 (Jan 1994 - Dec 1996)

\begin{tabular}{lrrr}
\hline & SA & Zim & Bots \\
\hline SA & 1.000 & -0.032 & -0.028 \\
Zimbabwe & & 1.000 & 0.082 \\
Botswana & & & 1.000 \\
\hline
\end{tabular}

Note

single underline denotes correlation coefficient significantly different from zero at $5 \%$ 
Table 6a

Correlations of Stock Market Returns (US dollars)

Entire Period (June 1989 - June 1996)

\begin{tabular}{lllllllll}
\hline \multicolumn{2}{r}{ SA } & Zim & Bots & EM & LA & Asia & US & UK \\
\hline SA & 1.000 & 0.082 & $\underline{0.299}$ & $\underline{0.254}$ & $\underline{0.154}$ & $\underline{0.195}$ & 0.034 & $\underline{0.245}$ \\
Zimbabwe & 1.000 & $\underline{0.174}$ & 0.024 & 0.067 & 0.004 & 0.032 & $\underline{0.151}$ \\
Botswana & & 1.000 & -0.076 & 0.032 & $\underline{-0.128}$ & 0.008 & $\underline{0.257}$ \\
Ema. Mkts. & & & 1.000 & $\underline{0.524}$ & $\underline{0.915}$ & $\underline{0.259}$ & $\underline{0.205}$ \\
Latin Am. & & & & 1.000 & $\underline{0.183}$ & $\underline{0.232}$ & $\underline{0.159}$ \\
Asia & & & & & 1.000 & $\underline{0.193}$ & $\underline{0.145}$ \\
IIS & & & & & & 1.000 & $\underline{0.355}$ \\
UK & & & & & & & 1.000 \\
\hline
\end{tabular}

Note: sinale underline denotes correlation coefficient sianificantlv different from zero at $5 \%$

Table 6b

Correlations of Stock Market Returns (US dollars)

Period 1 (June 1989 - Dec 1993)

\begin{tabular}{lllllllll}
\hline \multicolumn{1}{r}{ SA } & Zim & Bots & EM & LA & Asia & US & UK \\
\hline SA & 1.000 & $\underline{0.145}$ & $\underline{0.237}$ & $\underline{0.227}$ & $\underline{0.122}$ & $\underline{0.197}$ & 0.023 & $\underline{0.236}$ \\
Zimbabwe & 1.000 & $\underline{0.339}$ & 0.034 & $\underline{0.109}$ & 0.002 & 0.009 & $\underline{0.216}$ \\
Botswana & & 1.000 & $\underline{-0.114}$ & 0.017 & $\underline{-0.155}$ & 0.036 & $\underline{0.321}$ \\
Ema. Mkts. & & & 1.000 & $\underline{0.448}$ & $\underline{0.958}$ & $\underline{0.257}$ & $\underline{0.168}$ \\
Latin Am. & & & & 1.000 & $\underline{0.216}$ & $\underline{0.211}$ & $\underline{0.108}$ \\
Asia & & & & & 1.000 & $\underline{0.211}$ & $\underline{0.131}$ \\
US & & & & & & 1.000 & $\underline{0.330}$ \\
UK & & & & & & & &
\end{tabular}

Table 6c

Correlations of Stock Market Returns (US dollars)

Darind 2 (.Ian 1.994 - June 1996)

\begin{tabular}{|c|c|c|c|c|c|c|c|c|}
\hline & SA & Zim & Bots & EM & LA & Asia & US & UK \\
\hline SA & 1.000 & -0.013 & $\underline{0.413}$ & $\underline{0.331}$ & $\underline{0.201}$ & $\underline{0.203}$ & 0.064 & $\underline{0.284}$ \\
\hline Zimbabwe & & 1.000 & -0.032 & 0.017 & 0.033 & 0.018 & 0.062 & 0.014 \\
\hline Botswana & & & 1.000 & -0.015 & 0.021 & -0.084 & -0.024 & 0.120 \\
\hline Ema. Mkts & & & & 1.000 & $\underline{0.744}$ & $\underline{0.741}$ & $\underline{0.284}$ & $\underline{0.351}$ \\
\hline Latin Am. & & & & & 1.000 & 0.139 & $\underline{0.289}$ & $\underline{0.291}$ \\
\hline Asia & & & & & & 1.000 & $\underline{0.148}$ & $\underline{0.210}$ \\
\hline US & & & & & & & 1.000 & $\underline{0.440}$ \\
\hline UK & & & & & & & & 1.000 \\
\hline
\end{tabular}

Table 6d

Tost of Hunnthesis of Equal Correlation Coefficients. Periods 1 and 2

\begin{tabular}{lllllllr}
\multicolumn{7}{l}{ Tost of Hunnthesis of Equal Correlation Coefficients. Periods 1 and 2 } \\
\hline SA & Zim & Bots & EM & LA & Asia & US & UK \\
SA & 1.422 & -1.769 & -1.012 & -0.730 & -0.059 & -0.370 & -0.464 \\
Zimbabwe & & $\underline{3.457}$ & 0.161 & 0.686 & -0.138 & -0.469 & 1.844 \\
Botswana & & & -0.892 & -0.043 & -0.645 & 0.545 & 1.904 \\
Ema. Mkts. & & & & -4.283 & $\underline{8.647}$ & -0.268 & -1.769 \\
Latin Am. & & & & 0.718 & -0.746 & -1.709 \\
Asia & & & & & 0.590 & -0.731 \\
US & & & & & & -1.162 \\
UK & & & & & & \\
\hline
\end{tabular}

Critical value (0.05): 1.960. Entry with single underline denotes rejection of null 
However, correlations in US dollars reflect both changes in the market indices and changes in exchange rates. In the case of Botswana and South Africa, where the pula/rand exchange rate has been reasonably stable (in that movements have been within a fairly narrow range), the high correlation coefficients may reflect similar movements of the two countries' currencies against the dollar rather than stock market returns. In order to evaluate this further, the Botswana and Zimbabwe indices were also expressed in rand terms, thus using this as the common currency rather than the US dollar. The results of correlations of returns in the three markets, expressed in SA rand terms, are shown in Table $5 \mathrm{~d}$ to $5 \mathrm{f}$. These results are more similar to the local currency results than to the US dollar results, thus confirming that the correlations in the latter case were primarily due to exchange rate movements rather than stock market movements.

Taking the entire set of markets under scrutiny, we have 28 pairwise correlation coefficients. Over the entire period, 19 of these are significantly different from zero. The markets that appear to be most strongly related to other markets are the UK (where returns are correlated with all 7 of the other markets) and South Africa (correlated with 5 markets). Again, however, there appear to be differences between the two sub-periods. In Period 1, 22 of the 26 correlation coefficients are significantly different from zero, while in Period 2 this had fallen to 14. This would suggest that the degree of correlation of short run stock market returns between these markets has decreased in recent years, despite greater liberalisation and international economic integration. This is investigated further in Table $6 \mathrm{~d}$, which shows the results of testing the hypothesis that the correlation coefficients in the two sub-periods are equal (i.e., that there has been no change in the level of correlation of returns between a pair of markets). This shows that for 25 out of the 28 pairwise correlation coefficients, there is no statistically significant difference (at the $5 \%$ level) between Periods 1 and 2. Of the three cases where correlations in the two sub-periods are not the same, they have risen in one case and fallen in two, from Period 1 to Period 2. The results of the correlation analysis do not therefore indicate any strengthening of market linkages over time, and indeed appear to indicate the opposite.

\section{Long Term Relationships Between Markets}

The correlation coefficients reported above provide some information regarding the relationship between weekly returns in Southern African stock markets, emerging markets, and developed markets on a pairwise and short term basis. They indicate that among the Southern African markets, returns in South Africa and Botswana appear to be related. Furthermore, the South African market appears to be related to both other emerging markets and the UK. The other Southern African markets, Zimbabwe and Botswana, however, do not appear to be related to other emerging markets.

However, as noted in section 3 above, correlation techniques only provide a partial insight into the existence of relationships between stock markets, and there is a real danger that any long term relationships can be obscured by short term trading noise. In order to investigate these relationships more fully, and in particular to explore whether there is any long-term relationship between Southern African, emerging and developed markets, it is necessary to employ different statistical techniques. We follow what is now standard practice in the literature, by examining whether there are long term cointegrating relationships between markets (whether between pairs of markets, or larger groupings). This involves first testing for whether the individual markets are characterised by unit roots (their order of integration). 


\section{Unit Root tests}

We test for unit roots using the sequential method outlined in section 5 above. The Augmented Dickey-Fuller (ADF) and Phillips-Perron (PP) tests were used throughout for unit root testing. The ADF tests were carried out with whatever lag length was found necessary to remove autocorrelation from residuals, which was found to be up to six lags. The PP tests were carried out with a truncation lag of eight periods throughout. ADF tests were also carried out on first differences in order to check whether the non-stationary variables were $\mathrm{I}(1)$ or $\mathrm{I}(2)$. The results are shown in Tables $7 \mathrm{a}$ to $7 \mathrm{c}$. Key conclusions relating to the period as a whole (Table $7 \mathrm{a}$ ) are as follows:

- For the southern African markets, Zimbabwe and South Africa are I(1), in both local currency and US dollar terms. The Botswana market is $I(0)$ in both local currency and US dollar terms.

- The three emerging markets indices are I(1)

- The UK is $I(0)$ with a trend, while the US is $I(1)$.

- Model 3 (without trend or drift) is appropriate for the $\mathrm{I}(1)$ series.

For the two sub-periods (Tables $7 \mathrm{~b}$ and $7 \mathrm{c}$ ), the results are the same for most markets across the two periods, and are in accordance with the whole-period results. However, for a few markets, different results are obtained.

- Botswana is $\mathrm{I}(0)$ in Period 1 but $\mathrm{I}(1)$ in period 2, in both local and foreign currency terms.

- The UK is probably $I(0)$ in Period 1 , but is $I(1)$ in Period 2.

It should be noted that rejecting the null of a unit root is not particularly robust to changing the lag length in the $\mathrm{ADF}$ test. If the lag is extended from 4 to 15 periods, in all cases the null is accepted.

Testing for unit roots is equivalent to testing whether a stock market index is characterised by a random walk (with or without trend and/or drift), and therefore whether a market is weak form efficient. Markets that are not efficient according to this test are Botswana and the UK in Period 1. All markets are weak-form efficient in Period 2. The result for Botswana is not particularly surprising: the market was only established in 1989, and the early years were marked by a small number of market participants, and little experience in reacting to information which might be relevant to stock prices. Over time, however, the sophistication and number of market participants has increased. In particular, the number of foreign investors - representing a variety of emerging market investment funds - on the Botswana Stock Exchange has risen, and indeed they have dominated market activity in 1995 and 1996. It is therefore not unexpected (but nevertheless quite encouraging) that the market has begun to behave in a more mature manner in recent years. This is compatible with other evidence that the increased presence of foreign investors in emerging markets has positive effects on those markets (Richards, 1996).

\section{Cointegrating Relationships Between Markets}

Unit root tests are interesting in themselves, in that they provide information as to whether markets are weak form efficient. They are also necessary as a prerequisite for testing whether long term cointegrating relationships exist between markets. For those markets where the indices are non-stationary (i.e., the I(1) markets), cointegration tests indicate whether there are long term associations between movements in stock market price indices, whether as pairs or larger groups of markets. The Johansen technique (Johansen (1988) and Johansen and Juselius (1989)), using cointegrating VARs, is used to investigate the cointegration of market indices over the period as a 


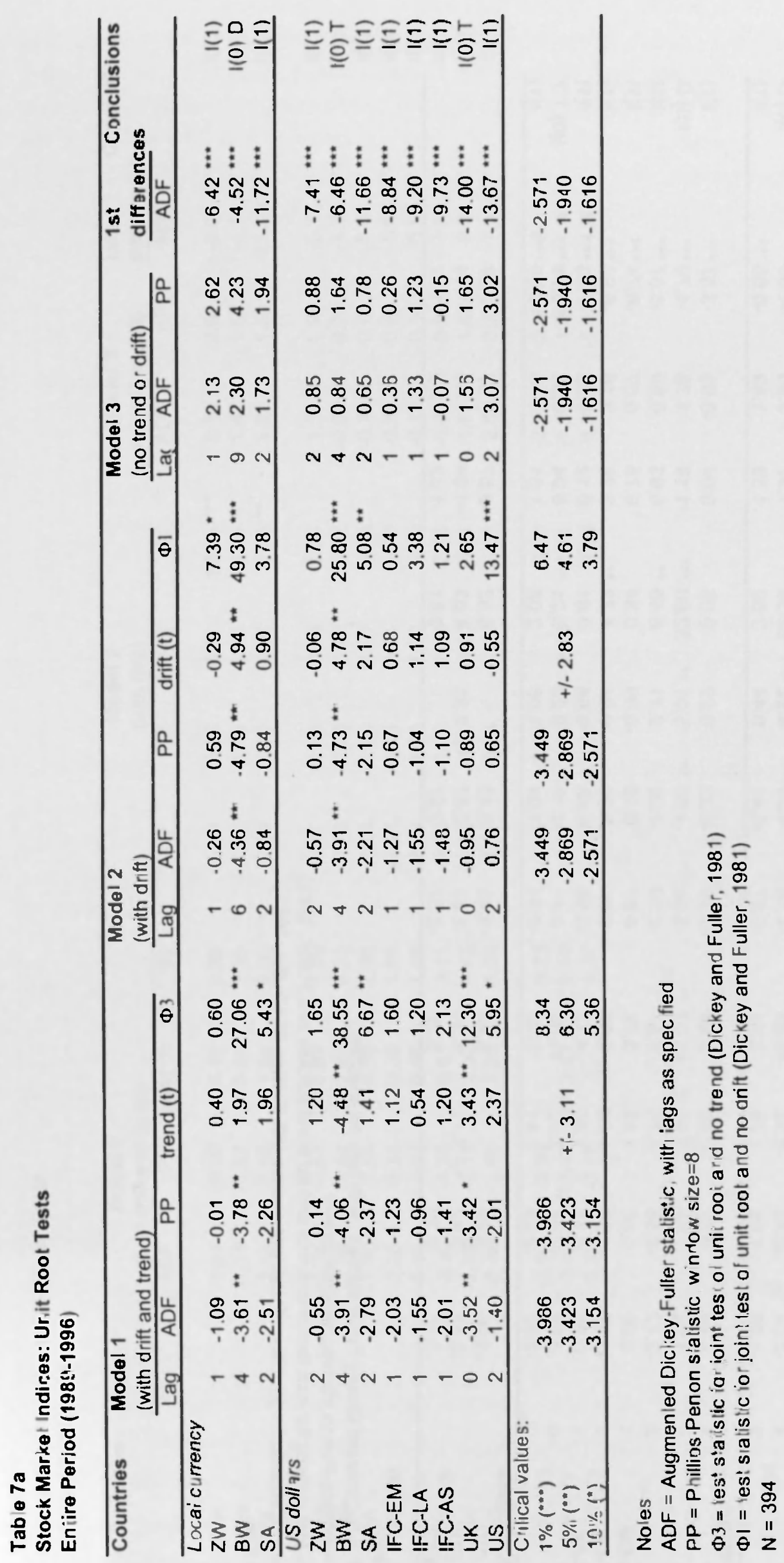




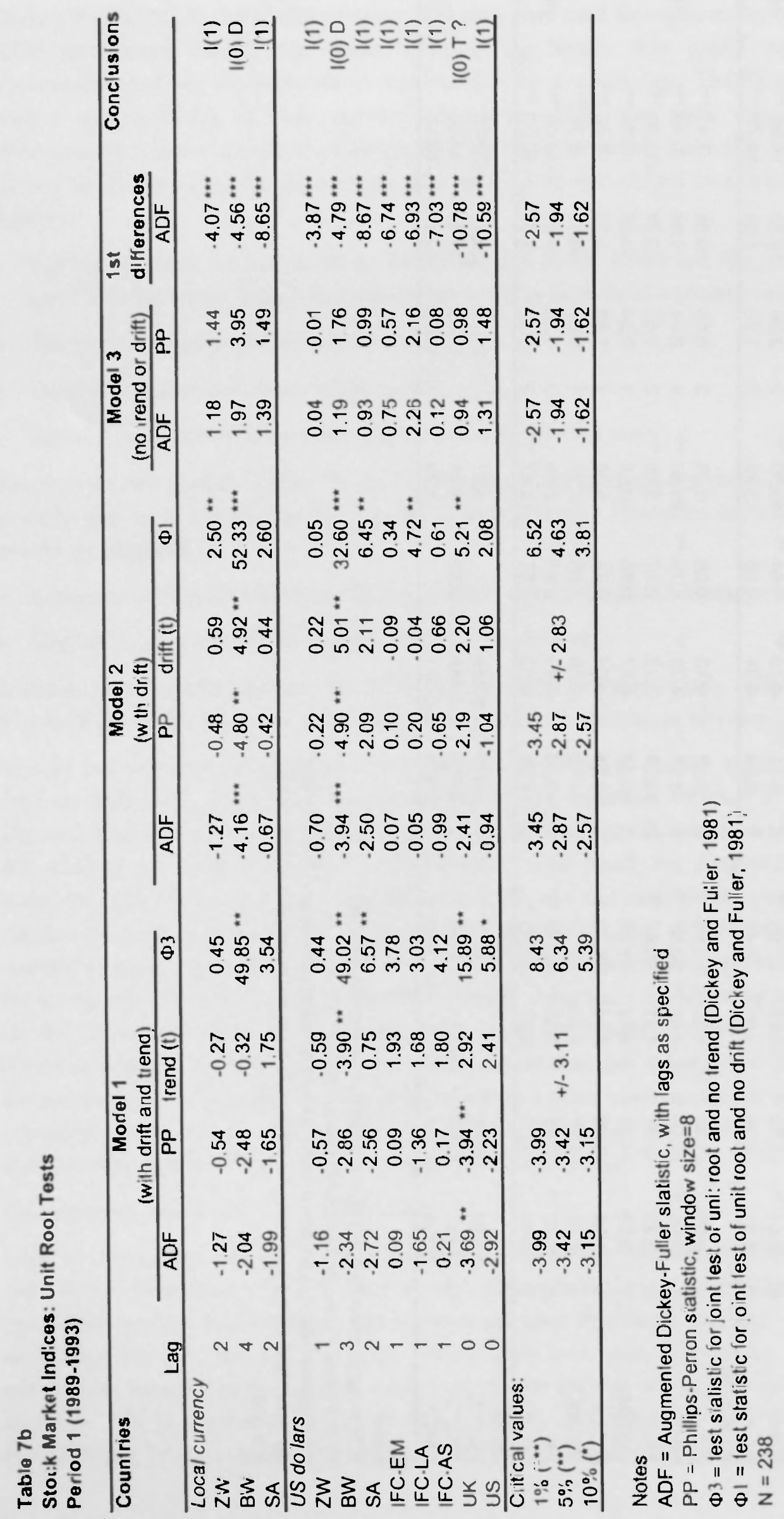




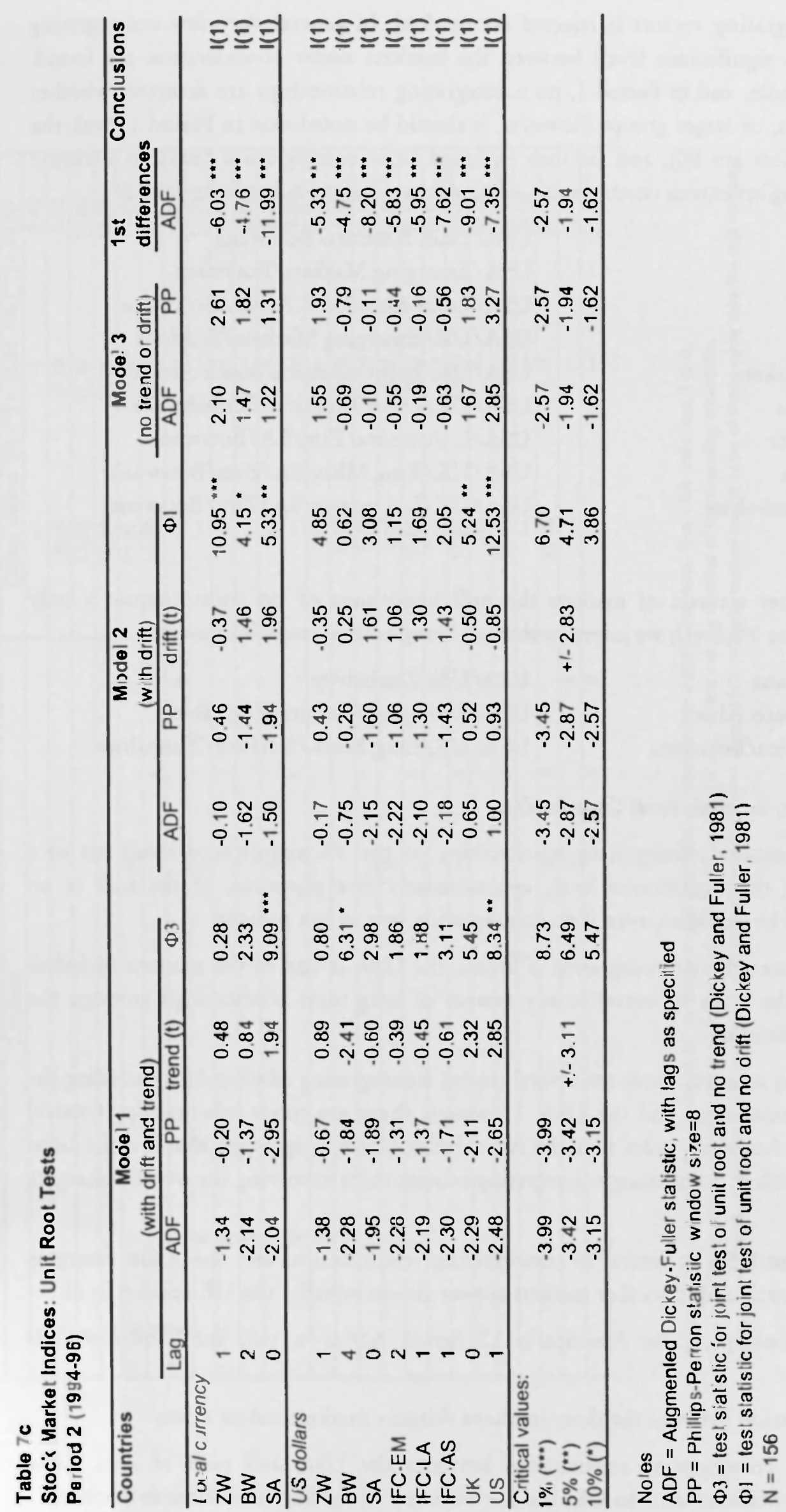


whole and in Periods 1 and 2. Results are shown in Table 8, and sets of markets for which the hypothesis of no cointegrating vectors is rejected are marked. In general very few cointegrating relationships (at the $5 \%$ significance level) between the markets under consideration are found. Over the period as a whole, and in Period 1, no cointegrating relationships are detected, whether between pairs of markets, or larger groups (however, it should be noted that in Period 1, both the Botswana and UK markets are $1(0)$, and are thus excluded from cointegration tests). In Period 2 (1994-1996), the following seventeen cointegrating relationships (at the $5 \%$ level) are found:

USA/Emerging Markets
USA/Latin America
USA/Asia
USA/UK
USA/UK/Emerging Markets
USA/UK/Latin America
USA/Latin America/Asia
UK/Latin America/Asia
USA/Latin America/Zimbabwe
USA/UK/Botswana

USA/Latin America/Botswana

USA/Emerging Markets/Botswana

USA/Latin America/S.Africa/Botswana

USA/UK/Emerging Markets/S. Africa

USA/UK/Latin America/South Africa

USA/UK/Latin America/Zimbabwe/SA

USA/L. America/Zim/SA/Botswana

USA/UK/Emg.Mkts/SA/Zim/Botswana

USA/UK/L.America/SA/Zim/Botswana

In addition, for a further six sets of markets the null hypothesis of no cointegration is only marginally accepted at the $5 \%$ level; we interpret these as being cointegrated. These are:

USA/Zimbabwe/Botswana

USA/Latin America/South Africa

USA/Emg. Mkts./S.Africa/Botswana
USA/UK/Zimbabwe

USA/Emerging Markets/Zimbabwe

USA/UK/Emg.Mkts./S.Africa/Zimbabwe

The following points can be made from these results:

- the results show nineteen cointegrating relationships (at the $5 \%$ significance level) out of a possible 102. Using this significance level, approximately five rejections of the null of no cointegration would be expected, even if no cointegration was in fact present;

- in all cases except one where cointegration is found, the USA is one of the markets included. This suggests that the USA is central to any system of long term relationships amongst the stock markets in question;

- in terms of emerging markets, there are several (eight) cointegrating relationships including the IFC emerging markets index and the USA. However, there are more relationships (twelve) involving the Latin American index than the Asian index (three), suggesting that it is the Latin American index which is dominating cointegrating relationships involving the overall emerging markets index;

- after noting that the USA is central to cointegrating relationships, and the Asian emerging markets are largely excluded, the other markets appear almost equally: the UK appears in 11

- cointegrating relationships, Latin America in 12, South Africa in ten, and Zimbabwe and Botswana in nine.

- there is no cointegration between the three southern African markets, taken alone;

- there are bivariate cointegrating relationships between the USA and each of Asia, Latin America, Emerging Markets, and the UK, but not with any of the Southern African markets; 


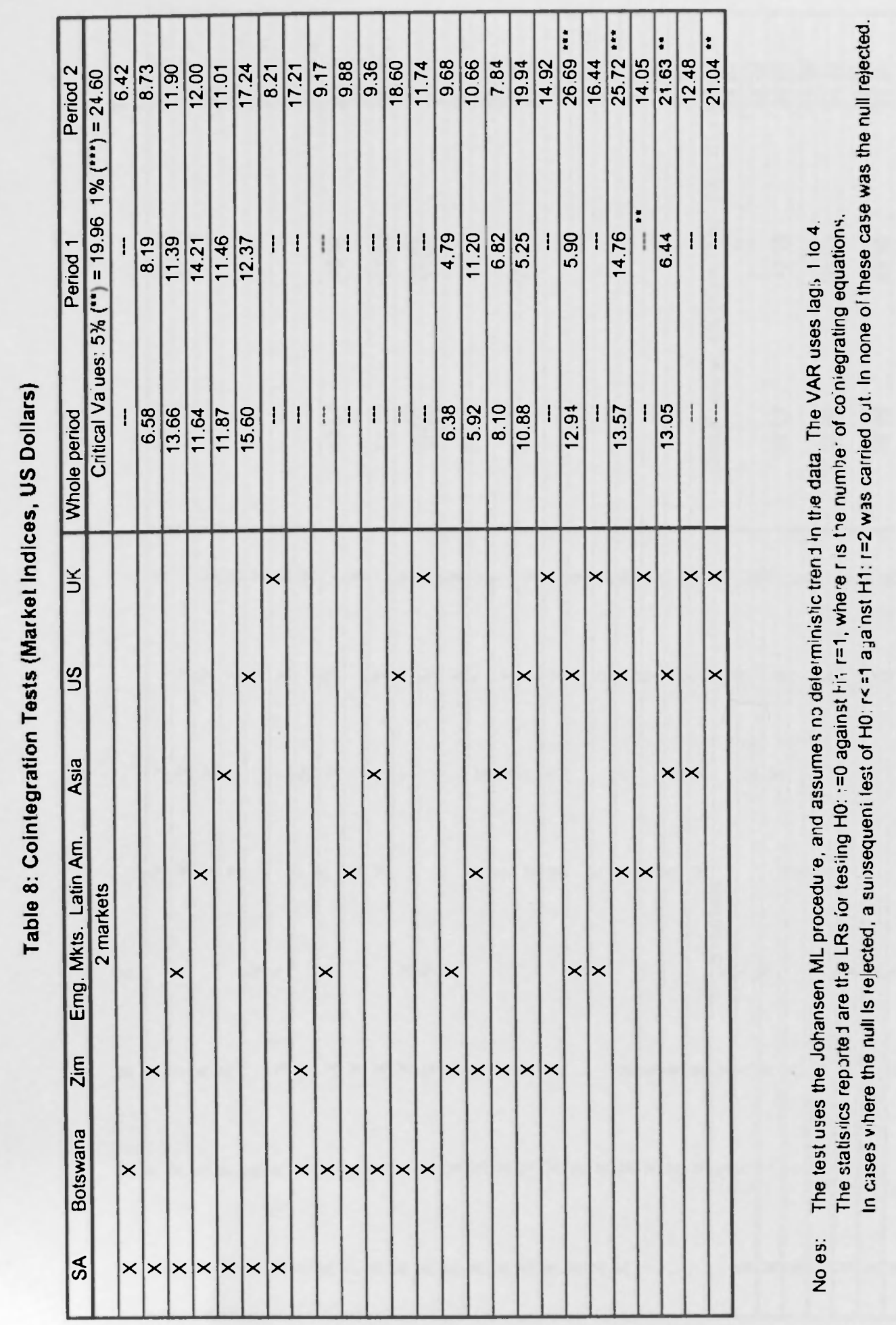




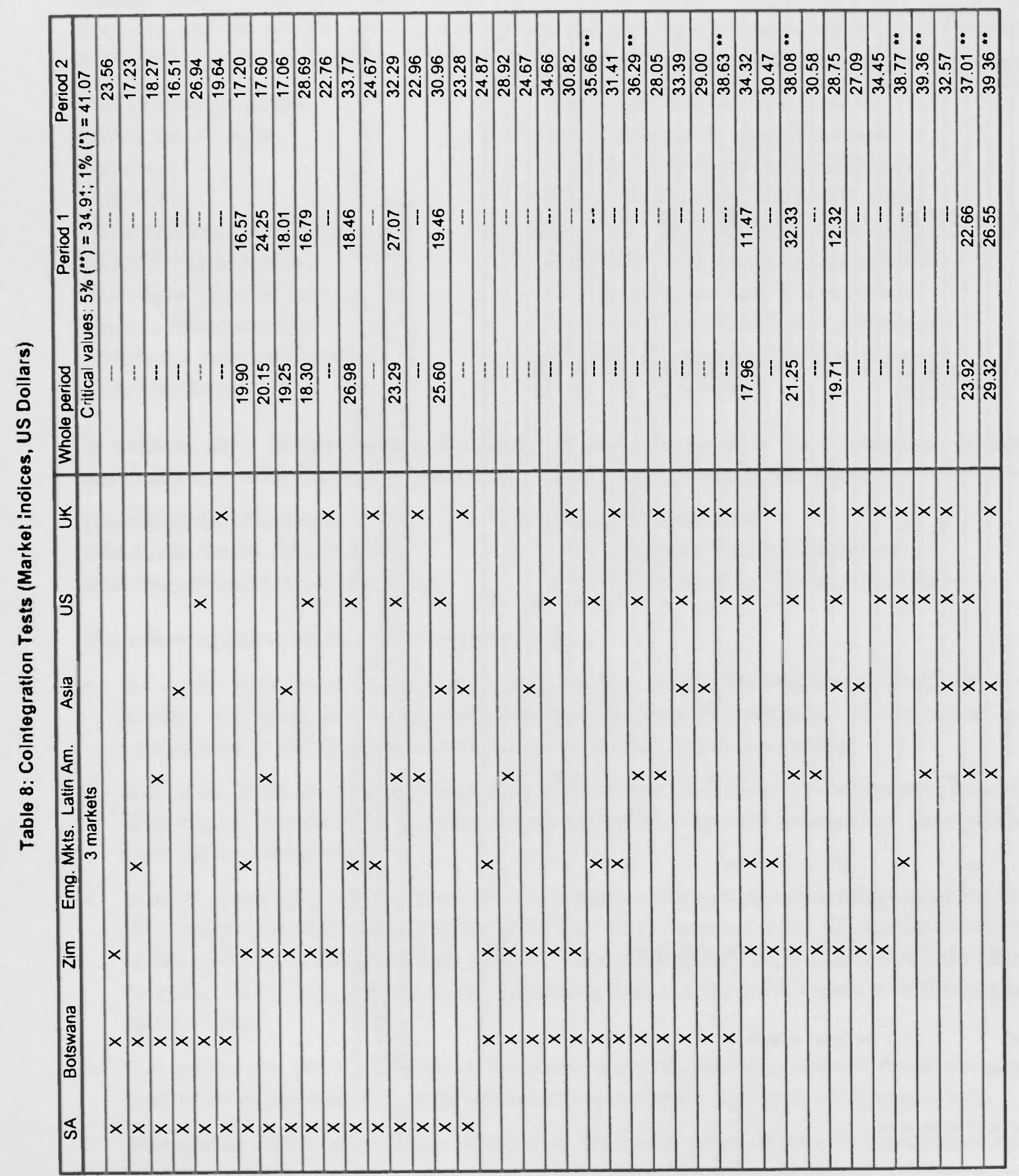




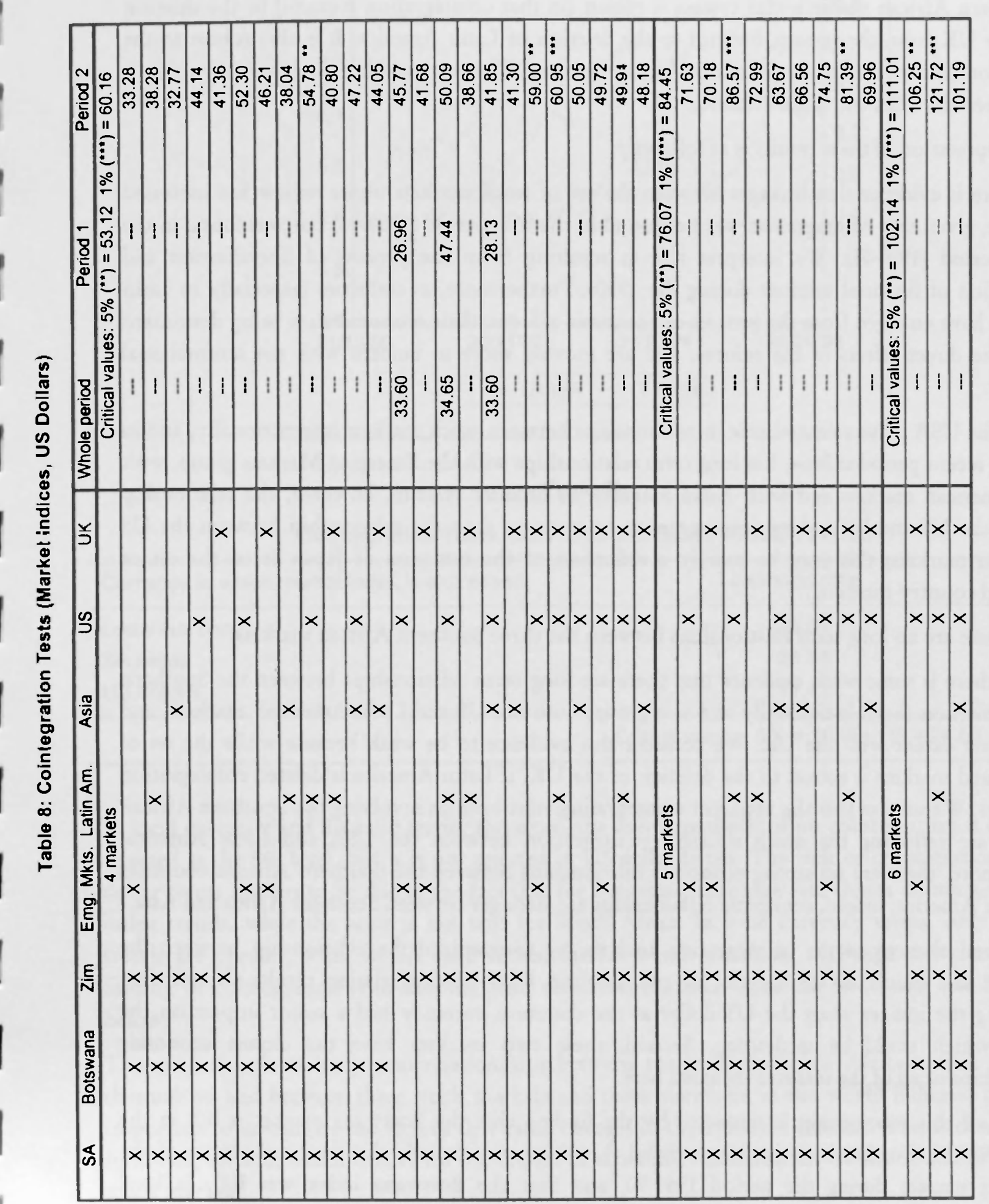


- there are cointegrating relationships between the USA, Latin America and each of the Southern African markets, and between the USA, Latin America and the Southern African markets as a group;

- the broadest cointegrated system includes the USA, the UK, Latin America, and the three southern African markets; this system is robust (in that cointegration remains) to the deletion of the UK from the system, but not to the deletion of Latin America. It is also robust to the deletion of any or all of the Southern African markets. This suggests that the key relationship is between the USA and Latin America.

Our interpretation of these results is as follows.

First, there is evidence that linkages between the set of stock markets under review has increased over time, given that cointegration was not found in the first period (1989-93) but was found in the second period (1994-96). We interpret this as resulting from the process of liberalisation and globalisation of financial markets during the 1990s. Furthermore, as countries (especially in Latin America) have emerged from the process of economic reform, their economies are being dominated less by the direct effects of the reform, and are moving more in tandem with the international economy.

Second, the USA plays a central role in relationships between stock markets internationally, and in the more recent period at least, has long term relationships with the Emerging Markets group, with Latin American markets and with Asian markets. In broader systems, however, the relationship between the US and Latin America appears to be stronger than the relationship between the US and Asian markets; this may be mainly a reflection of the omission of Japan from the set of developed country markets.

Third, there are no long term relationships between the three Southern African markets.

Fourth, there is some weak evidence that there are long term relationships between the Southern African markets (both individually and as a group) with the US and Latin American markets, and to a certain extent with the UK. We consider this evidence to be weak because while the set of cointegrated markets is robust to the deletion of the UK, if Latin America is deleted cointegration disappears. We suspect that the apparent cointegrating relationships involving the Southern African markets are reflecting the much stronger cointegration between the USA and Latin America. Furthermore, there are no strong economic relationships between the Southern African countries and Latin America; indeed, economic relationships are stronger between Southern Africa and Asia.

In the final element of the cointegration analysis we re-examined the relationship between the Botswana and South Africa indices, for two reasons. First, the correlation results showed that expressing the indices using the US dollar as the common currency had a major impact on the results, which could be misleading. Second, these two markets have the closest economic relationships of all of the markets included here.

Analysis of this relationship is restricted by the finding that the Botswana market is $I(0)$ in the period 1989-93. Further investigation revealed that this was primarily due to the character of the Botswana market during the period 1989-90, and that the Botswana index was I(1), in local currency, US dollar and SA rand terms during the period 1991-96. Cointegration tests were therefore run for the Botswana and South African markets over this period. The results are summarised in Table 8 b. 


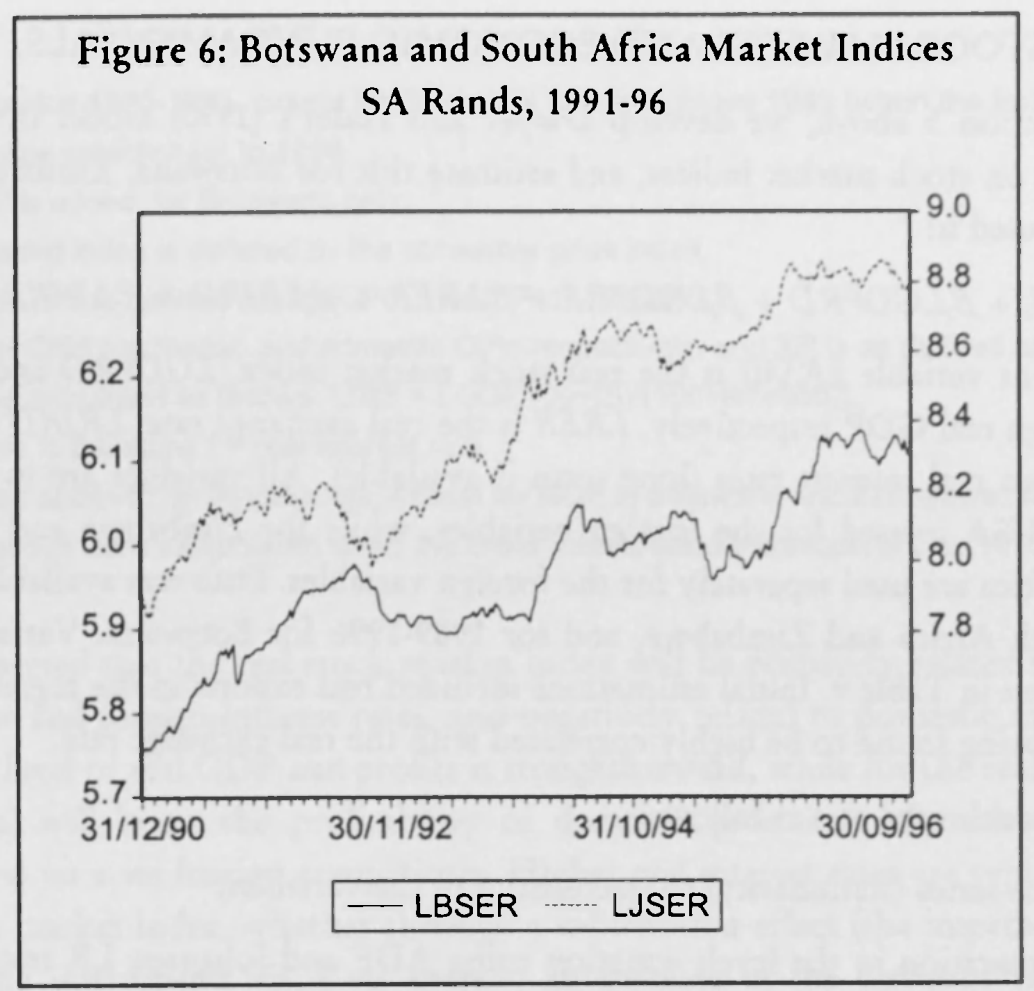

Table 8b

Cointegration Tests, Botswana and South Africa, 1991-96

\begin{tabular}{lc}
\hline Currency in which market index is expressed: & Likelihood ratio \\
\hline Local currency & 23.91 \\
SA rands & 24.38 \\
US dollars & 11.42 \\
\hline
\end{tabular}

Critical values: $5 \%=19.96 ; 1 \%=24.60$

In local currency and SA rand terms, therefore, the null hypothesis of no cointegration is strongly rejected at the $5 \%$ level, but it is not rejected in US dollar terms. The lack of cointegration in US dollar terms appears to be due to the fact that for Botswana, exchange rate trends dominate market index trends, while the same is not true for South Africa. In local currency terms, only market trends are present, while in SA rand terms, market trends dominate exchange rate trends. The finding of cointegration is in keeping with the visual evidence from the two series (see Figure 5 below) $)^{22}$.

The general lack of long term relationships between the three Southern African stock markets themselves, and between these stock markets and those elsewhere in the world indicates that it is important to investigate the factors that cause changes in these market indexes. This is done in the following section, which deals with the impact of economic fundamentals on the Southern African stock markets.

Although the results are not reported here, no cointegration was found between the ZSE index and either the BSE or JSE index, expressed in $\mathrm{S} A$ rand terms. 


\section{RESULTS: STOCK MARKETS AND ECONOMIC FUNDAMENTALS.}

As explained in section 5 above, we develop Dwyer and Hafer's (1990) model of the impact of economic variables on stock market indices, and estimate this for Botswana, Zimbabwe and South Africa. The model used is:

$$
L R S M I=\beta_{0}+\beta_{l} L G D P R D+\beta_{2} L G D P R F+\beta_{3} L R E R+\beta_{4} L R I R D+\beta_{4} L R I R F
$$

where the dependent variable $L R S M I$ is the real stock market index, $L G D P R D$ and $L G D P R F$ are domestic and foreign real GDP respectively, $L R E R$ is the real exchange rate, $L R I R D$ and $L R I R F$ are domestic and foreign real interest rates (long term if available). All variables are in log form. For South Africa, the USA is used for the foreign variables, while for Zimbabwe and Botswana, the USA and South Africa are used separately for the foreign variables. Data was available quarterly for 1985-1995 for South Africa and Zimbabwe, and for 1989-1996 for Botswana. Variable definitions and sources are given in Table 9. Initial estimations included real exports in the regressions, but this was dropped after being found to be highly correlated with the real exchange rate.

The empirical approach used was as follows:

(i) assess the time series (stationarity) characteristics of the variables;

(ii) test for cointegration in the levels equation using ADF and Johansen LR tests, and derive a long run model, if appropriate;

(iii) estimate a short run model (in first differences), using an error correction approach, if applicable.

\begin{tabular}{|c|c|c|c|}
\hline \multicolumn{4}{|c|}{$\begin{array}{l}\text { Table } 9 \\
\text { Variable Definitions - Economic Fundamentals }\end{array}$} \\
\hline $\begin{array}{l}\text { Variable } \\
\text { name }\end{array}$ & Note & Definition & Source \\
\hline \multicolumn{4}{|c|}{ Original data variables $[1,6]$} \\
\hline SMI & & Stock market index & National stock exchanqes \\
\hline $\mathrm{CPI}$ & & Consumer price index & IFS line 64 \\
\hline$X R$ & & Exchange rate (US\$ per local currency; end of period) & IFS line aq \\
\hline IS & & Short term interest rate (T-Bills or equivalent) & IFS line $60 \mathrm{c}$ \\
\hline IL & & Long term interest rate (on qovernment bonds) & IFS line 61 \\
\hline GDPR & & real GDP & IFS (for South Africa); Bank of Botswana: \\
\hline NMGDPR & {$[2]$} & real non-mineral GDP & Bank of Botswana \\
\hline \multicolumn{4}{|c|}{ Calculated variables (all in logs) } \\
\hline LRSMI & ¡3] & real stock market index & \\
\hline LRERUS & {$[4]$} & real exchange rate (vs. US dollar) & \\
\hline LRERSA & {$[4]$} & real exchange rate (vs. SA rand) & \\
\hline LRIS & [5] & domestic short term real interest rate & \\
\hline LRIL & {$[5]$} & domestic long term real interest rate & \\
\hline LRISUS & {$[5]$} & US short term real interest rate & \\
\hline LRILUS & {$[5]$} & US long term real interest rate & \\
\hline LRISSA & $\lceil 5\rceil$ & SA short term real interest rate & \\
\hline LRILSA & [5] & SA long term real interest rate & \\
\hline$\underline{\mathrm{LCPI}}$ & & consumer price index & \\
\hline
\end{tabular}


Notes:

1. Data covers the period 1985-1995, except for Botswana where it covers 1989 (when the Botswana Stock Exchanqe was established) to 1996.

2. Non-mineral GDP is added, for Botswana only.

3. The real stock market index is deflated by the consumer price index.

4. The real exchange rate is defined as: $\log (C P I f)$ - log(CPId) - log(XR). where CPIf and CPId are foreign and domestic CPIs respectively, and XR is as defined above.

5. Real interest rates calculated as follows: LRIS $=L O G[(100+\mid S) /(100+\operatorname{lnflation})]$. The actual variable is therefore $1+$ real interest rate

6. Quarterly data was obtained on all variables, except for GDP in Botswana and Zimbabwe. The missing quarterly observations were interpolated using the linear interpolation technique of Diz (1970).

A priori, it is expected that the real stock market index will be positively related to real GDP, the real exchange rate and foreign interest rates, and negatively related to domestic interest rates. The link between the level of real GDP and profits is straightforward, while for the real exchange rate, a rise (depreciation) will boost the profitability of domestic producers of tradables (exports and import substitutes) vis a vis foreign competitors. Higher real interest rates are typically expected to depress the stock market index, whether through a substitution effect (the improved attractiveness of interest bearing instruments vis a vis shares), an increase in the discount rate (and hence a reduced present value of future expected profits), or a depressing effect on investment and hence on future expected profits. The expected sign on foreign real GDP is uncertain. If exports are important, then the growth of export markets should boost profits and hence share values. However, at the same time higher foreign GDP will boost the attractiveness of foreign shares, and this may depress (at least in relative terms) domestic share prices. It is worth noting that Dwyer and Hafer found a negative impact for changes in US real GDP when included in their regressions for stock market returns in Canada, Japan, and Germany.

The results for South Africa, Zimbabwe and Botswana are described below.

\section{South Africa}

Unit root tests (see Table 10) indicated that all of the South African variables were I(1), with the exception of the short term real interest rate, which was $\mathrm{I}(0)$. These tests also indicated that the US long term real interest rate was $I(0)$. Bivariate cointegration tests were then run between the real stock market index and each of the other variables.

Inspection of the residuals from the regressions indicated the presence of a major outlier in the LRSMI series in the second and third quarters of 1987 , and a dummy variable was introduced to deal with this. The results also indicated a significant trend in the LRSMI series, and all regressions therefore included a constant, trend and dummy terms. The two test procedures gave contrasting results: the ADF statistic rejected cointegration in all cases, while the Johansen ML tests accepted it in all cases when both an intercept and trend was included, but only in two cases (LRIL and LGDPUSR) when only an intercept was included ${ }^{23}$ (see Table 11).

Running an unrestricted $V A R$ and testing for lag length indicated that the appropriate value was 2. It also indicted that both drift and trend terms were present in the VAR. 


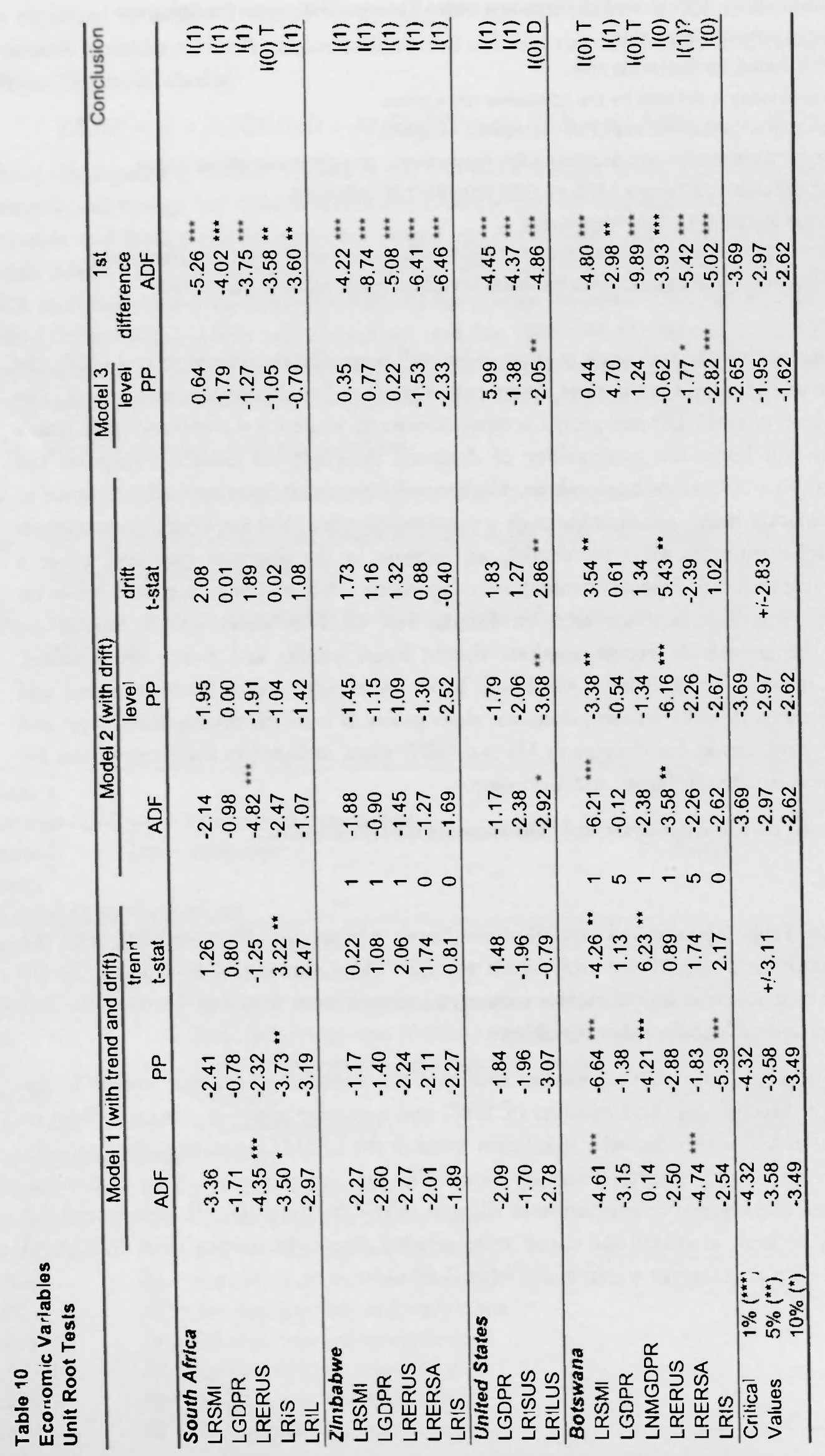




\section{Table 11}

\section{Economic Variables - Cointegration Tests South Africa}

\begin{tabular}{lrrr}
\hline & ADF & \multicolumn{2}{c}{ Johansen ML } \\
\cline { 3 - 4 } & & trend \& int. & int. \\
& {$[1]$} & {$[2]$} & {$[3]$} \\
\hline LRSMI against: & & & \\
LRERUS & -4.064 & $32.725^{* *}$ & 11.706 \\
LGDPR & -3.152 & $21.852^{* *}$ & 14.779 \\
LRIL & -3.103 & $21.512^{* *}$ & $16.343^{* *}$ \\
LRGDPUSR & -3.234 & $21.916^{* *}$ & $19.114^{* *}$ \\
LRISUS & -4.288 & $30.366^{* *}$ & 7.566 \\
\hline c.v. 5\% & -4.406 & 19.220 & 15.870 \\
\hline Full model & n/a & $47.584 * *$ & $33.994 *$ \\
c.v. 5\% & n/a & 34.700 & 31.480 \\
\hline
\end{tabular}

Note:

[1] with trend, drift and dummy

[2] unrestricted intercept, restricted trends

[3] restricted intercept, no trends

For the Johansen tests, the statistic quoted is for the null hyothesis that the number of cointegrating vectors is zero, against the null of one cointegrating vector.

$*$ siqnificant at $5 \%$

The full model was then tested for cointegration using the Johansen ML test (the number of variables exceeded the six for which ADF critical values are presented, and so this test could not be used $)^{24}$. This indicated one cointegrating vector under various different trend/intercept specifications. The cointegrating vector for two of these specifications is shown in Table 12. While the signs and magnitudes of the estimated coefficients in the two vectors are consistent with each other and with prior expectations, significance levels differ sharply between the two specifications. The model with (restricted) trend and intercept shows the real exchange rate, real GDP and the real interest rate to be significant, but not US real GDP. The model with (restricted) intercept and no trend shows the opposite. In terms of making a choice between the two, there is no obvious reason why the cointegrating relationship should exhibit a trend, but the unrestricted VAR strongly rejects restricting the trend to zero ${ }^{25}$. We therefore favour the VAR with trend, which shows that the real stock market index is positively related to the real exchange rate and real GDP, and negatively related to the long term interest rate. Re-estimating this model without US real GDP strengthens the initial results (see Table 12).

The full model included the I(1) variables LRSMI, LRER, LGDPR, LRIL, plus LGDPUSR entered as an exogenous variable; and $D 87 Q 23$ and LRILUS entered as $I(O)$ variables.

"s $L R$ test of the "no trend" restriction gives a $\dot{X}(S)$ statistic of 16.141 , which rejects the restriction at the $1 \%$ level $($ prob. $=0.006)$. 
Table 12

\section{Economic Variables - Cointegrating Vector \\ South Africa}

\begin{tabular}{lccc}
\hline & Trend \& int & Intercept & Trend \& int \\
\hline LRSMI & -1.000 & -1.000 & -1.000 \\
& & & \\
LRER & 0.682 & 0.215 & 1.383 \\
& $(0.284)$ & $(0.389)$ & $(0.396)$ \\
LGDPR & 3.257 & 0.131 & 2.457 \\
& $(1.201)$ & $(0.961)$ & $(1.195)$ \\
LRIL & -4.256 & -3.678 & -6.582 \\
& $(1.842)$ & $(2.887)$ & $(2.808)$ \\
LGDPUSR & -2.150 & 4.214 & \\
& $(1.914)$ & $(1.318)$ & \\
Trend & 0.027 & & 0.025 \\
& $(0.008)$ & & $(0.005)$ \\
Intercept & & -66.662 & \\
& & $(23.484)$ & \\
\hline
\end{tabular}

The general restriction is imposed that the coefficient

on LRSMI is equal to minus one.

Order of $\mathrm{VAR}=2$

Standard errors are given in brackets

The next step was to estimate a short run model of changes in the real stock market index. Given that a long run cointegrating relationship had been found, the appropriate approach was to use an error correction model, with the saved residuals from the OLS regression as the error correction term. The results of the error correction model are shown in Table 13. These results show that changes in real domestic long term interest rates, US interest rates, the real exchange rate, and domestic GDP all have an impact on stock returns, and all with the expected signs. However, all except for changes in GDP only have an impact after lags of up to three quarters, which is relatively slow and suggest that the impact of changes in these variables on stock prices may be indirect rather than direct. The error correction term is highly significant and supports the finding of cointegration, and its relatively large magnitude $(70 \%)$ shows that there is rapid adjust ment to the long term equilibrium relationship each quarter. It is worth noting that the $\mathrm{R}^{2}$, at $51 \%$, is much higher than the explanatory power of Dwyer and Hafer's similar regressions, which only managed to explain between $8 \%$ and $19 \%$ of stock returns through contemporaneous changes in the equivalent economic variables, thus supporting the merits of the error correction formulation.

\section{Zimbabwe}

A similar approach was followed for Zimbabwe. However, data on long term interest rates was not available, so data for short term rates was used instead. The unit root tests (reported in Table 10) indicate that all variables are $I(1)$. Inspection of the residuals from the regressions indicated the presence of major outliers in the LRSMI series between 1992Q4 and 1993Q4 - a period when major structural adjustment measures were being introduced - and a dummy variable was introduced to deal with this. Bivariate cointegration tests showed very little evidence of cointegration on either 
the ADF or Johansen ML approaches, with some slight evidence that the real stock market index is cointegrated with the real short term interest rate and US real GDP (see Table 14. However, testing for cointegration in the multivariate case is more rewarding. The full model (including domestic and foreign real GDP and interest rates, and the real exchange rate) does indicate cointegration, although more strongly in the case of the USA being the foreign partner than in the case of South Africa. Similarly, a domestic model including real GDP and interest rates strongly indicates cointegration. In each case, one cointegrating vector was indicated.

\section{Table 13}

\section{South Africa - Economic Variables - Error Correction Model}

Ordinary Least Squares Estimation

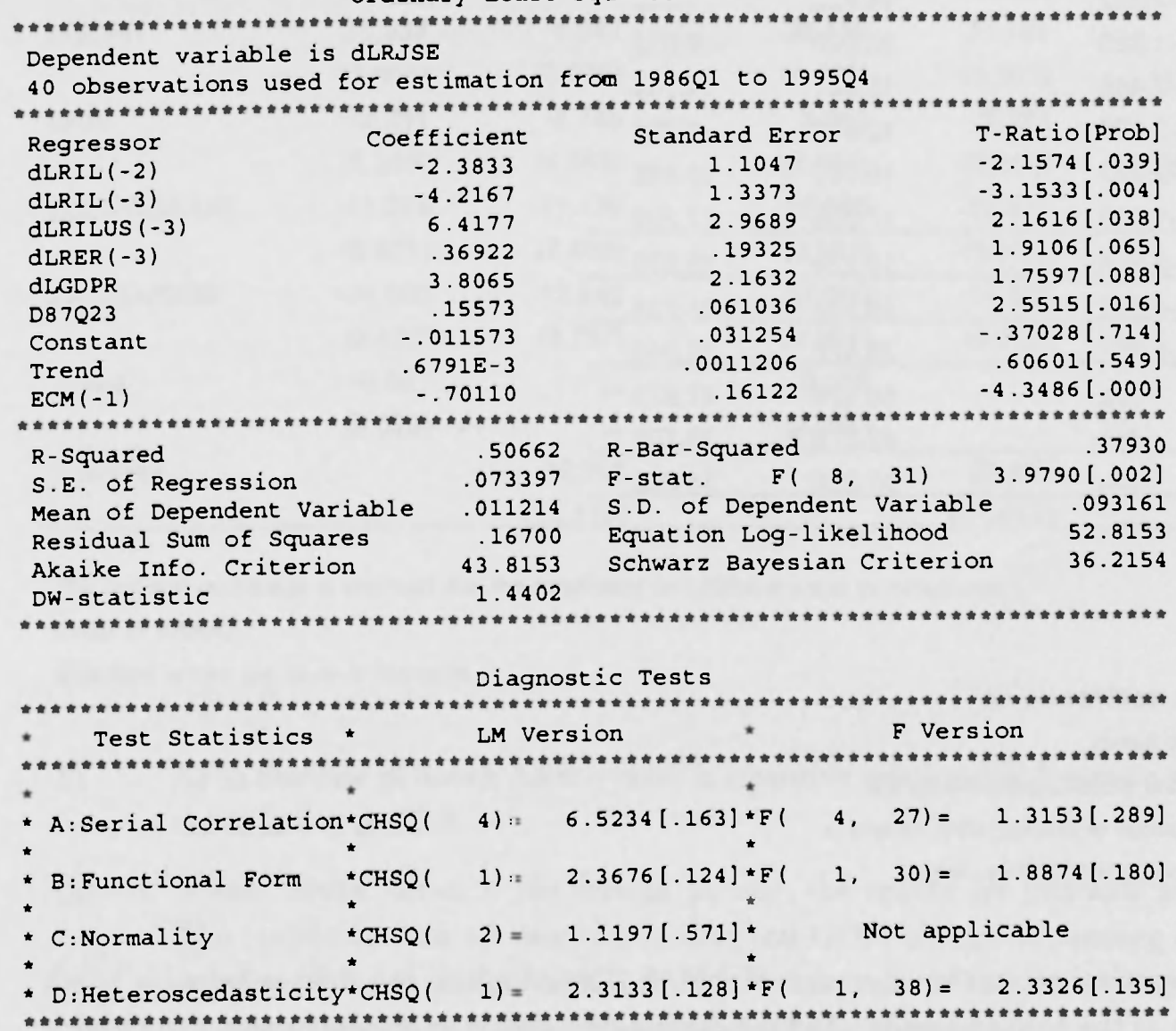

Test of Serial Correlation of Residuals (OLS case)

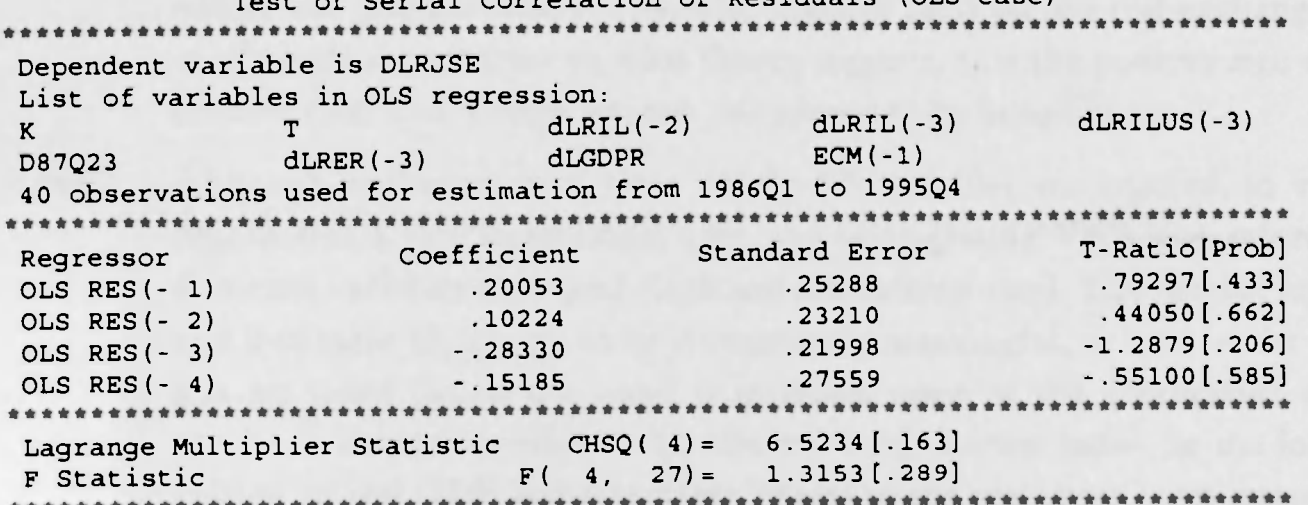

Autoregressive Conditional Heteroscedasticity Test of Residuals (OLS Case)

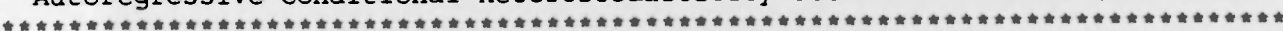

Lagrange Multiplier Statistic CHSQ( 4)= 3.6426[.457]

F Statistic $F(4,27)=.67628[.614]$

(1) 
Table 14

Economic Variables - Cointegration Tests

Zimbabwe

\begin{tabular}{|c|c|c|c|}
\hline \multirow[b]{2}{*}{ LRSMI with: } & \multirow{2}{*}{$\begin{array}{l}\text { ADF } \\
{[1]}\end{array}$} & \multicolumn{2}{|c|}{ Johansen ML } \\
\hline & & $\begin{array}{r}\text { trend } \& \text { int } \\
121\end{array}$ & $\begin{array}{l}\text { int } \\
131\end{array}$ \\
\hline LRERUS & -2.281 & 9.961 & 6.562 \\
\hline LRERSA & -2.503 & 9.110 & 8.475 \\
\hline LGDPR & -2.452 & 14.796 & 11.806 \\
\hline LRIS & -1.825 & $25.020^{\star *}$ & 6.033 \\
\hline LGDPRSA & -2.448 & 15.881 & 14.762 \\
\hline LIRLSA & -2.226 & 12.012 & 6.292 \\
\hline LRGDPUSR & -2.197 & 15.099 & $19.492^{* *}$ \\
\hline LRISUS & -1.839 & 17.765 & 17.209 \\
\hline c.v. $5 \%$ & -3.944 & 19.220 & 15.870 \\
\hline LRIS LGDPR & -4.258 & $39.574^{* *}$ & $31.735^{* *}$ \\
\hline c.v. $5 \%$ & -4.362 & 25.420 & 22.040 \\
\hline Full model (US) & $n / a$ & $50.526^{* *}$ & $47.872 * *$ \\
\hline Full model (SA) & n/a & $47.875^{\star *}$ & $38.798^{* *}$ \\
\hline c.V. $5 \%$ & $\mathrm{n} / \mathrm{a}$ & 37.850 & 34.690 \\
\hline
\end{tabular}

Notes:

[1] with drift, no trend

[2] unrestricted intercept, restricted trends

[31 restricted intercept, no trends

For the Johansen tests, the statistic quoted is for the

null hyothesis that the number of cointegrating vectors is

zero. against the null of one cointegrating vector.

* siqnificant at $5 \%$

A variety of cointegrating vectors are shown in Table 15. These include the full model with South Africa and the USA as the foreign partner, and the domestic model, in each case reported both with and without trend. The results are summarised below. 
Table 15

Economic Variables - Cointegrating Vector

Zimbabwe

\begin{tabular}{|c|c|c|c|c|c|c|}
\hline \multirow{2}{*}{ Foreian $=$} & \multicolumn{2}{|c|}{ South Africa } & \multicolumn{2}{|c|}{ United States } & \multicolumn{2}{|c|}{ None } \\
\hline & Trend 8 int. & Intercent & Trend \& int & Interceot & & \\
\hline LRSMI & -1.000 & -1.000 & -1.000 & -1.000 & -1.000 & -1.000 \\
\hline \multirow[t]{2}{*}{ LRERSAUUS } & 0.076 & -0.195 & -2.902 & -2.228 & & \\
\hline & $(0.786)$ & $(1.199)$ & $(1.047)$ & $(0.809)$ & & \\
\hline \multirow[t]{2}{*}{ LGDPR } & 15.337 & 6.941 & 20.119 & 21.181 & -39.221 & 4.752 \\
\hline & (3.063) & $(3.030)$ & $(4.670)$ & (5.501) & $(113.426)$ & $(0.385)$ \\
\hline \multirow[t]{2}{*}{ LRIS } & 13.251 & -8.745 & 3.963 & 5.284 & -42.988 & -3.616 \\
\hline & (5.289) & $(4.567)$ & $(2.365)$ & (2.893) & $(102.128)$ & $(0.810)$ \\
\hline \multirow[t]{2}{*}{ LGDPRSAIUS } & 11.874 & -11.136 & -25.668 & -19.520 & & \\
\hline & $(6.651)$ & $(7.496)$ & $(9.391)$ & (6.693) & & \\
\hline \multirow[t]{2}{*}{ LRILSA/SUS } & -24.685 & 12.948 & 17.000 & 14.358 & & \\
\hline & $(9.436)$ & (9.757) & (9.091) & $(8.822)$ & & \\
\hline \multirow[t]{2}{*}{ Trend } & -0.097 & & 0.052 & & 0.400 & \\
\hline & $(0.029)$ & & $(0.038)$ & & $(1.031)$ & \\
\hline \multirow[t]{2}{*}{ Intercept } & & 72.164 & & 91.427 & & -45.116 \\
\hline & & $(76.115)$ & & $(51.417)$ & & $(3.811)$ \\
\hline
\end{tabular}

The general restriction is imposed that the coefficient on LRSMI is equal to minus one.

Order of VAR $=2$

Standard errors are given in brackets

(i) As in the case of South Africa, there is a positive relationship between the real stock market index and real GDP.

(ii) Where South Africa is the foreign partner, the results are unstable and not very helpful. The coefficients on all variables (except real GDP) change depending on whether or not a trend is included in the VAR. Likelihood ratio tests of the exclusion of the South African variables indicate that such restrictions cannot be rejected.

(iii) Where the USA is the foreign partner, the coefficients in cointegrating vectors are more stable, but give perverse results. The negative signs on the real exchange rate and US GDP coefficients are contrary to what theory suggests, as is the positive sign on the domestic real interest rate. The foreign interest rate appears to be insignificant.

(iv) Although exclusion restrictions on the US variables are rejected, in view of the perverse results which this formulation gave, the cointegrating VAR was reformulated in terms of domestic variables only (real GDP and real interest rate). The results, reported in columns 5 and 6 of table 15, appear to be economically meaningful, at least in the VAR with intercept but no trend (when the trend is included, none of the coefficients are significant). The results in column 6 indicate that the real stock market index, in the long run, is positively related to real GDP and negatively related to the real short term interest rate, in line with expectations. This formulation is used to derive the error correction term. 
The error correction formulation of the model for real stock market returns is shown in Table 16. Although it has a high $\mathrm{R}^{2}(74 \%)$, it does not appear to provide much additional insight into the determinants of real stock returns in Zimbabwe. Changes in real GDP have the expected positive impact, while lagged US real GDP has the same perverse negative impact as in the cointegration model. The only additional influences in the short run model are US real interest rates, which has an unexpectedly large and fast impact, and the lagged change in South African real GDP, which has the expected positive influence, possibly reflecting its impact on the profits of exporting firms. A surprising finding is that the real exchange rate has no impact on the real stock market index. The error correction term is highly significant, and indicates that $16 \%$ of the last quarter's disequilibrium from the long term relationship is eliminated in the current period. The error correction formulation also performs satisfactorily in terms of the diagnostic tests for serial correlation, normality of residuals, heteroscedasticity etc.

\section{Table 16}

\section{Zimbabwe - Error Correction Model}

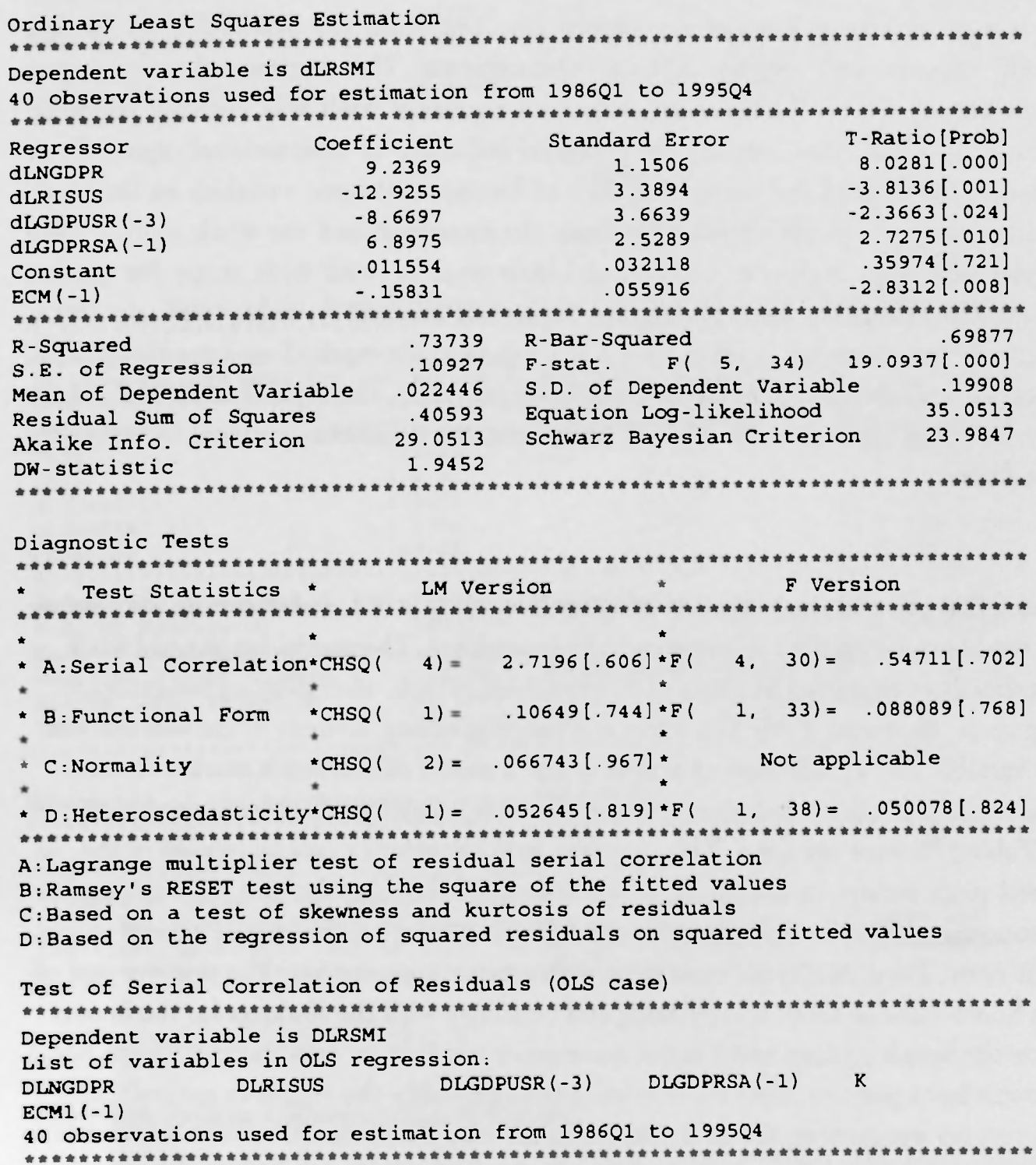




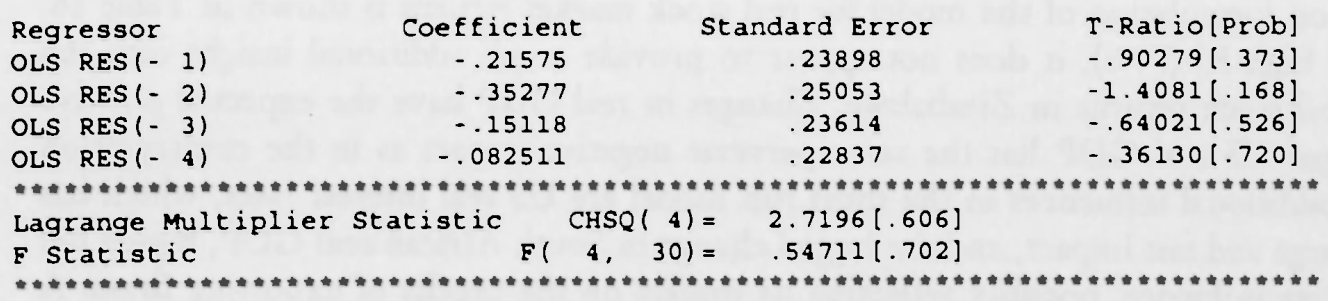

Overall, the findings for Zimbabwe indicate that some of the domestic economic fundamentals real GDP and interest rates - have had the expected impact on the real stock market index. However, those economic variables concerned with the economy's international relationships, either do not have an impact, or have one which is contrary to expectations; this applies to the real exchange rate, and US real GDP and interest rates (as a proxy for international economic conditions more generally). This may reflect the relatively closed nature of the Zimbabwean economy, especially during the first part of the period under review. Prior to the ESAP programme, Zimbabwe had a strongly inward-looking economic environment, with high tariffs on imports, as well as strict exchange control regulations that restricted the availability of foreign currency for both current and capital account transactions. The regime, therefore, was unfavourable to the export sector. Furthermore, the stock exchange itself was virtually closed to foreigners until the early 1990s, thus limiting the potential influence of international capital flows on the market. Hence, the limited and perverse impact of foreign economic variables on the stock market is perhaps not surprising. More generally, both the economy and the stock market have been subject to relatively high degrees of control and intervention, with little scope for market processes. Although Zimbabwe has been undergoing structural adjustment since the early 1990s, and both the economy and the stock market have been substantially opened up over this period, this may be too recent to show up in the results here. More generally, the type of structural change that the economy has been through may make it unrealistic for consistent patterns of economic relationships to be found.

\section{Botswana}

Unit root tests show that the real stock market index for Botswana is $\mathrm{I}(0)$, and therefore the cointegration approach could not be used (as this applies to I(1) variables). The model for the real stock market index was therefore estimated in terms of $\mathrm{I}(\mathrm{O})$ variables, which, after deleting insignificant variables, gave the result shown in Table 17a. After rearranging, taking account of the fact that the lagged dependent variable had a coefficient of almost unity, a model of real stock market returns (i.e., change in the real stock market index) was obtained. After correction for serial correlation, the results shown in Table $17 \mathrm{~b}$ were obtained. This provides an economically credible model of the determinants of real stock returns in Botswana, which are positively related to the real exchange rate and lagged economic growth in both Botswana and South Africa, and negatively related to real short term interest rates. These results are consistent with a prior expectations. The positive sign of the coefficient on South African GDP is interesting and contrasts with the findings for the impact of foreign GDP on the South African and Zimbabwean stock markets. It indicates that South African economic growth has a positive effect on Botswana (and probably the region in general), and that from a stock returns perspective, the two economies are complements rather than substitutes. 
Table $17 \mathrm{a}$

\section{Botswana - Economic Variables Model I}

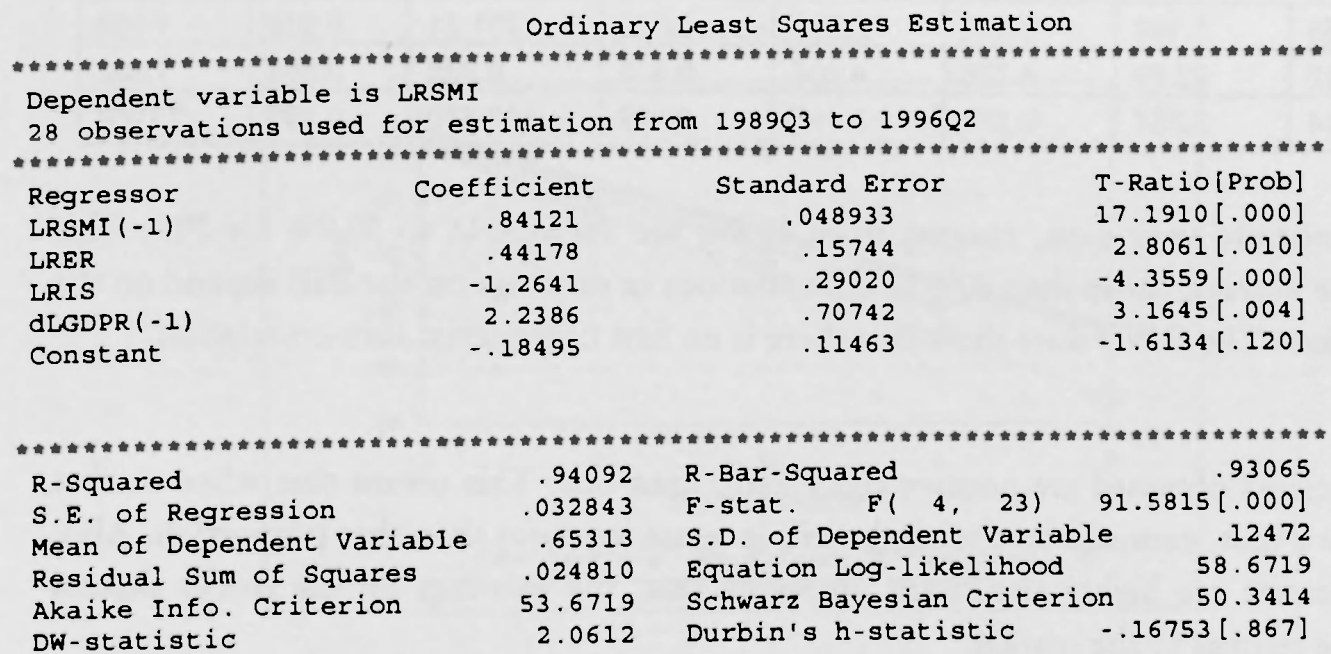

Table 17b

\section{Botswana - Economic Variables Model II}

Exact AR (2) Newton-Raphson Iterative Method converged after 7 iterations

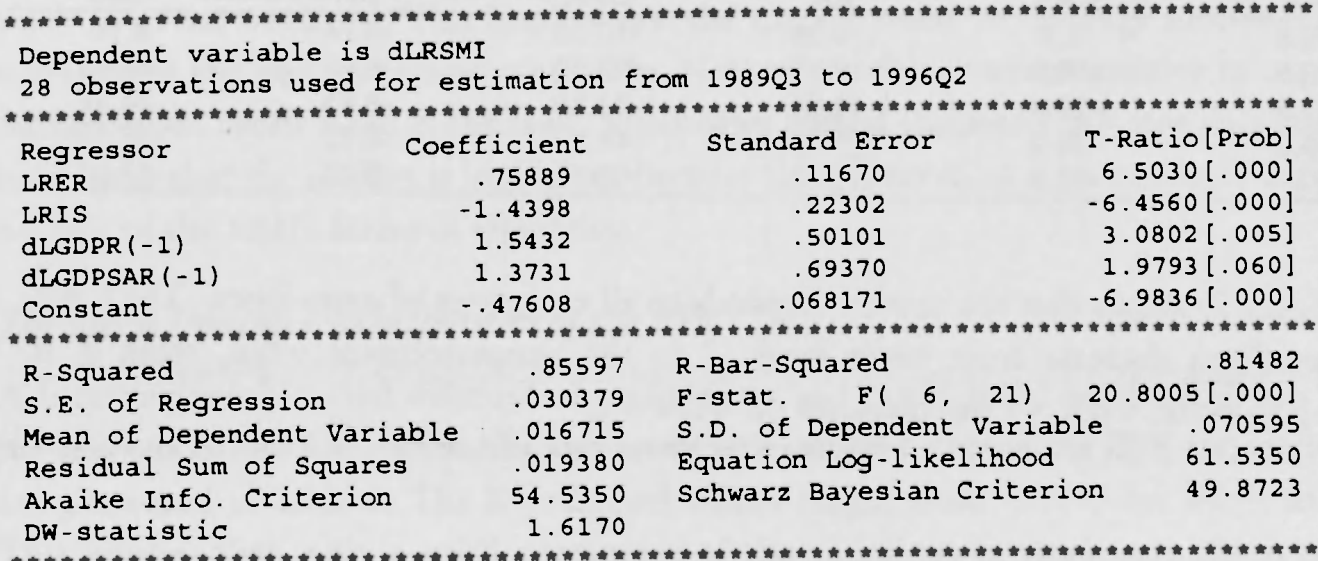

Parameters of the Autoregressive Error Specification

:

$U=-.077749 * U(-1)+\quad-.66898 * U(-2)+E$

$(-.55350)[.586](-4.7625)[.000]$

T-ratio(s) based on asymptotic standard errors in brackets

Log-likelihood ratio test of AR(1) versus OLS CHI-SQ(1) = .065037[.799]

Log-likelihood ratio test of $A R(2)$ versus AR(1) CHI-SQ(1) $=13.3517[.000]$

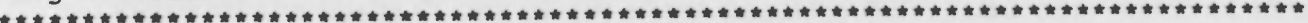

\section{RESULTS: EVENT STUDY}

\section{The Stock Pricing Characteristics of the BSE}

A sixty-week period data obtained from the BSE on three firms each from the retail and banking sectors is used to estimate the BSE model parameters. The estimation of the parameters is done for each firm and the results obtained are reported in table 18 below. 
Table 18: Estimation of the BSE model parameters using equally weighted market returns for 60-weeks (1996-1997)

\begin{tabular}{|l|r|r|r|r|r|r|r|r|}
\hline FIRM & $\alpha \mathbf{i}$ & Seai & t-ratio $\alpha \mathbf{i}$ & $\beta i$ & Se $\beta i$ & t-ratio $\beta i$ & $\mathbf{R}^{2}$-bar & DW \\
\hline BARCLAYS & 6.599 & 7.019 & 0.940 & 2.880 & 0.497 & 57.870 & 0.983 & 1.910 \\
\hline FNB & 0.052 & 2.714 & 0.019 & 6.242 & 0.043 & 146.35 & 0.997 & 1.917 \\
\hline STANCHART & 12.248 & 9.317 & 1.135 & 3.824 & 0.079 & 48.24 & 0.975 & 2.028 \\
\hline PEP & -1.656 & 1.169 & -1.416 & 3.723 & 0.015 & 251.21 & 0.999 & 1.958 \\
\hline SEFALANA & 155.42 & 32.89 & 4.726 & 4.107 & 0.445 & 9.235 & 0.588 & 1.892 \\
\hline ENGEN & -2.944 & 3.381 & -0.871 & 3.497 & 0.029 & 117.470 & 0.996 & 2.086 \\
\hline
\end{tabular}

The $\mathrm{R}^{2}$-bar obtained are very high, ranging from $58.8 \%$ for SEFALANA to $99.9 \%$ for PEP. This implies that, on the average, more than $80 \%$ of the variations in earnings on the BSE depend on the returns to the market. The DW-values show that there is no first order serial auto-correlation.

All the beta coefficients obtained are positive and greater than one. This means that when market returns increase by a unit, earnings on the stocks will increase by more than that proportion. Also, all the beta coefficients are highly significant, implying that, the earnings on the stocks depend significantly on the returns to the market.

Analysis of Cumulative Abnormal Returns (CAR): BSE

Table 19: Cumulative Abnormal Returns, BSE

\begin{tabular}{lllcccc}
\hline $\begin{array}{l}\text { Event } \\
\text { Week }\end{array}$ & \multicolumn{2}{c}{ Good News } & \multicolumn{2}{c}{ Bad News } & \multicolumn{2}{c}{ No News } \\
\hline-2 & AR & CAR & AR & CAR & AR & CAR \\
-1 & -9.8 & -9.8 & -10.25 & -10.25 & -8.74 & -8.74 \\
0 & -9.8 & -19.6 & -12.10 & -23.35 & -8.92 & -17.68 \\
+1 & -9.8 & -29.4 & -11.04 & -33.39 & -8.65 & -26.31 \\
+2 & -9.8 & -39.2 & -11.30 & -44.69 & -8.72 & -35.03 \\
\hline
\end{tabular}

The CAR plot (Figure 7) shows that the market responds to all categories of news items. The CAR for the good news firms decrease from event week -2 to the announcement week, week 0 . It continues to fall up to event week +1 but increases on week +2 . 


\section{Cumulative Abnormal Returns}

Figure 7

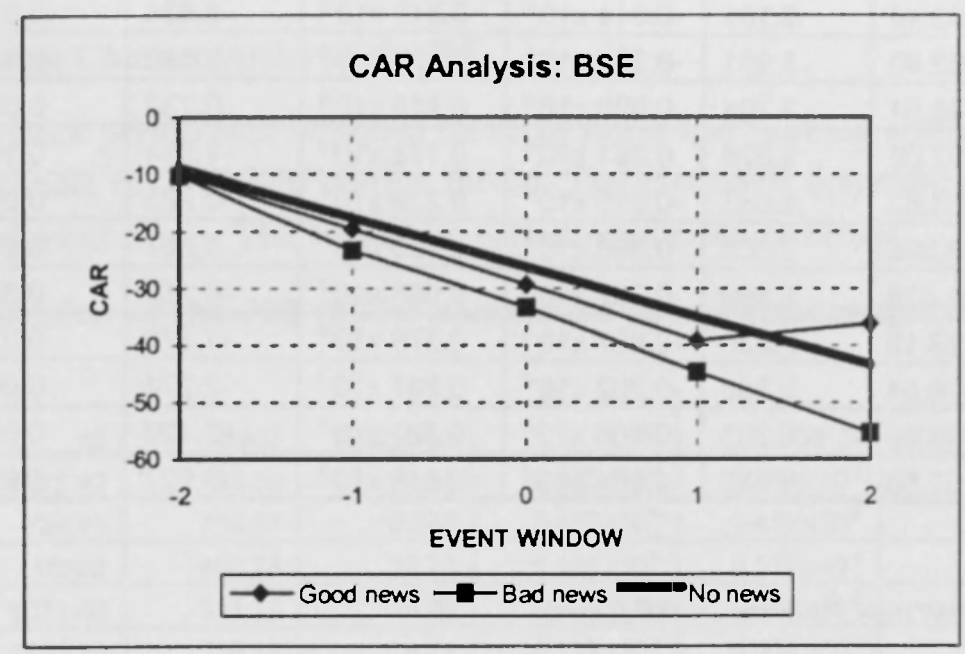

The CAR for the bad news and no news also decrease from week -2 through the announcement week to event week +2 . This implies that the market reacts to earnings announcements even two weeks after the announcement was made. Not only is this counter-intuitive to expectations, it is a disingenuous result since at the least, good news should increase CAR not decrease them. This an indication that the market is inefficient because this observation is inconsistent with the conditions for any of the EMH forms of efficiency.

\section{The Stock Pricing Characteristics of the ZSE}

A fifty-two week period database of retail stores and banks listed on the ZSE has been developed for analysis of the ZSE. Six banks and seven retail stores listed on the ZSE are analysed. The results are presented in table 2. The $R^{2}$-adjusted values ranges from -0.0095 for FNH to 0.306 for FMB. This implies that, only a small percentage of the variations in stock earnings is explained by the market returns. The DW values show that our estimated results do not suffer from auto-correlation problems. Table 20 shows that the betas of the firms dealt with ranges from $-0.964 \times 10^{-6}$ for TRUW to $0.890 \times 10^{-7}$ for DUNL. This implies that when market returns increases by one unit stock earnings will increase by a far lesser proportion.

The majority of the firms ( 9 out of 13) show negative betas, and only three of these; FMB, MEIK and TRUw, are significant. This implies that there is a negative correlation between stock earnings and market returns for these firms. Of the four firms with positive betas, only the beta for TEDC is significant. 
Table 20: Estimation of the ZSE model parameters using equal weighted market returns for 52 weeks (1997)

\begin{tabular}{|l|r|r|r|r|r|r|r|r|}
\hline FIRM & $\alpha \mathbf{i}$ & Seai & t-ratio $\alpha \mathbf{i}$ & $\beta \mathbf{i}$ & Se $\beta \mathbf{i}$ & $\mathbf{t}$-ratio $\beta \mathbf{i}$ & $\mathbf{R}^{2}$-bar & DW \\
\hline BARCLAYS & 3725.40 & 506.37 & 7.35 & $-0124 \times 10^{-6}$ & $0111 \times 10^{-6}$ & -1.113 & 0.012 & 1.943 \\
\hline DCZ & 208.13 & 28.65 & 7.264 & $-0.804 \times 10^{-7}$ & $0.914 \times 10^{-7}$ & -0.880 & 0.114 & 1.956 \\
\hline FINH & 683.68 & 83.46 & 8.191 & $-0.344 \times 10^{-8}$ & $0.546 \times 10^{-8}$ & -0.631 & -0.009 & 1.931 \\
\hline FMB & 6921.10 & 1162.90 & 5.951 & $-0.324 \times 10^{-5}$ & $0.124 \times 10^{-5}$ & -2.599 & 0.306 & 2.105 \\
\hline NMBZ & 2772.8 & 748.51 & 3.704 & $0.599 \times 10^{-6}$ & $0.819 \times 10^{-6}$ & 0.732 & 0.002 & 2.006 \\
\hline UDC & 201.32 & 57.06 & 3.528 & $0.261 \times 10^{-6}$ & $0.172 \times 10^{-6}$ & 1.514 & 0.103 & 2.015 \\
\hline DELT & 2154.40 & 323.82 & 6.653 & $-0.225 \times 10^{-7}$ & $0.228 \times 10^{-7}$ & -0.983 & 0.027 & 2.012 \\
\hline DUNL & 119.78 & 16.398 & 7.305 & $0.890 \times 10^{-7}$ & $0.103 \times 10^{-6}$ & 0.867 & 0.037 & 1.947 \\
\hline EDGA & 724.74 & 81.476 & 8.895 & $-0.762 \times 10^{-8}$ & $0.505 \times 10^{-7}$ & -0.151 & 0.020 & 1.977 \\
\hline HADD & 645.44 & 123.19 & 5.239 & $-0.907 \times 10^{-5}$ & $0.578 \times 10^{-5}$ & -1.570 & 0.032 & 1.971 \\
\hline MEIK & 3712.80 & 378.54 & 9.808 & $-0.202 \times 10^{-6}$ & $0.887 \times 10^{7}$ & -2.274 & 0.082 & 1.939 \\
\hline TEDC & 188.48 & 29.99 & 6.283 & $0.106 \times 10^{-8}$ & $0.501 \times 10^{-7}$ & 2.126 & 0.094 & 2.020 \\
\hline TRUW & 991.48 & 57.56 & 17.316 & $-0.964 \times 10^{-8}$ & $0.246 \times 10^{-6}$ & -3.927 & 0.281 & 2.019 \\
\hline
\end{tabular}

Analysis of Cumulative Abnormal Returns (CAR): ZSE

The parameters from which the abnormal returns (AR) and subsequently the cumulative abnormal returns (CAR), are shown in appendix 2. The AR and CAR are analysed by 67 good news, 84 bad news and 5 no news is presented below.

Table 21: Cumulative Abnormal Returns, ZSE

\begin{tabular}{|c|c|c|c|c|c|c|}
\hline \multirow{2}{*}{$\begin{array}{l}\text { Event } \\
\text { Week }\end{array}$} & \multicolumn{2}{|c|}{ Good News } & \multicolumn{2}{|c|}{ Bad News } & \multicolumn{2}{|c|}{ No News } \\
\hline & AR & CAR & AR & CAR & AR & CAR \\
\hline-2 & 124.31 & 124.31 & -89.49 & -89.49 & -10.75 & -10.75 \\
\hline-1 & 89.51 & 213.82 & -87.21 & -176.70 & -9.50 & -20.25 \\
\hline 0 & 30.76 & 244.58 & -111.29 & -288.99 & -10.75 & -31.00 \\
\hline+1 & 64.32 & 308.70 & -101.69 & -391.68 & -12.00 & -43.00 \\
\hline+2 & 54.98 & 363.68 & -110.99 & -502.67 & -7.27 & -50.27 \\
\hline
\end{tabular}

Figure 8

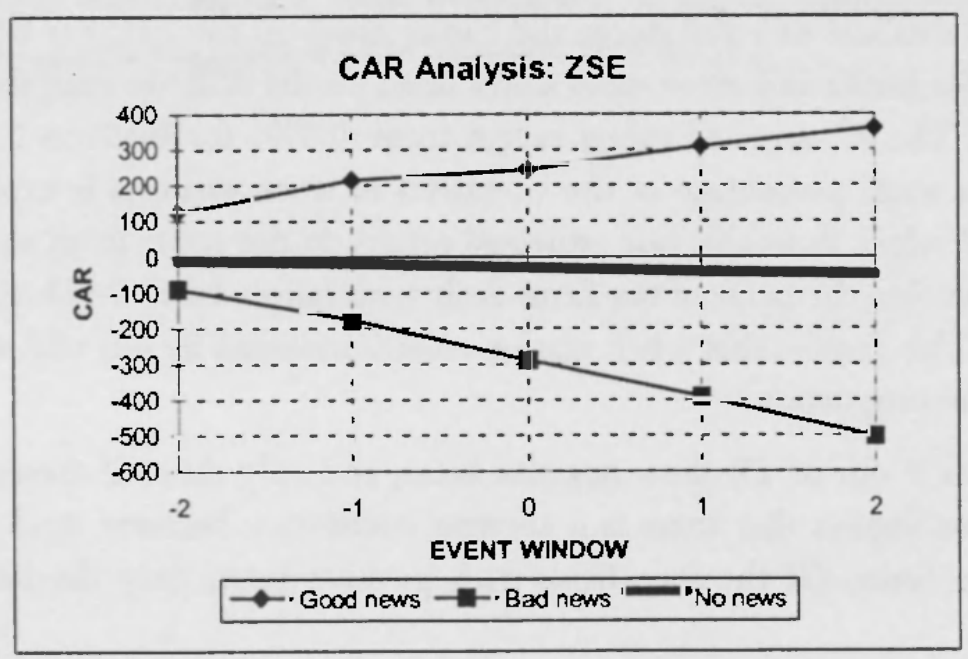

The CAR plot in Figure 8 shows evidence that the ZSE responds to both favourable and unfavourable earnings announcements. The CAR for good news firms increases from event week - 2 
to the announcement week, event week 0 . There is a sharp increase from week 0 to week +1 and then a gradual increase from event week +1 to event week +2 . The CAR for bad news firms dropped from event week -2 to event week 0 . There is a sharp drop after week 0 up to event week +2 . This observation is inconsistent to instantaneous and unbiased reaction to new information. The CAR for no news firms dropped continuously from event week -2 to event week +2 .

\section{The Stock Pricing Characteristics of the JSE}

A forty- three-week period data obtained on retail stores and banking sector firms listed on the JSE was used to estimate the standard market model. The exercise is done for thirteen listed banks and seventeen listed retail stores. The results are presented in table 22 below.

Table 22: Estimation of the JSE model parameters using equal weighted market returns for 43 weeks (1997)

\begin{tabular}{|c|c|c|c|c|c|c|c|c|}
\hline FIRM & $\alpha \mathbf{i}$ & Seai & $t$-ratio $\alpha \mathbf{i}$ & $\beta i$ & Se $\beta i$ & t-ratio $\beta \mathbf{i}$ & $\mathbf{R}^{2}$-bar & DW \\
\hline ADCORP & 1978.40 & 86.59 & 22.84 & $0.953 \times 10^{-8}$ & $0.268 \times 10^{8}$ & 0.35 & 0.064 & 1.957 \\
\hline ABSA & 739.45 & 759.87 & 0.973 & $0.113 \times 10^{-8}$ & $0.415 \times 10^{-7}$ & 2.74 & 0.753 & 1.899 \\
\hline $\mathrm{BDZ}$ & 15828 & 490.74 & 32.25 & $0.194 \times 10^{-6}$ & $0.105 \times 10^{-8}$ & 1.84 & 0.512 & 1.993 \\
\hline FIDELITY & 5071.60 & 311.19 & 16.29 & $0.646 \times 10^{-8}$ & $0.344 \times 10^{8}$ & 1.87 & 0.563 & 1.911 \\
\hline FIRST BANK & 2993.20 & 308.12 & 9.71 & $0.737 \times 10^{-7}$ & $0.209 \times 10^{-7}$ & 3.52 & 0.468 & 2.044 \\
\hline GENSEC & 5239.10 & 1323.30 & 3.96 & $0.354 \times 10^{-7}$ & $0.193 \times 10^{-8}$ & 0.183 & 0.698 & 2.028 \\
\hline NRB & 482.17 & 91.12 & 5.29 & $0.489 \times 10^{8}$ & $0.275 \times 10^{-8}$ & 1.77 & 0.711 & 1.952 \\
\hline ORION & 859.24 & 69.45 & 13.37 & $0.211 \times 10^{-7}$ & $0.698 \times 10^{-8}$ & 3.03 & 0.593 & 1.867 \\
\hline PSG & 1179.80 & 53.59 & 22.02 & $0.162 \times 10^{8}$ & $0.869 \times 10^{-7}$ & 1.87 & 0.534 & 1.893 \\
\hline STANBIC & 19921.0 & 2241.70 & 8.88 & $0.542 \times 10^{-7}$ & $0.917 \times 10^{-7}$ & 0.59 & 0.158 & 1.995 \\
\hline SAAMBOU & 1088.70 & 31.47 & 34.57 & $-0.451 \times 10^{8}$ & $0.270 \times 10^{-7}$ & -0.17 & 0.003 & 1.873 \\
\hline SASFIN & 1829.70 & 152.78 & 11.97 & $-0.820 \times 10^{-8}$ & $0.701 \times 10^{-8}$ & -1.17 & 0.57 & 1.983 \\
\hline TIGON & 1144.00 & 169.97 & 6.73 & $-0.189 \times 10^{-7}$ & $0.124 \times 10^{-8}$ & -0.15 & 0.703 & 1.966 \\
\hline BEARMAN & 206.01 & 47.37 & 4.34 & $0.110 \times 10^{-8}$ & $0.139 \times 10^{-8}$ & 0.79 & 0.567 & 1.977 \\
\hline CHARIOT & 426.51 & 30.47 & 13.99 & $-0.839 \times 10^{-7}$ & $0.538 \times 10^{-7}$ & -1.55 & 0.640 & 1.939 \\
\hline ITTILE & 2092.00 & 60.16 & 34.77 & $0.127 \times 10^{-8}$ & $0.213 \times 10^{-8}$ & -0.60 & 0.319 & 1.957 \\
\hline INVICTA & 679.80 & 50.50 & 13.46 & $-0.152 \times 10^{-8}$ & $0.116 \times 10^{-8}$ & -0.11 & 0.743 & 1.975 \\
\hline FOSCHINI & 1540.30 & 193.60 & 7.96 & $-0.123 \times 10^{-7}$ & $0.555 \times 10^{-7}$ & -0.22 & 0.699 & 1.989 \\
\hline HOMECHOICE & 503.33 & 35.36 & 14.23 & $-0.394 \times 10^{-7}$ & $0.887 \times 10^{-7}$ & -0.44 & 0.629 & 2.005 \\
\hline EDGARS & 7511.68 & 4159.80 & 1.80 & $0.371 \times 10^{-8}$ & $0.645 \times 10^{-6}$ & 0.57 & 0.792 & 2.015 \\
\hline LA STORES & 783.68 & 79.87 & 9.81 & $-0.508 \times 10^{-6}$ & $0.600 \times 10^{-8}$ & .0 .84 & 0.605 & 1.939 \\
\hline MCARTHY & 1285.80 & 618.03 & 2.08 & $-0.630 \times 10^{-7}$ & $0.336 \times 10^{-8}$ & -0.18 & 0.790 & 2.001 \\
\hline METCASH & 528.68 & 47.04 & 11.24 & $-0.173 \times 10^{-8}$ & $0.119 \times 10^{-7}$ & -1.45 & 0.418 & 2.031 \\
\hline MATHOMO & 484.91 & 86.72 & 5.59 & $-0.175 \times 10^{-8}$ & $0.346 \times 10^{-6}$ & -0.51 & 0.753 & 1.989 \\
\hline NUCLICKS & 503.92 & 68.09 & 7.400 & $0.845 \times 10^{-7}$ & $0.520 \times 10^{-7}$ & 1.625 & 0.526 & 1.899 \\
\hline OCEANIA & 1195.90 & 153.12 & 7.810 & $-0.665 \times 10^{-8}$ & $0.514 \times 10^{-6}$ & -1.302 & 0.714 & 1.946 \\
\hline PEP & 988.02 & 111.16 & 8.888 & $0.790 \times 10^{-7}$ & $0.441 \times 10^{-7}$ & 1.791 & 0.606 & 1.897 \\
\hline SHOPRITE & 907.35 & 103.96 & 8.727 & $0.136 \times 10^{-8}$ & $0.272 \times 10^{-7}$ & 0.049 & 0.679 & 1.979 \\
\hline SPECIALTY & 349.70 & 60.81 & 5.751 & $0.861 \times 10^{-7}$ & $0.129 \times 10^{-6}$ & ô. 665 & 0.661 & 1.965 \\
\hline WOOLTRU & 2167.00 & 563.19 & 3.848 & $-0.485 \times 10^{-7}$ & $0.139 \times 10^{-8}$ & -0.348 & 0.667 & 2.01 \\
\hline
\end{tabular}

The $\mathrm{R}^{2}$-adjusted values ranges from 0.003 for SaAmBOu to 0.792 for EdgaRs. These values are very high relative to those obtained for the ZSE model. The $\mathrm{R}^{2}$-adjusted implies that on the average more than $40 \%$ of the variations in the stock earnings is explained by the market returns. The DW indicate no severe auto correlation problem.

Of the thirty stocks analysed, sixteen firms show positive betas while the rest have negative betas. All the betas are far less than unity. Only a very few listed stocks, ABSA, FIRST Bank and OrIon show positive and significant betas at least at the $5 \%$ level. All the negative betas are insignificant. 


\section{Analysis of Cumulatize Abnormal Retums (CAR): JSE}

The results of the ARs are in appendix 3. The AR and CAR for the thirty firms considered on the JSE, analysed from 106 good news, 112 bad news and 11 no news are presented below.

Table 23: Cumulative Abnormal Returns, JSE

\begin{tabular}{lcccccc}
\hline Event & \multicolumn{2}{c}{ Good Nows } & \multicolumn{2}{c}{ Bad Nows } & \multicolumn{2}{c}{ No Nows } \\
Weok & AR & CAR & AR & CAR & AR & CAR \\
\hline-2 & 102.87 & 102.87 & -119.15 & -119.15 & -3.49 & -3.91 \\
-1 & 97.48 & 200.35 & -139.22 & -225.65 & 2.42 & -1.49 \\
0 & 84.50 & 284.85 & -134.22 & -392.87 & -6.12 & -7.61 \\
+1 & 91.72 & 376.57 & -157.92 & -550.79 & -2.21 & -9.82 \\
+2 & -182.80 & 193.77 & -121.51 & -429.28 & -3.47 & -8.03 \\
\hline
\end{tabular}

Figure 9

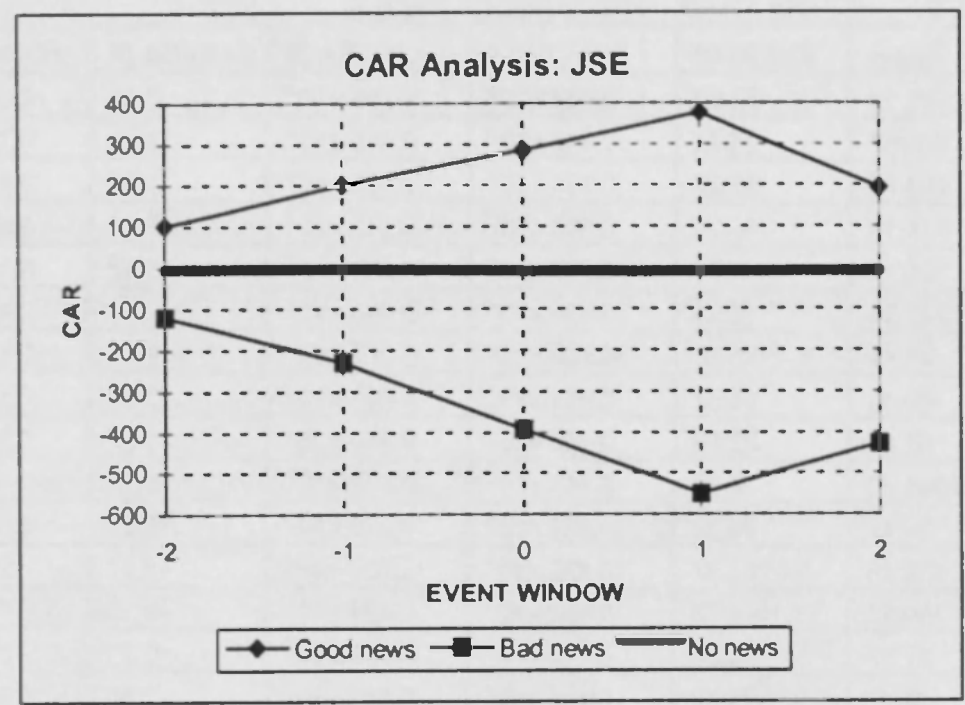

The CAR plots in Figure 9 for the good news firms show that, initially the CAR increases gradually from event week -2 to the announcement week. It then increased sharply up to event week +1 and then falls sharply in event week +2 .

The CAR plots for the bad news firms depicts an initial sharp drop from event week -2 up to the announcement week. There is a gradual drop from week 0 to week +1 and then a drastic increase in week +2 . The CAR for the no news firms increases from week -2 to week -1 . It falls sharply in week 0 , gradually in week +1 and finally improved in week +2 .

\section{Event Study: Findings and Conclusions .}

In analysing the three southern African markets using event study methodology, two main objectives were accomplished. Using sample of data of stocks from the retail and banking sectors we have analysed the earnings characteristics and tested the efficiency of these markets. Specifically, we have tested the hypotheses that (a) both the BSE and ZSE are inefficient, and (b) the JSE is weak-form efficient. The exercise is performed for retail stores and banks listed on these markets ${ }^{2 b}$.

${ }^{26}$ Due to lack of readily available data, this does not apply to the JSE; where the analysis was not conducted for all the stocks that are classified in the two sectors. 
The analyses of the pricing characteristics of the three market reveals mixed results, except in the case of the BSE where the betas are consistently positive and significant.

The CAR analyses confirm the hypothesis that both the BSE and the ZSE are inefficient markets, because they are inconsistent to instantaneous reaction to new earnings announcement releases. The JSE analysis indicates that this market is more efficient than the other two markets. This market tends to normalise after the event week +1 .

The level of cross-sectional variation of returns is often indicative of the level of efficiency of the market in which stocks are listed. The hypothesis that changes in relative risk affect expected earnings and abnormal returns, measured by the slope of the earnings response coefficient - how quickly investors respond to new information - is now quite common knowledge. From the outset of this study we have had as an underlying premise that earnings changes have systematic economic determinants (events) (see for example Ball, Kothari, and Watts (1991)), which are likely to be associated with variations in unexpected returns across markets, and as such might suggest the extent to which they are integrated. The results suggest that the relationship between market crosssection returns variability is probably due to the presence of differential information, and the information variability of returns is higher for the ZSE than it is for the BSE. However, the relative (cross-market) behaviour of cumulative abnormal returns makes conclusions regarding the integration of the three markets questionable. The differences in the level of efficiency (as deduced from the CAR analysis) between the JSE and the two other markets, makes the likelihood of integration low.

However some caveats to our results exist. Firstly, the infrequency of trading on the BSE and the ZSE, and the paucity of stock price and cross section data on earnings and dividend announcement data in Botswana and Zimbabwe, means that the results are subject to returns estimation bias. Secondly, it has also been established that JSE market efficiency is also affected by infrequency of trading. Indeed, although their methodology was criticised by Gilbert and Roux (1978) and Clark (1979), Saloner and Strebel (1978) have identified the impact of infrequent trading on beta values of stocks listed on the JSE. Their findings (Saloner and Strebel (1978)), suggest that the EMH only fits the behaviour of shares with average trading volumes in excess of 250,000 per year, at the time applicable to half the shares listed on the JSE. We did not analyse the volume of trades of the JSE listed stocks that we used in our analysis This could be an area for future research.

\section{CONCLUSIONS}

This research project has covered a wide range of issues relating to the characteristics of Southern African stock markets, including linkages between those markets, the efficiency of those markets, and their relationships with economic developments. There are a range of findings, which we draw together here to present broad conclusions regarding the stock markets under review.

One of the main conclusions is that within the Southern African markets, there is evidence of linkages between the Botswana and South African markets, but little evidence of linkages between the Zimbabwe market and either of the other two markets. The Botswana and South Africa markets appear to be linked in the long term, as manifested in the cointegration of the stock market indices, but not in the short term, as shown by the results of correlation tests. These findings may reflect the strength of the relative economic linkages between the three countries. Botswana and South Africa have a highly open economic relationship: they are partners in the Southern African Customs Union; Botswana obtains around $75 \%$ of its imports from South Africa, which is also an increasingly important export market, especially for non-mineral exports; even though Botswana 
left the Rand Monetary Area in 1976, the Botswana pula is pegged to a basket of currencies containing the SA rand; and South African firms are a major source of foreign direct investment in Botswana. Many economic developments in South Africa also have a direct effect on Botswana.

Zimbabwe, too, has close economic links with both Botswana and South Africa. There is substantial trade between Zimbabwe and South Africa, and significant trade between Zimbabwe and Botswana (although its importance has declined in recent years). Zimbabwe too is affected by regional economic developments. However, the Zimbabwean economy is in some ways less integrated into the region; although it is part of SADC (Southern African Development Community), it is not part of SACU, which is a much stronger economic grouping. Historically the Zimbabwean economy has been quite isolated (especially during the UDI years), and many of its firms are purely locally owned rather than linked to larger regional or international groups. Nor has its currency been particularly linked to those of Botswana or South Africa. The Zimbabwe Stock Exchange may therefore respond predominantly to local events rather than regional or international ones. The limited evidence of linkages between Zimbabwe and the other two markets - from correlation coefficients - suggests that the degree of co-movements between the Zimbabwe Stock Exchange and those of Botswana and South Africa has diminished since the Zimbabwean economy (and stock exchange) have become more liberalised and, presumably, more integrated with the regional economy ${ }^{27}$. However, this liberalisation has been part of Zimbabwe's Economic Structural Adjustment Programme (ESAP), which the country has been undertaking since the early 1990s. This has caused a particular set of economic developments in Zimbabwe, which are very specific to its own conditions, and not particularly related to regional or international developments. Zimbabwe has also been through the sharpest change in economic policy during the period under consideration (compared to Botswana and South Africa, where economic policy has been much more consistent), and this may also be an explanation for the sharp turnaround in the performance of the Zimbabwe Stock Exchange between the two periods. Furthermore, Zimbabwe has a much higher degree of dependence upon agriculture than Botswana or South Africa, and thus drought and related factors tend to have a much greater effect on the economy, and presumably the stock market, in Zimbabwe than in mineral-dependent Botswana or the relatively diversified South African economy.

It should also be noted that the different sectoral composition of different countries' stock market indices may be a cause of the lack of co-movements. For instance, the JSE has a large number of stocks, reflecting South Africa's diversified economy, but by international standards there is a relatively prominent role for the mining sector. Botswana and Zimbabwe have much less diversified economies, and hence their stock exchanges have a different sectoral composition. Economic or other developments that affect certain industrial sectors more than others may then weaken the impact of forces which would otherwise tend to cause markets to move together.

A second conclusion concerning linkages between stock markets is that the southern African markets, both individually and as a group, are not closely linked to either the two major developed country stock markets (the USA and the UK) or to other emerging stock markets. There is some weak evidence that the Southern African markets are linked to the USA and Latin American markets, but this is hardly conclusive and may benefit from further investigation. It is also unlikely that there would be a strong linkage between these markets and Latin America, as broader economic links between the two are undeveloped. However, one explanation could be that

"However it should be noted that although Zimbabwe has extensively liberalised the current account of the balance of payments, exchange control restrictions on capital movements, especially outflows, remain quite strict. 
Zimbabwe and South Africa are going through similar types of economic reform programmes as some of the Latin American countries, and their business sectors, previously heavily protected from international competition, are being progressively exposed to competition as tariff barriers come down.

In terms of short term relationships (correlations of returns), the South African market appears to be more closely linked than Botswana and Zimbabwe to the emerging and developed markets. To this extent, South Africa is more vulnerable than Botswana and Zimbabwe to "Tequila effect" type disturbances, or contagion from other emerging markets. Indeed, this is supported by casual observation of movements of the JSE index during the recent (late 1997) disturbances in Asian markets. We interpret this as resulting from the much larger size of the JSE, and the existence of more efficient mechanisms for transmitting international influences, as compared to Botswana and Zimbabwe. It also has a much greater weight in international fund managers' portfolios, and is therefore more likely to be affected by any general portfolio readjustment related to emerging market stocks. Nevertheless, these short term linkages are not manifested in long term relationships between South Africa and other stock markets internationally.

A further conclusion is that there is some evidence that international linkages between the stock markets reviewed here has increased over time; whereas no cointegration was found for the 1989-93 period, or over the $1989-96$ period as a whole, it was present for the $1994-96$ period. This is compatible with the expected effects of liberalisation and globalisation on international stock market linkages. However, the period reviewed (especially the second sub-period) is relatively short, and would benefit from further investigation when another year or two of data are available.

Moving from linkages between markets, to considering the markets individually, we find that there is some evidence of weak form inefficiency, for Botswana and the UK, in the first sub-period. For Botswana, this is not entirely surprising. This period marked the first few years after the establishment of the BSE, and the market was characterised by low liquidity, and few buyers and sellers. Share prices rose steadily during this period, largely influenced by adjustment to the existence of the new market (shares were previously much less liquid, and hence worth less), and the deliberate underpricing of new issues in order to attract first-time share buyers. The second period is one of greater maturity for the BSE, and in particular a much greater foreign presence, which added participants with a more sophisticated understand of market processes. Thus the finding of weak form efficiency in period 2 is welcome, although not entirely surprising. What is surprising is that the Zimbabwe market was found to be efficient in both sub-periods, and also experienced an opening up to foreign investors in 1994; it was expected that it too would be found to be inefficient in the first period.

In terms of relationships between stock markets and economic factors, the JSE demonstrates the closest relationship to variables that are expected to be important. The real stnck market index has a positive long term relationship (over the period 1985-95) with real GDP and the real exchange rate, and a negative relationship with the real long term interest rate. The main transmission of international influences is through the real exchange rate; there is no long term relationship with either US GDP or real interest rates. The ZSE also has long term relationships with some economic variables, but the direction of the relationship with some of the economic variables is perverse. In terms of international influences, it appear to be more closely linked to US (or global) economic factors than to South African economic factors. But overall, the ZSE is only related in the expected manner with domestic real GDP and domestic real interest rates. We interpret this as indicating that the rather odd relationship between the ZSE and economic factors, especially international 
influences, has been primarily affected by the high level of control over market processes which the economy has experienced over much of this period, and the isolation of its capital market from the international economy, which prevents the normal relationships from emerging. However, they may do so over time. As for Botswana, the BSE index was stationary over the $1989-96$ period, and hence could not exhibit any long term relationship with (non-stationary) economic variables. Nevertheless, in the short term economic variables do appear to have an influence in line with expectations - with the real exchange rate, domestic and South African real GDP growth all having a positive influence, and domestic real interest rates having a negative influence. This is an encouraging result, and indicates that as the BSE matures, it will reflect the impact of economic variables in the long term in a way that will enable it to play a more effective role in the economy.

A number of policy conclusions can be drawn from the results of this research, relating to international capital flows and portfolio diversification, stock market development, and regional integration. The lack of cointegration between the Southern African markets and other international markets - both developed and emerging markets - suggests that Southern Africa will continue to experience capital inflows, as fund managers seek the international diversification of risk that these market can apparently offer. However, the long term relationship between the Botswana and South Africa markets suggests that there may be few diversification benefits from investing in both markets, which - given the much larger size of the JSE - will tend to work against Botswana. Nevertheless, Zimbabwe can offer the potential for diversification gains, even for those who are already investing in South Africa.

This conclusion is however supportive of the overall needs of the three countries. Botswana has experienced a current account surplus for many years, and is therefore a capital exporter; in aggregate terms, it has little need for the finance that portfolio capital inflows bring (although it may benefit from the skills that these more sophisticated foreign market participants bring with them). South Africa and Zimbabwe are capital importers, and thus portfolio capital inflows can potentially help to relieve the constraints imposed by a shortage of domestic savings.

Nevertheless, dependence upon portfolio capital inflows can be problematic, due to its potential volatility. For countries to benefit, supportive policies must be in place, and there should be macroeconomic stability - as instability is a primary reason for the volatility of portfolio capital. If a country receives substantial portfolio inflows, efforts should be made to prevent appreciation of the real exchange rate, excessive monetary expansion, or speculative asset price bubbles - a combination that can be quite demanding of policymakers, particularly the monetary authorities.

A second policy conclusion relating to portfolio capital inflows is that, even with potential diversification gains on offer, these flows may still be inhibited by other problems at the level of stock markets themselves. For instance. restrictions on foreign shareholdings still exist in Zimbabwe and Botswana. And although the three markets are reasonably well monitored by the relevant authorities, there still remain potential insider trading problems that may deter foreign investors. More generally, the authorities need to ensure that the rules and regulations governing stock markets, as well as the transparency of their administration, evolves in line with international best practice. Other areas where reforms are needed include clearing and settlement (which can still be quite slow) and custody arrangements, especially for foreign-owned shares. .

With regard to the process of stock market development, and its relationship to the broader process of economic development, we have seen that all of the three Southern African markets considered are illiquid by world standards, even though there have been steady improvements in recent years. Other researchers have noted that liquidity (relative to both market size and GDP) is one of the 
key factors determining the overall economic impact of stock markets. However, low liquidity results primarily from the presence of large blocks of shares held by controlling interests or institutions, who may have few other opportunities for investment; this may be due to exchange controls (in all three of the countries reviewed), or relatively underdeveloped financial sectors (for Botswana, and to a lesser extent, Zimbabwe). While the former point can be dealt with fairly quickly, the latter cannot, and overall, liquidity is likely to increase only slowly, even with supportive policies in place. Other factors which can help to boost liquidity include encouraging more listings - which is a crucial need in Botswana in particular, with only 12 listed stocks - and the establishment of more brokers.

A third area of policy concern is that of regional economic integration. The evidence from this study suggests that the extent of capital market linkages is greater between South Africa and Botswana than between Zimbabwe and either of the other two countries. This may reflect Botswana's history of relatively liberal exchange controls, or simply the close economic relations that exist between the two countries. By contrast, Zimbabwe, and to a lesser extent South Africa, have maintained relatively strict capital controls, at least until recently. Greater regional economic integration - in the sense of development of a regional capital market - will still require significant further policy reforms, to allow the free flow of capital at least between countries in the region (say, the SADC countries). For instance, Botswana has a surplus of domestic savings over its investment needs, while South Africa and Zimbabwe are in the opposite position. From a regional perspective, there would be some logic in allowing firms to raise capital on the Botswana Stock Exchange (tapping into Botswana's surplus funds), and allowing this capital to be used to finance investment in other countries of the region. At present, such a scenario would not be automatically permitted under Botswana's exchange control regulations (although this does not mean that a request to do so would be turned down). This would help to provide Botswana savers with a greater range of financial instruments (which they lack at present) and regional investors with an additional source of funds ${ }^{28}$. Nevertheless, any regional capital market will remain dominated by South Africa for the foreseeable future, given the very large size of the JSE relative to other stock markets in the region.

:A As this report was being completed, in early 1998, further capital account liberalisation was undertaken in Botswana, which permitted foreign companies to float domestic currency bonds and export the capital proceeds in foreign currency. However, this is not yet possible with new share issues, although dual listings of existing foreign stocks are permitted. 
Appendix 1: Estimates of the BSE abnormal returns using equal weighted market returns

\begin{tabular}{|l|r|r|r|r|r|r|r|}
\hline Firm & $\alpha \mathbf{i}$ & Se $\alpha \mathbf{i}$ & $\mathbf{t}$-ratio $\alpha \mathbf{i}$ & $\beta \mathrm{i}$ & Se $\beta \mathrm{i}$ & t-ratio $\beta \mathbf{i}$ & $\mathbf{R}^{2}$-bar \\
\hline BARCLAYS & -10.56 & 47.3 & -0.22 & 2.987 & 0.333 & 8.965 & 0.898 \\
\hline FNB & -19.69 & 5.41 & -3.63 & 6.555 & 0.0834 & 78.52 & 0.997 \\
\hline StANCHART & 0.63 & 30.72 & 0.021 & 3.917 & 0.262 & 14.9 & 0.96 \\
\hline PEP & $0.35 \times 10^{-13}$ & $0.242 \times 10^{-12}$ & 0.147 & 3.703 & 0.305 & 121 & 1 \\
\hline SEFALANA & -14.99 & 24.36 & -0.61 & 6.461 & 0.32 & 20.141 & 0.978 \\
\hline ENGEN & -5.761 & 13.6 & -0.42 & 3.519 & 0.121 & 29.024 & 0.983 \\
\hline
\end{tabular}

Appendix 2: Estimates of the ZSE abnormal returns using equal weighted market returns

\begin{tabular}{|l|r|r|r|r|r|r|r|}
\hline Firm & $\alpha \mathbf{i}$ & Se $\alpha \mathbf{i}$ & t-ratio $\alpha \mathbf{i}$ & $\beta \mathbf{i}$ & Se $\beta \mathrm{i}$ & t-ratio $\beta \mathbf{i}$ & $\mathbf{R}^{2}$-bar \\
\hline BARCLAYS & 5421.9 & 641.9 & 8.44 & $-0.506 \times 10^{-6}$ & $0.143^{*} 10^{-6}$ & -3.5387 & 0.5615 \\
\hline DCZ & 272.53 & 43.5 & 6.25 & $-0.255 \times 10^{-6}$ & $0.126^{*} 10^{-6}$ & -2.0236 & 0.2559 \\
\hline FINH & 445.17 & 106.6 & 4.17 & $0.789 \times 10^{-6}$ & $0.631^{*} 10^{-6}$ & 1.2512 & 0.0388 \\
\hline FND & 3865.1 & 3928.6 & 0.98 & $-0.171 \times 10^{-6}$ & $0.420^{*} 10^{-5}$ & $-0.407^{*} 10^{-1}$ & -0.1248 \\
\hline NBMZ & 2543.5 & 1513.3 & 1.68 & $0.830 \times 10^{-6}$ & $0.165^{*} 10^{-5}$ & 0.50239 & -0.0564 \\
\hline UDC & 34.284 & 61.9 & 0.55 & $0.718 \times 10^{-6}$ & $0.183^{*} 10^{-6}$ & 3.9071 & 0.5646 \\
\hline DELT & 2865.1 & 637.4 & 4.49 & $-0.648 \times 10^{-7}$ & $0.424^{*} 10^{-7}$ & $0.424^{*} 10^{-7}$ & 0.1286 \\
\hline DUNL & 225.83 & 92.1 & 2.45 & $0.416 \times 10^{-6}$ & $0.587^{*} 10^{-6}$ & -1.04 & 0.0111 \\
\hline EDGARS & 723.28 & 138.3 & 5.22 & $-0.458 \times 10^{-6}$ & $0.901^{*} 10^{-7}$ & $0.508^{*} 10^{-1}$ & -0.076 \\
\hline HADD & 764.14 & 320.1 & 2.38 & $-0.123^{*} 10^{-4}$ & $0.147^{*} 10^{-4}$ & -0.837 & -0.0342 \\
\hline MEIK & 3669.7 & 1304.4 & 2.81 & $-0.94^{*} 10^{-4}$ & $0.292^{*} 10^{-4}$ & -0.665 & -0.066 \\
\hline TEDC & 177.78 & 66.4 & 2.67 & $0.126^{*} 10^{-6}$ & $0.109^{*} 10^{6}$ & 1.1582 & 0.0238 \\
\hline TRW & 1411.7 & 807.9 & 1.74 & $-0.272^{*} 10^{-5}$ & $0.353^{*} 10^{-5}$ & -0.783 & -0.0448 \\
\hline
\end{tabular}


Appendix 3 Estimates of JSE abnormal returns using equal weighted market returns

\begin{tabular}{|c|c|c|c|c|c|c|c|}
\hline FIRM & $\alpha \mathbf{i}$ & Seai & t-ratio $\alpha i$ & $\beta i$ & Se Bi & t-ratio $\beta i$ & $\mathbf{R}^{2}$-bar \\
\hline ADCORP & 1993 & 264.42 & 7.537 & $0.120 \times 10^{-6}$ & $0.952 \times 10^{-6}$ & 0.126 & 0.075 \\
\hline ABSA & 830.58 & 900.88 & 0.922 & $0.116 \times 10^{-6}$ & $0.496 \times 10^{-7}$ & 2.352 & 0.1926 \\
\hline $\mathrm{BDZ}$ & 14006 & 737.22 & 18.99 & $0.662 \times 10^{-6}$ & $0.185 \times 10^{-6}$ & 3.571 & 0.566 \\
\hline FIDELITY & 5109.8 & 240.62 & 21.24 & $0.660 \times 10^{-6}$ & $0.282 \times 10^{-6}$ & 2.339 & 0.242 \\
\hline FIRST BANK & 2689 & 393.89 & 6.82 & $0.955 \times 10^{-7}$ & $0.267 \times 10^{-7}$ & 3.27 & 0.456 \\
\hline Gensec & 4275.6 & 522.26 & 8.18 & $0.236 \times 10^{-6}$ & $0.719 \times 10^{-6}$ & 3.57 & 0.522 \\
\hline NRB & 458.3 & 83.65 & 5.48 & $0.602 \times 10^{-6}$ & $0.289 \times 10^{-6}$ & 2.08 & 0.193 \\
\hline ORION & 1010.9 & 46.93 & 21.54 & $0.986 \times 10^{-9}$ & $0.543 \times 10^{-6}$ & 0.182 & -0.07 \\
\hline PSG & 1108 & 27 & 41.03 & $0.363 \times 10^{-7}$ & $0.421 \times 10^{-7}$ & -863 & -0.02 \\
\hline Stanbic & 18620 & 3045.2 & 6.114 & $0.975 \times 10^{-7}$ & $0.126 \times 10^{-6}$ & 0.773 & -0.03 \\
\hline SAAMBOU & 1104.3 & 64.68 & 17.07 & $-0.361 \times 10^{-7}$ & $0.562 \times 10^{-7}$ & -0.17 & -0.04 \\
\hline SASFIN & 11764.8 & 33.24 & 53.08 & $-0.497 \times 10^{-6}$ & $0.389 \times 10^{-6}$ & -12.76 & 0.81 \\
\hline TIGON & 1602.2 & 181.37 & 0.83 & $-0.394 \times 10^{-6}$ & $0.123 \times 10^{-6}$ & -3.2 & 0.327 \\
\hline BEARMAN & 151.71 & 181.37 & 0.836 & $0.326 \times 10^{-6}$ & $0.561 \times 10^{-6}$ & 0.58 & -0.08 \\
\hline CHARIOT & 483.01 & 22.27 & 21.68 & $0.221 \times 10^{-6}$ & $0.413 \times 10^{-7}$ & -5.35 & 0.664 \\
\hline ITTILE & 2112.01 & 81.21 & 26.02 & $-0.21 \times 10^{-6}$ & $0.268 \times 10^{-6}$ & -0.78 & -0.02 \\
\hline INVICTA & 645.16 & 27.24 & 23.68 & $-0.110 \times 10^{-6}$ & $0.812 \times 10^{-7}$ & -1.63 & 0.11 \\
\hline FOSCHINI & 2560 & 231.57 & 11.06 & $-0.334 \times 10^{-6}$ & $0.703 \times 10^{-7}$ & -4.75 & 0.607 \\
\hline HOMECHOICE & 450.6 & 29.99 & 15.03 & $0.114 \times 10^{-6}$ & $0.812 \times 10^{-7}$ & 1.409 & 0.065 \\
\hline EDGARS & -743.13 & 1111 & -0.066 & $0.164 \times 10^{-5}$ & $0.170 \times 10^{-5}$ & 0.96 & 0 \\
\hline LA STORES & 792.46 & 68.27 & 11.61 & $-0.840 \times 10^{-6}$ & $0.579 \times 10^{-6}$ & -1.45 & 0.073 \\
\hline MCARTHY & 4549 & 636.66 & -5.06 & $-0.174 \times 10^{-5}$ & $0.345 \times 10^{-6}$ & -5.06 & 0.733 \\
\hline METCASH & 485.99 & 42.94 & 11.31 & $-0.826 \times 10^{-8}$ & $0.106 \times 10^{-7}$ & -0.77 & -0.02 \\
\hline MATHOAMO & 748.52 & 36.94 & 20.26 & $-0.150 \times 10^{-5}$ & $0.156 \times 10^{-6}$ & -9.58 & 0.866 \\
\hline NuClicKs & 759.19 & 34.06 & 22.28 & $-0.112 \times 10^{-6}$ & $0.259 \times 10^{-7}$ & -4.345 & 0.665 \\
\hline OCEANIA & 1168.6 & 69.58 & 16.79 & $-0.747 \times 10^{-6}$ & $0.259 \times 10^{-6}$ & -3.077 & 0.714 \\
\hline PEP & 1375.2 & 72.64 & 18.93 & $-0.87 \times 10^{-7}$ & $0.314 \times 10^{.7}$ & -2.76 & 0.322 \\
\hline SHOPRITE & 1058.6 & 72.64 & 18.93 & $-0.87 \times 10^{-7}$ & $0.314 \times 10^{-7}$ & -2.77 & 0.322 \\
\hline SPECIALTY & 334.63 & 53.95 & 6.2 & $0.176 \times 10^{-6}$ & $0.137 \times 10^{-6}$ & 1.283 & 0.067 \\
\hline WOOLTRU & 4176 & 892.35 & 4.67 & $-0.112 \times 10^{-6}$ & $0.259 \times 10^{7}$ & -4.345 & 0.665 \\
\hline
\end{tabular}




\section{BIBLIOGRAPHY}

ABURACHIS, A. T. (1993) “International Financial Markets Integration: an overview”, in STANSELL, S. R. (ed.) International Financial Market Integration.

ADERHOLD, R., CUMMING, C. \& HARWOOD, A. (1988) "International linkages amongst equities and the October 1987 market break", Federal Reserve Bank of New York Quarterly Reriew, Summer, pp34-46.

BALL R, KOTHARI S.P \& WATTS R.L (1991) “Economic Determinants of the Relation Between Earnings Changes and Stock Returns", Working Paper, University of Rochester.

BALL, R. \& BROWN, P.(1968) “An Empirical Evaluation of Accounting Income Numbers", Journal of Accounting Research, $159-178$.

BANZ R. W (1981) “The Relationship Between Return and the Market Value of Common Stocks”, Journal of Financial Economics 9, 3-18.

BASU S.(1983) “The Relationship Between Earnings Yield, Market Value and Return for NYSE Common Stocks: Further Evidence", Journal of Financial Economics 12, 129-156.

BENNETT, P. \& KELLEHER, J. (1988) "The international transmission of stock price disruption in October 1987", Federal Reserve Bank of New York Quarterly Review, Summer, pp.17-29

BHANDARI L.C (1988) "Debt/ Equity Ratio and Expected Common Stock Returns: Empirical Evidence", Journal of Finance 43, 507-528.

BOARD J., POPE P., \& SKERRATT L (1991) “Databases for Accounting Research" Research Report of Institute of Chartered Accountants in England and Wales.

BROWN, S. \& WARNER, J. (1985) “Using Daily Stock Returns: The Case of Event Studies”, Journal of Financial Economics, 14, 3-31.

CAMPBELL J. Y, LO A .W \& MACKINLAY A. C (1997) The Econometrics of Financial Markets, Princeton University Press.

CHAN, K. C. \& LAI, P. (1993) "Unit Root and cointegration tests of world stock prices", in STANSELL, S. R. (ed.) International Financial Market Integration.

CHAN, K.C., GUP, B.E. \& PAN, M. (1992) "An Empirical Analysis of Stock Prices in Major Asian Markets and the United States", The Financial Review, vol.27 no.2 (May), pp.289-307.

CHEN, N., ROLL, R. \& ROSS, S. (1986) "Economic Forces and the Stock Market”, Journal of Business, 59, pp.383-403.

CHISAMBI, K. \& MATOME, T. (1993) Risk Analysis of the Botswana Share Market", Conference on Accounting and Economic Development, University of Botswana.

CHOU, R., NG, V. \& PI, L. (1994) “Cointegration of International Stock Market Indices”, IMF Working Paper, WP/94/94 (Washington DC: International Monetary Fund).

CLARK K.F(1979) "An Investigation into the Effect of Trading Volume on the Log-Price-Relative for Selected Shares on the JSE", MBA thesis, University of the Witwatersrand.

DOLADO, J.J., JENKINSON, T., \& SOSVILLA-RIVERO, S. (1990) "Cointegration and Unit Roots", Journal of Economic Surveys, vol.4, pp.275-284.

DOLLEY J. C (1933) "Characteristics and Procedures of Common Stock Split-Ups”, Harvard Business Review, 11, 316-326

DWYER, G.P. \& HAFER, R.W. (1988) “Are national stock markets linked?”, Federal Reserve Bank of St. Louis Review, Nov/Dec, pp.3-14

DWYER, G.P. \& HAFER, R.W. (1990) “Do Fundamentals, Bubbles or Neither Explain Stock Prices? Some International Evidence", in DWYER, G.P. \& HAFER, R.W. (eds.) The Stock Market: Bubbles, Volatzlity, and Chaos. Proceedings of the Thirteenth Annual Economic Policy Conference of the Federal Reserve bank of St. Louis (Boston: Kluwer) 
ENGLE, R. \& GRANGER, C.W. (1987) “Co-integration and Error Correction: Representation, Estimation, and Testing.", Econometrica 55 (March), pp.251-276

EUN. C.S. \& SHIM, S. (1993) "International Transmission of Stock Market Movements", in ST ANSELL, S. R. (ed.) International Financial Market Integration.

FAMA, E. \& FRENCH, K (1992) “The Cross- Section of Expected Stock Returns” Journal of Finance, 47, 427-465.

FAMA E. \& FRENCH K.(1995) “Size and Book-to-Market Factors in Earnings and Returns", Journal of Finance L, 1, 131-155.

FAMA, E. (1970) "Efficient Capital Markets: A Review of Markets and Empirical Work", Journal of Finance, 25, 383-423.

FAMA, E. (1981) "Stock Returns, Real Activity, Inflation and Money", American Economic Review 71, pp.545-565.

FAMA, E. (1990) “Stock Returns, Expected Returns, and Real Activity”, Journal of Finance, vol.65, Pp.1089-1108.

GILBERTSON, B.P \& ROUX, F.J.P (1978) “Some further comments on the Johannesburg Stock Exchange as an Efficient Market", The Investment Analysts Journal 20, 3545.

GRANGER, C.W. (1986) "Developments in the Study of Cointegrated Economic Variables", Oxford Bulletin of Economics and Statistics (August), pp.213-228.

GRUBEL, H. (1968) “Internationally diversified portfolios: welfare gains and capital flows", American Economic Review, 58, 1299-1314.

HARRIS, L. \& SMITH, G. (1996) “Integration of European Capital Markets: Evidence from Cointegration Tests", Discussion Paper, SOAS, University of London.

HARRIS, R. (1995) Using Cointegration Analysis in Econometric Modelling (London: Prentice HallHarvester Wheatsheaf)

INTERNATIONAL FINANCE CORPORATION (IFC) (1997) Emerging Markets Factbook 1996 (Washington DC: IFC)

JEFFERIS, K. (1995) "The Botswana Share Market and its Role in Financial and Economic Development", World Development, vol.23 no.4, pp.663-678.

JOHANSEN, S. \& JUSELIUS, K. (1989) "Maximum Likelihood Estimation and Inference on Cointegration with Application to the Demand for Money", Oxford Bulletin of Economics and Statistics, vol.52, no.2.

JOHANSEN, S. (1988) "Statistical Analysis of Cointegration Vectors", Journal of Economic Dynamics and Control, 12, pp.231-54.

KENDALL, M. \& STUART, A. (1967) The Advanced Theory of Statistics (London: Charles Griffin).

KENDEL, S. \& STAMBAUGH R.F (1995) "Portfolio Inefficiency and the Cross-Section of Expected Returns", Journal of Finance, L,1, 157-184.

KORMENDI R. \& LIPE R(1987) “Earnings Innovations, Earnings Innovations and Stock Returns", Journal of Business, 60, $323-345$.

KOTHARI S.P., SHANKEN J., \& SLOAN R.G (1995) “Another Look at the Cross-Section of Expected Stock Returns", Journal of Finance, L, 1, March , 185-224.

LEASE R, MASULIS R, \& PAGE L. (1991) “An Investigation of Market Microstructure impacts on event study returns", Journal of Finance 46, 1523-1536.

LEVINE, R. \& ZERVOS, S. (1995) “Policy, Stock Market Development and Long-Run Growth", paper presented to the World Bank Conference on Stock Markets, Corporate Finance and Economic Growth, February 16-17.

LEVINE, R. \& ZERVOS, S. (1998) “Stock Markets, Banks and Economic Growth", American Economic Review, 88(3), 537-558 
LINTNER, J. (1965) “Security Prices, Risk and Maximal Gains from Diversification”, Journal of Finance, 20, 587-615.

MA, C. (1993) "Financial Market Integration and Cointegration tests", in STANSELL, S. (ed.) International Financial Market Integration

MACDONALD, R. \& TAYLOR, M.P. (1988) "Metal Prices, Efficiency and Cointegration: Some Evidence from the London Metal Exchange”, Bulletin of Economic Research 40 (June), pp.235239

MACDONALD, R. \& TAYLOR, M.P. (1989) “Foreign Exchange Market Efficiency and Cointegration: Some Evidence from the Recent Float." Economic Letters 29: 63-68.

MACKINLAY A. G (1997) “Event Studies in Economics and Finance”, Journal of Economic Literature, XXXV (March) Pp 13-39.

MADURA, J. (1985) “International Portfolio Construction”, Journal of Business Research 13: 87-95

MALDONADO, R. \& SAUNDERS, A. (1981) "International portfolio diversification and the inter-temporal stability of international stock market relationships 1957-78", Financial Management, Autumn, 54-63.

MA TOME, T.T. (1997) "Return predictability investigations on four Southern African stock markets, with an emphasis on the Botswana Stock Exchange”, PhD. Thesis submitted to the University of Birmingham.

OKEAHALAM C.C (1994) "Data Problems and the Specification of a Dynamic Non-Linear MBAR Earnings Model”, Capital Markets Research Symposium 1, 114 -138.

PANTON, D., LESSIG, V., \& JOY, O. (1976) “Comovements of International Equity Markets: A Taxonomic Approach”, Journal of Financial and Quantitative Analysis, 11 (September), Pp.415-432.

REMOLONA, E.M. (1991) "Do international reactions of stock and bond markets reflect macroeconomic fundamentals?”, Federal Reserve Bank of New York Quarterly Review, Autumn 1991, pp.1-13.

RICHARDS, A. (1996) "Volatility and Predictability in National Stock Markets: How Do Emerging and Mature Markets Differ”, IMF Staff Papers, Vol.43 no.3, pp.461-501.

RIPLEY, D.M. (1973) "Systematic elements in the linkage of national stock market indices", Review of Economics and Statistics, 55, pp.356-361

ROSS, S. (1976) “The Arbitrage Theory of Capital Asset Pricing” Journal of Economic Theory, 13, $341-360$.

SHARPE, W.(1964) “Capital Asset Prices : A Theory of Market Equilibrium under Conditions of Risk" Journal of Finance, 19, 425- 442.

STANSELL, S. R. (ed.) (1993) International Financial Market Integration, (Oxford: Blackwell).

TAYLOR, M. \& TONKS, I. (1989) “The Internationalisation of Stock Markets and the Abolition of U.K. Exchange Control", Review of Economics and Statistics, Vol.71 no.2, pp.332-336, May.

VON FURSTERNBERG, G.M. \& JEON, B.N. (1989) “International stock price movements: links and messages”, Brookings Papers on Economic Activity 1989 no.1, pp.125-179.

WORLD BANK (1993) Global Economic Prospects and the Developing Countries (Washington DC: World Bank)

YONG, O. (1993) “Inter-relationship between Malaysian and selected stock markets in the Far East and New York: parametric versus nonparametric approach revisited", Jurnal Pengurusan (Malaysia), vol.12, pp.65-84

ZHUPARRIS, M. (1993) Emerging Markets Investment Research - Africa (New York: Morgan Stanley) 


\section{BIDPA Publications}

\section{Working Paper Series}

\section{BIDPA Working paper 1}

Granberg, Per

A Note Concerning the Revision or rebuilding of the MEMBOT.Model. Some Preliminary Observations and Suggestions. BIDPA, 1996. RESTRICTED.

The paper discusses the structure of the existing MEMBOT model (Macroeconomic model for Botswana). The limitations of the current model are identified and a need to revise it is noted.

\section{BIDPA Working Paper 2}

Granberg, Per

A Study of the Potential Economic Effects of AIDS. Some Preliminary Thoughts. BIDPA, 1996.

Given the current rate of HIV/AIDS infection in Botswana, there seems a need to analyse its economic impact. It is suggested that BIDPA may take an initiative towards this end. The paper presents some preliminary and tentative ideas about such a project.

\section{BIDPA Working paper 3}

Duncan, Tyrrell (ed.).

Study on Poverty Alleviation in Botswana: Inception report. BIDPA, 1996

This inception report sets out the various steps planned in completing the study, which comprises a statistical review of poverty utilising the 1985/86 and 1993/94 Household Income and Expenditure Survey. The study will focus six special areas: Basic Education, Preventative Health, Labour Based Public Works, Destitute Policy, Financial Assistance Policy and Arable Lands Development Programme.

\section{BIDPA Working Paper 4}

Isaksen, Jan.

Main Ingredients for a Public - Private Sector Strategy for Private Sector Employment Creation in Botswana: Prepared for the Fourth Private Sector Conference on Employment Creation, Francistown 26 - 28 May 1996.

The paper attempts to draw lessons from policy experiences in Eastern Asia. On the basis of such lessons, the paper suggests a number of practical policy steps which hopefully would be relevant to the policy debate in Botswana It argues that a resumption of rapid economic growth through diversification and industrialisation are the most important contributions to the acceleration of employment creation in Botswana

\section{BIDPA Working Paper 5}

Granberg, Per.

A Revised Poverty Datum Line for Botswana. BIDPA, June, 1996

The paper is part of a larger study of poverty and poverty alleviation in Botswana, undertaken by BIDPA for the Ministry of Finance and Development Planning. The paper presents revised estimates of the Poverty Datum Line (PDL) for Botswana, needed to analyse the household income and expenditure survey for 1993/94 and 1985/86 in terms of poverty.

\section{BIDPA Working Paper 6}

Gergis, Abdalla.

Regulation, Privatisation and Commitment in Botswana: Paper presented at BNPC's First Stakeholder Consultative Conference on Productivity: Productivity - Key to the future, November 6, 1996.

The paper notes the challenge facing Botswana, giving particular attention to the changing role of the state and the need to adjust the regulatory environment. Recent economic developments in Botswana are discussed, as are the questions of international competitiveness and the search for anew engine of growth for the economy. 


\section{B1DPA Working Paper 7}

Fidzani, N.H., P. Makepe and J. Thalefang

The impact of trade liberalisation on Botswana's beef and maize sectors. BIDPA 1997

The paper examines the Botswana beef and maize sectors in terms of structure, main activities and market distortions. The origins and sources of these distortions are analysed to determine how their removal would bear upon the various stakeholders. The paper also attempts to sketch implications of regional integration.

\section{BIDPA Working Paper 8}

\section{Isaksen, Jan.}

Data Requirements and Methodologies for Multi-country Research.

The paper was presented at a workshop on developing a research agenda for accelerated development in Sub-Sahara Africa Held in Harare, Zimbabwe, March 1997. It presents data and methodology for co-operation at national, regional and continental levels in research. It concludes that there is need for international co-operation build on national priority research.

\section{BIDPA Working Paper 9}

Gergis, Abdalla

"To Privatise", What is \& How? Paper presented at seminar on "Competition, Productivity and Privatisation: Commonwealth Experiences and for Botswana" organised by BIDPA and BNPC under the sponsorship of the Commonwealth Secretariat, Gaborone 21-23April, 1997 BIDPA, 1997

The paper was presented at a seminar on Competition, Productivity and Privatisation. It draws on lessons of experience as well as existing knowledge about privatisation, briefly addressing the main issues discussing how privatisation can be planned and implemented successfully.

\section{BIDPA Working Paper 10}

\section{Greener, Robert}

The Impact of HIVIAIDS and options for intervention: results of a five-company pilot study.

BIDPA, 1997

The paper was written for the Botswana National Task Force on AIDS at the workplace. It presents results from a study of the impact of HIV/AIDS, based on a sample of five companies in Botswana It concludes that the impact to date has been small, because the HIV epidemic is still too recent to have developed into an AIDS epidemic.

\section{BIDPA Working Paper 11}

Harvey, Charles.

The role of Africa in the global Economy: the contribution of regional co-operation, with particular reference to Southern Africa. BIDPA' 1997

The paper was written at the request of the Vice President and Minister of Finance and Development Planning. The paper notes that Africa's importance in the world economy has declined over the years and argues that this, and the extreme poverty in most of Africa, calls for analysis of ways to reverse the trend. Prospects for regional co-operation and integration are discussed as possible ways to accelerate economic growth in Southern Africa.

\section{BIDPA Working Paper 12}

Ditlhong, Molapisi.

Poverty Assessment and Poverty Alleviation in Botswana BIDPA 1997

The paper discusses the nature and extent of poverty in Botswana, drawing data from the Study of poverty and poverty alleviation in Botswana conducted by BIDPA for Ministry of Finance and Development Planning.

\section{BIDPA Working Paper 13}

Gergis, Abdalla

Competition, Productivity and Privatisation. BIDPA 1997.

A summary report of the proceedings of the Seminar on Competition, Productivity and Privatisation. 
Lisenda, Lisenda

Small and Medium-Scale Enterprises in Botswana: Their Characteristics,

Sources of finance and Problem BIDPA, December 1997.

The study analyses the characteristics of Small and Medium-Scale Enterprises (SMEs) in Botswana highlighting the educational background of owners and exposure to business related training, geographic location of enterprises, premises of operation, age of enterprise, and size of enterprise by number of employees, sales and total investment and activity. Also considered are administration and financial sources of the enterprises. Record keeping is assessed by size of enterprise, gender of operator and source of finance of enterprise. Problems faced by SMEs are highlighted.

\title{
BIDPA Working Paper No. 15
}

\section{Granberg, Per.}

\section{A simple formula for forecasting the Botswana urban population total. BIDPA,}

February 1998

The paper establishes a simple relationship between urbanisation and economic growth. The relationship is intended as a simple "annex" to the revised MEMBOT model (forthcoming), capable of providing quantitative estimates illustrating the likely nature of urban population changes under alternative economic scenarios.

\section{BIDPA Working Paper No. 16}

Sesinyi, Magdeline.

Minimum wages and employment: literature review and background on minimum wages in Botswana. BIDPA, 1998.

Gives a brief literature review on minimum wages and their possible effects on employment, with particular focus on the likely effects of minimum wage introduction on the two excluded sectors, namely the Domestic and Agricultural Sectors. It briefly outlines research results on minimum wages from past studies, highlighting their main recommendations. The paper concludes that minimum wage increases results in trade-off, and no matter how well intended come with a price in the form of lost jobs for some and increased benefits for others.

\section{BIDPA Working Paper No. 17}

\author{
Jefferis, Keith, Charles Okeahalam and Tebogo Matome \\ International Stock Market Linkages in Southern Africa. BIDPA, 1999
}

Stock markets are taking on an increasingly prominent role in financial development, and many developing and transition economies are establishing stock markets as part of financial reform processes. In theory stock markets can contribute to the mobilisation of savings and the allocation of investment, but there are questions as to whether this works in practice. One important issue is whether stock markets are efficient (in the financial sense), and a related question is whether share prices reflect economic fundamentals; both of these questions are important in addressing whether stock markets properly allocate capital. Another issue relates to the question of international linkages between markets: with greater integration of capital markets globally, financial market developments appear to be rapidly transmitted between markets around the world. While this can have beneficial impacts, in terms of improving the global allocation and pricing of capital, it may be disruptive if international capital flows are large relative to national markets and economies. This paper addresses pertinent issues in the context of stock markets in three southern African countries: Botswana, Zimbabwe and South Africa.

\section{BIDPA Working Paper No. 18}

Dumcombe, Richard

The Role of Information and Communication Technology in Small and Medium Enterprise Development in Botswana. BIDPA, October 1998

The paper analyses the role of information and communication technologies (ICTs) in small and medium enterprise (SME) development in Botswana. It outlines the economic and policy background to SME development, and presents an analysis of the SME sector with regard to firm size, location and market sector. It presents the results of a pilot survey of firms in the SME sector examining the information and communication practices of a small sample of firms. Current developments in information and communication technologies are outlined, and some preliminary findings relating to ICT impact on SMEs are summarised. Finally, some policy considerations are mentioned and the objectives of the main fieldwork phase of the project are outlined 


\section{By Haney. Charles}

\section{The impact on Southern. Africa of the financial crises in Asia and Russia BIDPA, June 1999}

The countries of southern Africa have not suffered seriously from "financial contagion", which is the short-term and sometimes devastating impact of financial crises in other countries. The first stage of financial contagion occurs through the markets for foreign exchange, shares and bonds. The second stage, which can be even more devastating, occurs if trouble in financial markets causes a crisis in the country's banking system, as happened in several Asian countries. South Africa's economy is potentially the most vulnerable in Southern Africa to financial contagion, because
it has highly developed financial markets which are open to inflows and outflows of foreign capital. However, the economic cost of financial contagion has been limited in South Africa because the country's banking system is sound. Zimbabwe has been similarly protected from the worst effects of financial contagion. Financial markets in the other countries of Southern Africa are very underdeveloped, which limits the first stage of financial contagion; this is fortunate. because some of them have unsound banking systems. All of these countries are actively trying to develop their financial sectors, however, so that their relative immunity to financial contagion may be reduced in the future. This will strengthen the case for maintaining macroeconomic balance, realistic exchange rates, and absolutely sound banking systems.

\section{BIDPA Working paper 20}

Jeferris, Keith The Long Term Impact of Structural Economic Change on Government Spending. BIDPA, June 1999

Botswana's current economic objectives centre on diversification away from its historical dependence on diamonds and government. Such diversification will change the structure of the economy, and has important implications for the abilitv of government to raise revenue through taxation and therefore for its ability to finance its expenditure. This paper explores the likely impact of diversification on government's revenue raising ability and hence on the magnitude of its overall role in the economy. It uses projections over a 20 -year period to simulate possible scenarios for taxation and the size of government. The kev point is that any diversification will cause government revenues to fall, in relative terms. The diamond sector is extremely profitable, and those profits are taxed at a very high rate; as the economy diversifies. other sectors will emerge that will be less profitable and less highly taxed. The projections in this paper show that under a variety of different assumptions about sectoral growth rates, and taxation and spending, government will have to significantly reduce its role in the economy. Such a change will have major implications for choices to be made about the allocation of public expenditure.

\section{Publications Series}

1. Gaolathe. Ndaba "Botswana's booms and recession experience: a discussion" IN: Salkin J.S., D. Mpabanga, D. Cowan, J. Selwe, M. Wright (eds.) Aspects of the Botswana Economy. Gaborone: Lentswe La Lesedi, 1997 pp: 37 - S2.

In the years around 1990, the Botswana economy experienced a period of "boom" conditions, eventually followed by a "burst". The paper sets out to analyse this experience, trying to explain the underlying factors, and to draw out policy lessons.

\section{Gergis, Abdalla (ed.) \\ Botswana's New Industrial Development Policy BIDPAMCI. Gaborone: Government Printer, 1997.}

The publication contains the proceedings of the joint BIDPA/MCI seminar held in September 1996. The volume includes the seminar report on group discussions of the draft industrial development policy and the background papers presented by speakers at the seminar. The report summarises the issues raised during the two days of discussions.

3. Gergis, Abdalla (ed.)

Prospects of EU/MCP relationship with particular reference to Botswana:

Conference held at the Grand Palm Hotel, Gaborone 25 - 26 September 1997:

Conference highlights Gaborone: Government Printer 1998.

This document presents highlights of the conference and of papers presented by speakers. The report captures the essence of the debate on the future of Lome Convention and highlights main issues that emerged from the consultation process. 
4. Granberg, Per.

Exchange rate, inflation and competitive: an analysis of the relationship between Botswana's Exchange and Inflation Rates and its implication for the competitive strength of her producers

The publication contains findings of the project: Study of Botswana's exchange rate policy. The publication details simple input/output based model for analysing the exchange rate question, and employs it to draw out the implications for various sectors of the economy, under alternative exchange rate scenarios. It goes on to analyse the available statistical evidence, and draw comparison to model results. Finally, it discusses the rationale, and possible revision, of the current exchange rate policy for a broader perspective with special reference to the likely implications of following a significantly different policy.

\section{Serials}

\section{BIDPA Briefing}

A quarterly newsletter, with topical supplements, that provides regular comment and analysis on all aspects ot Botswana economy.

\section{The BIDPA Newsletter}

A quarterly newsletter reporting on events, projects and general activities of the Botswana Institute for Development Policy Analysis (BIDPA). 


\section{(c) (1) (9)}

This work is licensed under a

Creative Commons

Attribution - NonCommercial - NoDerivs 3.0 License.

To view a copy of the license please see:

http://creativecommons.org/licenses/by-nc-nd/3.0/

This is a download from the BLDS Digital Library on OpenDocs

http://opendocs.ids.ac.uk/opendocs/ 